$12-1-1978$

\title{
Modification of Stimulation Seeking Behavior in Psychopaths using Hypnotic Sensory Imagery Conditioning
}

Franklin D. DeForest

How does access to this work benefit you? Let us know!

Follow this and additional works at: https://commons.und.edu/theses

\section{Recommended Citation}

DeForest, Franklin D., "Modification of Stimulation Seeking Behavior in Psychopaths using Hypnotic Sensory Imagery Conditioning" (1978). Theses and Dissertations. 2671.

https://commons.und.edu/theses/2671

This Dissertation is brought to you for free and open access by the Theses, Dissertations, and Senior Projects at UND Scholarly Commons. It has been accepted for inclusion in Theses and Dissertations by an authorized administrator of UND Scholarly Commons. For more information, please contact und.commons@library.und.edu. 
MODIFICATION OF STIMULATION SEEKING BEHAVIOR

IN PSYCHOPATHS USING HYPNOTIC SENSORY

IMAGERY CONDITIONING

by

Franklin D. DeForest

Bachelor of Science, University of North Dakota, 1970

Master of Arts, University of North Dakota, 1972

A Dissertation

Submitted to the Graduate Faculty

of the

University of North Dakota

for the degree of

Doctor of Philosophy

Grand Forks, North Dakota

December

1978 


\section{MODIFICATION OF STIMULATION SEEKING BEHAVIOR. \\ IN PSYCHOPATHS USING HYPNOTIC SENSORY \\ IMAGERY CONDITIONING \\ Franklin D. DeForest, Ph.D.}

The University of North Dakota, 1978

Faculty Advisor: Lynn S. Johnson

Recent theorizing has postulated that there exists for every individual an optimal level of arousal. Deviations from this optimal state produce discomfort which motivates behaviors aimed at remediation. Potential causes of underarousal include the attenuation of perceptual input and excessively rapid habituation to sensory input. Both of these processes have been linked dynamically to the psychopathic condition. Presumably, in the context of restricted opportunities for involvement in highly stimulating activities, the psychopathic individual attempts to alleviate the stress caused by chronic sensory deprivation through participation in illegal behaviors. The present investigation has attempted to clarify the dynamic picture with regards to psychopathy and the attenuation of sensation. It has further attempted to evaluate a therapeutic regimen designed to enhance the psychopath's perceptual sensitivity and thereby reduce his excessive reliance on stimulationseeking activities.

Experimental psychopathic and non-psychopathic subjects from the Minnesota State Reformatory were exposed to a three-week sensory imagery 
conditioning program which employed both self-hypnosis and heterohypnosis in order to facilitate the relaxation response and conditioning effect. Subsequent evaluation was made of changes in repressive perceptual tendencies, stimulation-seeking behavior, internal-external locus of control, and psychopathic orientation. The results indicate that, among incarcerated subjects, repression does not appear to be a consistent distinguishing characteristic of psychopaths. The results further indicate that the experimental procedure is capable of fostering a less repressive perceptual style and a consequent diminution of stimulationseeking activity, with these changes being generally more pronounced for the non-psychopathic subjects. The changes, however, tended to be either not enduring or did not generalize in a way which affected global measures of psychopathic orientation. An additional finding was that the extent of practice in autohypnosis tended to be unrelated in any consistent fashion to the changes observed.

The results are discussed in terms of their implications for a psycho-dynamic theory of psychopathy, the appropriateness of the measures employed, possible modifications in the experimental procedure which might enhance change and facilitate accurate assessment, and recommendations for relevant future research. 
This Dissertation submitted by Franklin D. DeForest in partial fulfillment of the requirements for the Degree of Doctor of Philosophy from the University of North Dakota is hereby approved by the Faculty Advisory Committee under whom the work has been done.
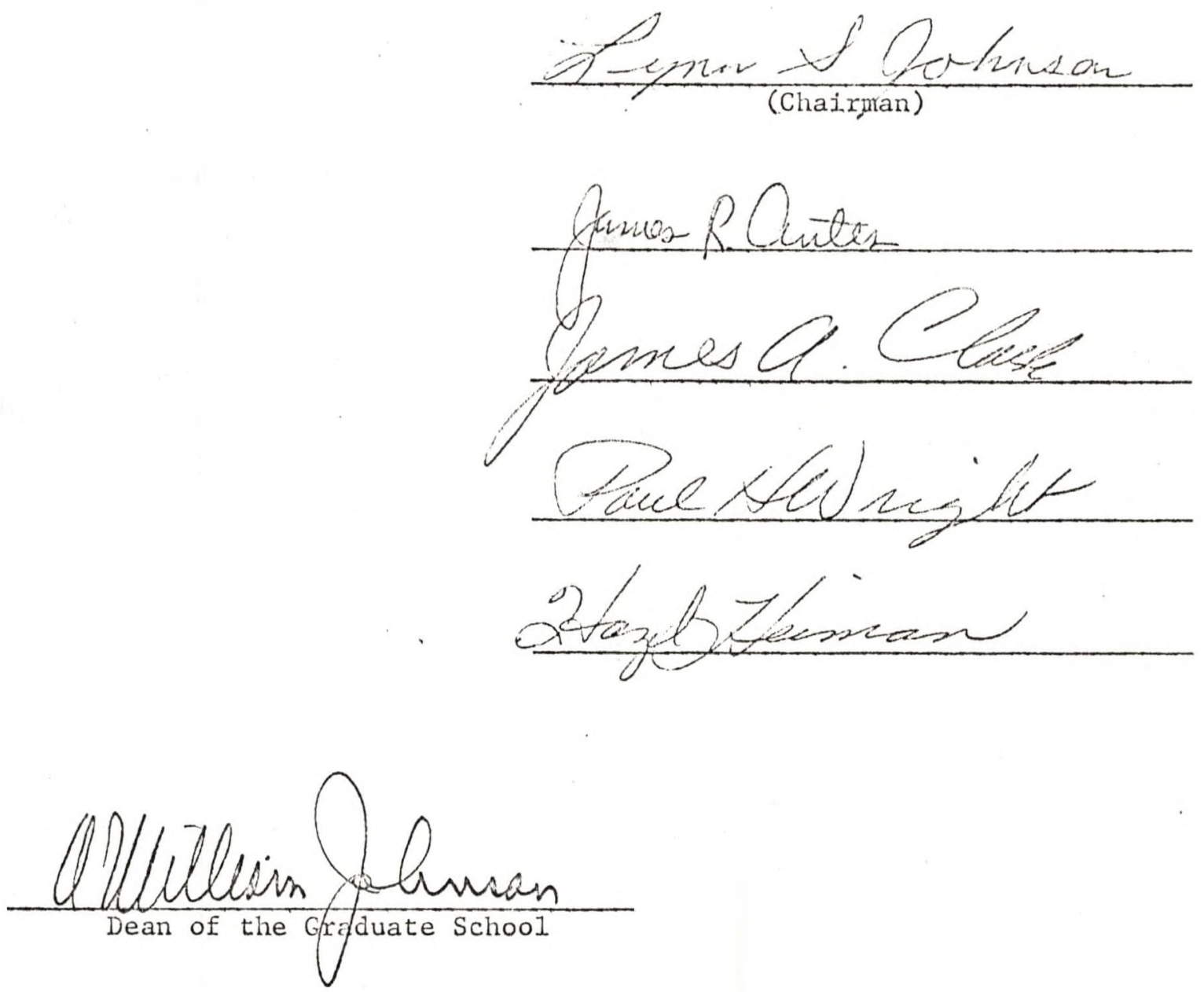


\section{Permission}

MODIFICATION OF STIMULATION SEEKING BEHAVIOR IN PSYCHOPATHS Title USING HYPNOTIC SENSORY IMAGERY CONDITIONING

Department Psychology

Degree Doctor of Philosophy

In presenting this dissertation in partial fulfillment of the requirements for a graduate degree from the University of North Dakota, I agree that the Library of this University shall make it freely available for inspection. I further agree that permission for extensive copying for scholarly purposes may be granted by the professor who supervised by dissertation work or, in his absence, by the Chairman of the Department or the Dean of the Graduate School. It is understood that any copying or publication or other use of this dissertation or part thereof for financial gain shall not be allowed without my written permission. It is also understood that due recognition shall be given to me and to the University of North Dakota in any scholarly use which may be made of any material in my dissertation.

Signature

Date 


\section{ACKNOWLEDGMENTS}

I wish to thank Dr. Lynn Johnson, my committee chairman, for his diligent supervision and insightful comments. His willingness to work with somewhat stringent deadlines has been sincerely appreciated. I would also like to thank the other committee members, Dr. James Antes, Dr. James Clark, Dr. Hazel Heiman, and Dr. Paul Wright, for their timely and helpful comments.

I am especially grateful to the staff at the Minnesota State Reformatory for Men, particularly Dr. John Needham, who allowed me the time and facilities necessary to enable the collection of data.

A special thanks is extended to the subjects of this study, without whom it would have been neither possible nor justifiable. It is hoped that whatever knowledge is gained from this research may further an understanding of their experience and promote more effective measures for confronting it. 
ACKNOWLEDGMENTS . . . . . . . . . . . . . . . . . iv

LIST OF TABLES . . . . . . . . . . . . . . . . . . . . . . vii

LIST OF FIGURES . . . . . . . . . . . . . . . . . . . . . . viii

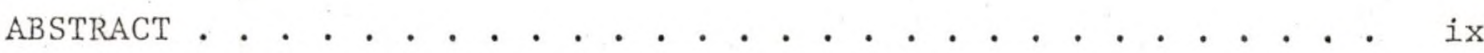

Chapter

I. INTRODUCTION . . . . . . . . . . . . . . . . . . 1

Nature of the Problem

Definition of Terms

Current Theories Related to the Etiology

II. REVIEW OF THE LITERAtURE . . . . . . . . . . . . . . . 10

Research on the Arousal Theory of Psychopathy

Clinical Implications of the Arousal Theory

Hypnosis and the Correlates of Psychopathy

Hypotheses to Be Tested

III. METHODOLOGY . . . . . . . . . . . . . . . . . . . .

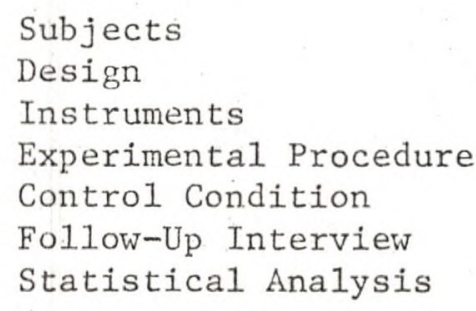

IV. RESULTS . . . . . . . . . . . . . . . . . . . 48

Repression-Sensitization as a Function of Pre-Experimental Psychopathic Orientation

Pre-Experimental Group Comparisons

Effects of Sensory Imagery Conditioning

Effect of Practice in Autohypnosis

Follow-Up Interview

V. DISCUSSION . . . . . . . . . . . . . . . . .

Initial Group Differences

Treatment Effects 
Classification Effects

Effects of Practice in Autohypnosis

Follow-Up Interview

Recommendations

REFERENCES ....................................... 81

APPENDIX A. SENSATION SEEKING SCALE V . . . . . . . . . . 91

APPENDIX B. INSTRUCTIONS FOR THE KINESTHETIC DETERMINATION OF AUGMENTATION AND REDUCTION . . . . . . . . 95

APPEINDIX C. STAINDARD HYPNOTIC INDUCTION . . . . . . . . 98

APPENDIX D. INSTRUCTIONS FOR AUTOHYPNOSIS USING POSTHYPNOTIC

SUGGESTION . . . . . . . . . . . . . . 100

APPEISDIX E. STANDARDIZED IMAGES . . . . . . . . . . . . . . . . . 101

APPENDIX F. FOLLOW-UP INTERVIEW . . . . . . . . . . . . . 121

APPENDIX G. AUTOHYPNOSIS PRACTICE TALLIES . . . . . . . . . 123 
LIST OF TABLES

Table

Page

1. Subject Assignment . . . . . . . . . . . . . . 34

2. Group Means and Standard Error for Test Scores Prior to Sensory Imagery Conditioning. . . . . . . . . . . . 50

3. F Ratios for Sources of Variation, Probability and $\omega^{2}$ for Mean Test Scores Prior to Sensory Imagery Conditioning . . 51

4. Group Means and Standard Error for Test Scores Following Sensory Imagery Conditioning.. . . . . . . . . . . 54

5. E Ratios for Sources of Variation, Probability and $\omega^{2}$ for Mean Test Scores Following Sensory Imagery Conditioning . 55

6. Product Moment Correlation Coefficients for the Relationship Between Change Scores and Practice in Autohypnosis . . .

7. Group Means and Standard Error for Change Scores on MMPI Subscales .. . . . . . . . . . . . . . . . 60

8. E Ratios for Sources of Variation in Change Scores on MMPI Subscales .. . . . . . . . . . . . . . . . 60

9. Mean Number of Behavior Reports Incurred During Investigation Period . . . . . . . . . . . . . . . . . . 61

10. F Ratios for Sources of Variation in Number of Behavior Reports .................... 61

11. Group Means and Standard Error for Likert-Scaled Follow-Up Measures . . . . . . . . . . . . . . . . .

12. E Ratios for Sources of variation among Scores on LikertScaled Follow-Up Measures . . . . . . . . . . . . . . 


\section{LIST OF FIGURES}

Figure

Page

1. Group Means for Pre- and Post-Testing . . . . . . . . 56

2. Number of Subjects Engaged in at Least Twenty Minutes of Practice on Each Experimental Day . . . . . . . . . . . 75 


\section{ABSTRACT}

Recent theorizing has postulated that there exists for every individual an optimal level of arousal. Deviations from this optimal state produce discomfort which motivates behaviors aimed at remediation. Potential causes of underarousal include the attenuation of perceptual input and excessively rapid habituation to sensory input. Both of these processes have been linked dynamically to the psychopathic condition. Presumably, in the context of restricted opportunities for involvement in highly stimulating activities, the psychopathic individual attempts to alleviate the stress caused by chronic sensory deprivation through participation in illegal behaviors. The present investigation has attempted to clarify the dynamic picture with regards to psychopathy and the attenuation of sensation. It has further attempted to evaluate a therapeutic regimen designed to enhance the psychopath's perceptual sensitivity and thereby reduce his excessive reliance on stimulation-seeking activities.

Experimental psychopathic and non-psychopathic subjects from the Minnesota State Reformatory were exposed to a three-week sensory imagery conditioning program which employed both self-hypnosis and heterohypnosis in order to facilitate the relaxation response and conditioning effect. Subsequent evaluation was made of changes in repressive perceptual tendencies, stimulation-seeking behavior, internalexternal locus of control, and psychopathic orientation. The results indicate that, among incarcerated subjects, repression does not appear 
to be a consistent distinguishing characteristic of psychopaths. The results further indicate that the experimental procedure is capable of fostering a less repressive perceptual style and a consequent diminution of stimulation-seeking activity, with these changes being generally more pronounced for the non-psychopathic subjects. The changes, however, tended to be either not enduring or did not generalize in a way which affected global measures of psychopathic orientation. An additional finding was that the extent of practice in autohypnosis tended to be unrelated in any consistent fashion to the changes observed. The results are discussed in terms of their implications for a psycho-dynamic theory of psychopathy, the appropriateness of the measures employed, possible modifications in the experimental procedure which might enhance change and facilitate accurate assessment, and recommendations for relevant future research. 


\section{CHAPTER I}

\section{INTRODUCTION}

\section{Nature of the Problem}

The term "psychopath" tends to arouse a number of negative connotations, perhaps the most frequent of which is the immutability of the condition. While many such widely held associations prove to be merely theoretical and not empirically substantiated, the supposition that the psychopathic condition is resistant to change tends to be supported by a considerable body of clinical and experimental evidence. In his comprehensive review of the subject, Cleckley (1964) noted that over a period of many years he has remained discouraged about the effect of treatment with the psychopath. In both his own experience and that of other therapists, he has observed that the fundamental pattern of inadequacy and antisocial activity remained essentially unchanged despite prolonged involvement in psychoanalysis, psychoanalytic-oriented psychotherapy, group and milieu therapy, or various other dynamic approaches.

McCord and McCord (1964) reviewed a number of empirical studies which lend support to Cleckley's observation. With few exceptions, traditional forms of psychotherapy, including psychoanalysis, group therapy, client-centered therapy and psychodrama have proven ineffective in the treatment of psychopathy. The results of psychosurgery, electroshock therapy and the use of various drugs have been equally discouraging. Greenacre (1947) has pointed out that, even when 
favorable changes do occur in therapy, they are often illusory and quickly vanish, leaving the fundamentally unsound organization of the personality untouched. The McCords reported some success in the treatment of 15 psychopathic children in a therapeutic milieu. However, the changes evidenced proved to be transitory, with a reversion to previous attitudes and behaviors accompanying the children's return to their home communities.

The encouraging finding that permanent change can be effected has been presented by Thorne (1959), who outlined conditions which he considers essential for success in the treatment of the psychopath. He recommended an extremely authoritarian approach, with the therapist controlling the psychopath's financial resources. Relatives and friends must agree not to rescue the psychopath from his difficulties, so he must face the consequences of his own behavior. The therapist makes it clear that he will be convinced of good intentions only through actions and not words. The psychopath is shown repeatedly that his behavior is self-defeating, and financial leverage is used to force socially acceptable behavior. Unfortunately, these conditions necessitate the expenditure of much time, money and patience. Thorne candidly admits that an expenditure of $\$ 15,000$ per year for as long as ten years is frequently necessary to effect a satisfactory outcome.

Robins (1966) presented data which suggest that, for many psychopaths, behavior tends to improve as a function of age, with improvement occurring most often between the ages of 30 and 40 . He noted that they tend to attribute their change to fear of further punishment or loyalty to their spouses. Robins, therefore, recommended supporting the pressures toward conformity in the psychopath's social environment and 
attempting to prevent his becoming isolated from family and friends who might serve as an incentive to limit his antisocial activities. Neither of the solutions presented by Thorne or Robins provides much in the way of viable alternatives to the practitioner engaged in conventional forms of psychotherapy.

The failure of conventional methods, therefore, may not necessarily be indicative of the resistance of the condition to amelioration, but rather may reflect the unsuitability of such approaches. Patterson (1966) summarized the commonalities of the various psychotherapies. Patients are assumed to be personally distressed and consequently motivated to change their behavior. A fundamental assumption is that the patient's present behavior is influenced by future expectations. The psychotherapeutic relationship relies on the development of an interpersonal relationship between the therapist and patient that is affective as well as cognitive and intellectual in nature. Finally, there is an expectation on the part of both the patient and therapist that therapy will have a satisfactory outcome. The general absence of remorse, the present orientation and the apparent lack of empathy, warmth and sincerity of the psychopath would, therefore, be incompatible with such a treatment approach. In light of these indications of inappropriateness, it is unlikely that expectations of success will be very high.

The psychopath's reaction has been perceived as untreatable for so long that very little research has been devoted to treatment. The problem is aggravated by the fact that the psychopath's symptoms are neither psychotic nor psychoneurotic in nature. Consequently, they give the impression of being basically normal people who simply refuse responsibility and who will not learn to be different. Until the 
etiological picture is clarified, systematic therapeutic approaches will be difficult to develop.

\section{Definition of Terms}

While many continue to view psychopathic behavior as merely an undisciplined indulgence in irresponsible and immoral conduct, psychopathy has over the years emerged as a distinct psychiatric entity. Pinel was the first to conceptualize the condition as a psychiatric phenomenon distinguishable from existing classification (Kavka, 1949). Pinel's conceptualization proved to be broader and more encompassing than that in current psychiatric nomenclature. This relative imprecision has tended for many years to impede the understanding of important features of psychopathy. Pinel's appellation "manie sans delire" helped place the psychiatric profession in a quandary which continues to perplex theorists and practioners alike. Henderson (1939) quoted Benjamin Rush, who, as early as 1812, admitted: "How far the persons whose diseases have been mentioned should be considered as responsible to human or divine laws for their actions, and. where the line should be drawn that divides free agency from necessity, and vice from disease, I am unable to determine" ( p. 13). Believing that the concept of "moral insanity" was an attempt to revert to a belief in demon possession, Ordronaux is quoted by Maughs (1941) as having responded in 1874 to Rush's dilemma: "The only disease to which moral nature is subject is $\sin ^{\prime \prime}(p .313)$.

In the context of concerns about morality and culpability, the emergence of psychopathy as an empirical construct has been slow. Ironically, however, it may be that the controversy surrounding the 
issue has contributed to the result that the psychopathic classification is viewed as one of the most reliable in psychiatric nosology. Davison and Neale (1978) noted that the personality disorders listed in the Diagnostic and Statistical Manual II of the American Psychiatric Association (19.68) generally have very little diagnostic reliability and are supported by few empirical data. They added, however, that the psychopathic personality is the single exception and will remain essentially unchanged in DSM III. Herein the psychopathic personality is described as "incapable of significant loyalty to individuals, groups or social values. They are grossly selfish, callous, irresponsible, impulsive, and unable to feel guilt or to learn from experience and punishment. Frustration tolerance is low. They tend to blame others and offer plausible rationalizations for their behavior" (p. 43).

While the reliability of psychiatric diagnosis may generally not be very impressive (Buss, 1966), research has demonstrated a high degree of agreement among clinicians on what characteristics are indicative of psychopathy. In a survey of 677 Canadian psychiatrists, Gray and Hutchison (1964) found that approximately 90 percent considered the concept of psychopathic personality a meaningful one. They viewed the following features as the most significant in the diagnosis of psychopathy: Does not profit from experience; lacks a sense of responsibility; unable to form meaningful relationships; lacks control over impulses; lacks moral sense; chronically or recurrently antisocial; punishment does not alter behavior; emotionally immature; unable to experience guilt; and self-centered.

The consistency evidenced by clinicians is duplicated by psychiatrists and psychologists engaged in research on the topic. Albert, 
Brigante and Chase (1959) subjected 70 articles on psychopathy to an intensive content analysis. The results indicate that there is a considerable degree of agreement among researchers concerning the main characteristics of psychopaths. This agreement was borne out with regard to psychopathic adults as well as children. The most salient factors proved to be antisocial aggression, inadequate superego, inability to identify with others, low ego strength, narcissism, absence of conflict, anxiety and guilt, temper tantrums, motor hyperactivity, and the absence of goal-directed behavior.

Current Theories Related to the Etiology of Psychopathy

Although there is considerable agreement regarding the descriptive features of the psychopathic personality, the search for the cause of the disorder has not resulted in a singularly acceptable outcome. In their review of the historical development of the concept of psychopathy, McCord and McCord (1956) observed that, throughout the nineteenth century, investigation into causes and treatment of psychopathy, as we11 as other mental disorders, was buried in speculative dispute. Those few who thought about the problem concerned themselves with theoretical, almost theological questions such as whether the moral sense can be diseased while the intellectual faculty remains unimpaired. Because of loose classification and lack of research, psychiatric pioneers were able to accomplish little, but they did stimulate an intellectual movement which, by the beginning of this century, had led to the accumulation of some observational data. With the increased emphasis on research came a diminished interest in the old theoretical conflicts. Terms such as "moral insanity," which carried unpleasant connotations, were replaced 
by "psychopathic inferiority," and objective observation led to the refining of the concept and gave it specific meaning.

Much of the work thus far has been correlational. Therefore, observed relationships may not mean that events are causally related, let alone allowing one to specify the direction such a relationship might take. Nevertheless, the observed correlates help to clarify the current dynamics supporting psychopathic behavior and give some point of reference in the generation of etiological hypotheses and their subsequent verification.

The role of the family as the primary agent of socialization has been studied by a number of investigators. McCord and McCord (1964) concluded on the basis of this line of research that a lack of affection and severe parental rejection were the primary causes of psychopathy. However, many individuals who come from what appear to be similarly disturbed social backgrounds do not become psychopaths. A number of neurotic and even psychotic conditions could be traced to similar beginnings (Wiggins, 1968). Therefore, it would appear that, while family experience may be important in the development of psychopathic behavior, this factor alone cannot provide an adequate explanation.

During the past hundred years, there have been repeated attempts to show that criminals are constitutionally inferior. It was generally believed that they suffered from some hereditary weakness of the nervous system; hence the term "constitutional psychopathic inferiority" was commonly used. While there has been no compelling evidence that requires a somatogenic hypothesis in a sweeping form, there is some evidence that a disposition toward psychopathic behavior may be inherited. Studies of adoptees (Hutchings and Mednick, 1974; Schulsinger, 1972) have found a 
higher rate of criminality and psychopathy in biological relatives of psychopaths than in the general population. The occurrence of an extra Y chromosome in a proportionately large number of extremely aggressive criminals has led to speculation that genetic aberration may help to account for such behavior (Montagu, 1968). Recent research (Witkin, 1976), however, has indicated that this connection may be artifactual. While not addressing themselves strictly to the etiological question, a number of investigators have noted physiological characteristics which tend to correlate highly with the psychopathic condition. Ellingson (1954) found a relatively high incidence of electroencephalogram abnormalities among psychopaths. Schwade and Geiger (1956) demonstrated a relationship between aggressive, destructive urges and the occurrence of the positive spike phenomenon in the EEG pattern. Research reviewed by McCleary (1966) indicated that lesions in the limbic system affect sensory and memory processes and make it difficult to learn to inhibit a punished response.

Lykken (1955) had earlier focused on this apparent inability of psychopaths to profit from punishing experiences, but he attributed this to the absence of anxiety rather than to neurological deficit. Subsequent research (Chesno and Kilman, 1975; Schacter and Letane, 1964; Schmauk, 1970) has demonstrated that the conditionability of the psychopath can be enhanced when the level of emotional arousal is increased through the injection of stimulants, manipulation of the experimental environment or the use of more appropriate incentives. Thus it appears that a consideration of motivational variables is essential to a clearer understanding of at least some of the distinguishing characteristics of psychopathic and non-psychopathic behavior. 
While both the psychogenic and somatogenic explanations of psychopathic behavior appear to have merit, the etiological picture is currently anything but clear. Since the development of management strategies has generally proceeded from a knowledge of causation, it is understandable why efforts to treat or change the behavior of the psychopath have been inconsistent and the results generally discouraging. The accepted clinical practice of first establishing the cause and then attempting to provide remedial experiences is clearly not always appropriate in this case. Likewise, the ex post facto approach of dea1ing with the criminal conduct itself has proven equally ineffective. Society's most common response to crimes committed by psychopaths has been incarceration. Many studies of the effects of this procedure indicate that it does little to reform the psychopath. While in prison, these men are guilty of greater numbers of offenses than other prisoners and spend more time in solitary confinement (Suinn, 1972).

Correlational research has yielded a number of variables which appear to be relevant to an understanding of the dynamics which support psychopathic behavior at any point in time. While the etiology of such variables may be inferred, the clinician remains called upon to devise an effective treatment regimen without the benefit of positive proof of causation. Therefore, it would appear that the development of practical procedures aimed at modifying these known correlates of psychopathy provides the most potentially fruitful avenue of pursuit in the conduct of therapy research. 
CHAPTER II

REVIEW OF THE LITERATURE

Research on the Arousal

Theory of Psychopathy

Sensory stimuli serve a function in addition to the provision of perceptual information and the consequent guidance of behavior. Stimulation also serves to increase the individual's level of activation or arousal. Lindsley (1952) has correlated the level of emotional arousal with awareness, EEG patterns and behavioral effectiveness. He found that extreme states of arousal in either direction produce disrupted awareness, behavioral inefficiency and unpleasant affect. Synchronized alpha rhythms, attentiveness, relaxation and improved behavioral functioning accompany a moderate level of arousal.

The role of the level of arousal in the development of psychopathic behavior has received considerable attention in recent years. Quay (1965) suggested that the impulsivity of the psychopath, his need to create excitement and adventure, his thrill-seeking behavior, and his inability to tolerate routine and boredom may be a manifestation of an inordinate need for increases or changes in the pattern of stimulation. He postulated that there exists an optimal level of arousal necessary for the maintenance of pleasant affect and that this level is much greater for the psychopath than for the ordinary individual. It may be that the psychopath typically suffers to some extent the unpleasant affect associated with sensory deprivation. Quay reasoned that this 
condition resulted when either the basal reactivity to stimulation is lowered, necessitating more sensory input to produce pleasurable cortical functioning, or there is a more rapid adaptation to stimulation, causing the need for stimulation variation to occur more rapidly and with greater intensity.

Hare (1970) has cited the importance of the reticular formation within the brain stem in the coordination of the correlates of arousal and the filtering out of repetitive or low intensity stimulation. He conceptualized the interplay between the reticular formation and cortical, autonomic, muscular and sensory functions as reciprocal. Consequently, it can be inferred that, while reticular activity is a prerequisite for sensory functioning, a certain amount of sensory input is likewise necessary for the maintenance of a pleasurable level of arousal.

Bearing in mind the cautions regarding cause and effect interpretations, the potential effect that mental states may have on physiological functioning has become well established. It is conceivable that familial experiences may have an effect on physiological functioning, which in turn produces alterations in attitudes and behaviors. An example of this would be the phenomenon of sensory adaptation: Any modality of stimulation repeatedly encountered tends to lose some of its special character as it gradually becomes typical (Helson, 1959). Hebb's (1946) neuropsychological theorizing suggested that encountering a variety of receptor inputs during infancy may help to innoculate one against fear of the unfamiliar and the strange. Similarly, Salama and Hunt (1964) found that, contrary to the fearful sensitizing one might expect on the 
basis of conditioning theory, repeated encounters with painful stimulation reduced its aversiveness and instigative potency.

This line of investigation leads one to conclude that early trauma may produce anomalies in sensory functioning, which in turn alter conditionability. Despite Cleckley's (1959) observation that he had not regularly encountered any specific type of error in parent-child relations in the early histories of his cases, subsequent research (e.g. Greer, 1964) has uncovered higher incidences of disruption in the childhoods of psychopaths than controls. Therefore, it appears that the need for sensory stimulation may prove to be a keystone in a consolidated theory of psychopathy.

Like Quay, Petrie (1967) also saw an excessive need for stimulation as instrumental in the development of psychopathic behavior. She identified two distinct perceptual styles. Those she termed "reducers" tended subjectively to decrease what is perceived, and "augmenters" increase what is perceived. She viewed the characteristic perceptual reactance of the psychopath to be one of reduction, a condition which leaves him in a state of actual or threatened stimulus deprivation. She cites as an example the juvenile delinquent who, subjected to solitary confinement, burns himself with cigarettes in an attempt to relieve his distress. Paradoxically, he will chose strong discomfort in some part of the body to relieve suffering from sensory lack. She found that reducers consistently expressed a preference for pain over confinement as a form of punishment.

A number of studies have provided empirical support for the notion that psychopaths are less sensitive to stimulation. Hare (1968) and Schoenherr (1964) both found that psychopaths had a higher shock- 
detection threshold than did non-psychopaths. Rose (1964) found that the two-flash discrimination threshold was also higher for the psychopaths. Petrie (1967) discussed essential differences between detection thresholds for pain and the tolerance of pain. She noted that the pain threshold may remain essentially unchanged, while tolerance for pain fluctuates over time. She determined that a change in pain threshold need not accompany increased tolerance for pain, whereas a tendency to attenuate perceptual input did accompany increased tolerance. Schallin and Levander (1964) found that psychopathic delinquents had higher pain and higher tolerance thresholds for electric shock than did nonpsychopathic delinquents. While the results of subsequent studies were somewhat more equivocal, Hare and Thorvaldson (1970) attributed the inconsistencies to motivational variables. They found that psychopaths tolerated significantly stronger shocks than did non-psychopaths when concrete incentives were made available.

While researchers have found an increased tolerance for painful sensory stimulation in the psychopathic group, intolerance for boredom had conversely been demonstrated. Hare (1970) speculated that psychopaths would perform poorly in vigilance tasks which are inherently tedious and monotonous. He noted that the performance decrement that usually occurs during these tasks is associated with a corresponding decrease in cortical and autonomic arousal. These speculations were supported by Orris (cited in Hare, 1970) who found that psychopathic delinquents performed less well in a simple visual monitoring task than did other delinquents.

As might be expected, psychopaths tend to show a stronger preference for novel and complex stimulation than do non-psychopaths. Skrzypek 
(1969) determined preferences for novelty and complexity among psychopathic and neurotic delinquents. He then subjected them to conditions of perceptual isolation and arousal. He found that the less anxious psychopathic group showed a greater preference for complexity and novelty than did the neurotics. Perceptual isolation tended to heighten this preference. Arousal had no effect on the psychopaths but increased the anxiety of the neurotics and decreased their preference for complexity.

Preference for complex stimulation has also been demonstrated to be associated with the perceptual reduction tendency as measured by Petrie's Kinesthetic After Effects T'est. Sales (1972) found that reducers react particularly positively to intense, complex auditory and visual stimuli. Consistent with an earlier finding by Petrie (1967) that reducers have relatively more friends than augmenters and that they are more likely to be socially extraverted, Sales further observed that reducers frequently expose themselves to intense stimulation in their ongoing social activities, tending to avoid simple stimulus situations. Sales (1971) had earlier proposed an arousal theory of need for stimulation similar to that of Quay, but without specific reference to psychopathy. He held that the optimal level of evoked stimulation tends to be similar for all individuals. He attributed observed differences in stimulation-seeking behavior to a tendency to attenuate or to amplify incoming stimuli.

In an effort to test Sales' hypothesis, Kish, Franke1, Masters and Berry (1976) correlated a measure of augmentation-reduction with the Sensation Seeking Scale (Zuckerman, 1971), a measure of individual differences in stimulation-seeking. Their findings tended to provide little 
support for the theory. However, they speculated that the problem may have been with the use of the absolute auditory threshold and the most comfortable level of loudness as a measure of augmentation and reduction. They cited a study by Zuckerman (1974) in which the relevant correlation had also been found to be non-significant when the visually evoked potential was used as the measure of perceptual reactance. Sales and Throop (1972) had found a low correlation between the absolute auditory threshold and the Kinesthetic After Effects Test. Consequently, Kish et al. concluded that there is little justification for the use of the psychophysical threshold as a substitute for the after effect measure. They also viewed their findings as calling into question Sales' analysis of the neurological underpinnings of the need for stimulation. In contrast to Zuckerman's findings, Spilker and Callaway (1969) had found a significant positive correlation between the amplitude of the averaged EEG visual evoked response and scores on the Kinesthetic After Effects Test. They further found that test-retest values on the two measures, which showed considerable day-to-day variability, changed together. They viewed their results as support for a general stimulus intensity control mechanism which influences sensory responsivity across modalities.

At this point, any conclusions regarding the origins of stimulationseeking behavior must be tentative. Quay (1965) noted that those who have argued for a constitutional origin have often cited early appearance of precursors of the condition in children four and five years of age. Keeping in mind a caution by Garmezy (1971) regarding the unreliability of case history material, particularly in the recollection of acute emotions and affectively tinged attitudes, there seems to be general 
agreement that early childhood emotional trauma is frequently present in the backgrounds of psychopaths. A variety of animal studies (Denenberg, 1959; Salama and Hunt, 1964) has indicated that traumatized (shocked) infant rats will exhibit less emotionality to the effects of an unfamiliar situation than will animals not so traumatized.

Eysenck (1957) has argued that the cortical reactivity pattern of the extrovert is constitutional, and recent research (Farley, 1977; Jacobs, 1977) has related the sensation-seeking motive to extroversion. Lynn and Eysenck (1961) had earlier equated the introversion-extraversion dimension with Petrie's concept of augmentation-reduction. In his neuropsychological model of emotion, Pribram (1967) viewed reduced states of cortical reactivity to be the result of cortical inhibitory mechanisms that influence the rate with which cells in the brain recover their excitability. He further suggested that these inhibitory mechanisms may underlie such processes as repression, suppression and perceptual defense, since each appears to be a form of defensive "gating out" of stimuli that initiate disturbing emotional states. Therefore, it would appear that this condition is related to the operation of inhibitory defensive mechanisms that exert control over sensory input that would ordinarily have disturbing consequences.

Sullivan (1953) has postulated a "self dynamism" which may facilitate a psychological conceptualization of such an inhibitory defensive mechanism. He noted that in certain situations a person may fail to notice clearly and carefully and may fail to attend to significant and relevant aspects of an object or situation because awareness of them would entail severe anxiety. Attention is always selective, and often the mere hint of anxiety is enough to set off this restrictive mechansim 
of the self. He viewed selective inattention as something not confined to the mentally ill, but rather saw it as a strategy employed to varying degrees by everyone. Sullivan extended his concept not only to the awareness of immediate perceptions, thoughts and feelings, but also to the recall of previous experience. He further made a point to distinguish his construct from "repression," the latter entailing the inhibition of drives rather than awareness.

Systematic investigation of perceptual defense has been considerable since the early studies of Bruner and Postman (1947). Research has generally centered on the correlates of individual differences in responding to tachistoscopically presented neutral and emotionallytoned stimuli. In support of Sullivan's theorizing, it has generally been found that individuals tend to fall along a continuum with respect to the characteristic way in which they respond to threatening stimuli (Byrne, 1961). Terminology has varied across experiments, with many different measures being used to determine response set. Several researchers have ignored Sullivan's distinction and have used "repressionsensitization" as anchor terms on the perceptual defense continuum. The recent popularity of Byrne's Repression-Sensitization Scale has enabled a more integrated analysis of findings in this area.

As might be expected, several of the correlates of psychopathy also tend to be similarly correlated with a repressive perceptual style. Kilpatrick, Cauthen and Roitzsch (1971) found that repression was highly correlated with lack of anxiety in a prison population. While they found no difference between normal and psychopathic prisoners on these dimensions, inmates exhibiting other psychiatric disturbances tended to demonstrate greater sensitization and anxiety. The results also 
indicated that normal and psychopathic prisoners showed significantly greater tendency to repress and demonstrated less anxiety than the general population. They concluded that the anxiety scale and the Byrne scale measured equivalent constructs. Eysenck and Eysenck (1969) have noted that sensitizers tend to be introverted, while repressors are more extroverted.

With regard to psychophysical functioning, Davidson and Bobey (1970) found greater tolerance for pain among repressors than sensitizers, thereby giving support to a hypothesis suggested earlier by Byrne (1961). Schill and Althoff (1968) demonstrated that repressors had a significantly higher auditory perceptual threshold for sexual sentences than did sensitizers. A finding that might contraindicate a constitutional inferiority explanation of perceptual style is that of Schuenaman, King, Sandman and Deabler (1970), who observed that the psychomotor reaction time was independent of the repression-sensitization dimension. Therefore, it might be inferred that the effects of repression are selectively felt on afferent rather than efferent impulses.

While not necessarily addressing the question of the constitutional origins of psychopathy, Whitehil1, Capin and Scott (1976) demonstrated a-positive relationship between sensation-seeking tendencies, as measured by susceptibility to boredom on a monotonous task, and psychopathy in preadolescent children. They reasoned that early detection of this precursor of psychopathic behavior and the implementation of appropriate management techniques might lead to more encouraging results than are currently being evidenced in the treatment of an established psychopathic orientation. They cited a study by Greenberg, O'Donnell and Crawford (1973) which demonstrated a variety of habituation patterns in normal 
eleven week old infants and the finding by Thomas, Chess and Birch (1968) that there are distinct individual differences in temperamental style from the earliest days of life as possibly providing clues to strategies for such early detection.

Moving instead in the opposite direction on the age continuum, Farley and Sewell (1976) have investigated the arousal theory as it relates to juvenile delinquency. They also used the Sensation Seeking Scale to show that delinquents demonstrated a stronger need for stimulation and variety of experience than did non-delinquents. Based on this finding, they elucidated an arousal theory of delinquency with two major components: 1) Stimulation-seeking based on an hypothesized "arousal deficit" that is in part inherited; 2) environmental opportunities for and canalization of stimulation. Delinquency is seen as marked stimulation-seeking of a socially misapprobative nature.

Some insight into the effect of age on the sensation-seeking motive and the development of psychopathic behavior has been provided by Farley (1977). Using global self-rating measures of the relevant variables, he found that stimulation-seeking and extraversion-introversion, a variable cited earlier as being equivalent to augmentation-reduction, are not significantly related in adolescents but are positively correlated in young adult males. While this finding may be due to age biases in the measurement devices, Farley and Cox (1971) had earlier observed that, a1though there were no significant age effects on sensationseeking from ages fourteen to seventeen, there was some evidence that sensation-seeking decreases beyond age thirty and perhaps before. This latter finding may have relevance to Robins' (1966) observation that, for many psychopaths, behavior tends to improve as a function of age, 
with improvement occurring most often between the ages of thirty and forty.

The relationship between an external orientation and stimulationseeking in adults has been substantiated by a number of investigators. Hil1 (1975) found that subjects identified as extroverts on the Eysenck Personality Inventory (Eysenck and Eysenck, 1964) tended to build more variety into their responses on a monotonous task than introverts. Examining intercorrelations between scores on Rotter's (1966) InternalExternal Control Scale, the Sensation Seeking Scale, and the EPI, Jacobs (1977) concluded that externality is related to high optimal levels of stimulation and a high degree of disinhibition. Shedding further light on the interplay between stimulation-seeking, extraversion and delinquent behavior, Farley and Sewe11 (1976) proposed that delinquency in part represents a predominance of behavioral or overt stimulation-seeking over covert or mental, with the latter being more characteristic of the highly creative normal youngster.

Considerable research has related externality to disruptive behavior in criminal populations. Wood, Wilson, Jessor and Hogan (1966) found that inmates labelled as trouble-makers were characterized as being externally oriented. Likewise, Seeman (1963) and Lefcourt and Ladwig (1966) depicted the externally oriented prisoner as possessing feelings of hostility toward his superiors, defensive in his relations with others, dogmatic in his views, alienated and pessimistic in his outlook on life. On the other hand, the internally oriented prisoner is described as being more sociable, self-confident and possessing a brighter outlook on his future. While these characteristics do not directly reflect an exaggerated stimulation-seeking tendency, the underlying 
dimension of externality has been related to several correlates of psychopathy and appears itself to be associated with maladaptive behaviors.

As was noted earlier, Quay's (1965) conceptualization of the level of arousal in the development of psychopathy suggested two possibilities. He reasoned that an excessive need for stimulation resulted either when the basal reactivity to stimulation is lowered or when there is more rapid adaptation to stimulation. Research has primarily been concentrated on the first condition, reduced basal reactivity. However, collateral research lends some support to the latter explanation. Watson (1977) found that high sensation-seekers habituated faster, as evidenced by greater increments in threshold on repeated exposures to pain, than did 1ows. Sma11 (1973) had noted that extraverts habituate faster than introverts when both groups view a threatening stimulus. The relevance of these findings to psychopathy, however, is rather tenuous, and further research will be needed to clarify the role of habituation to sensory stimuli in psychopathic development.

\section{Clinical Implications of} the Arousal Theory

- Regardless of the nature of the origin of the sensation-seeking motive, it appears that psychopathy may be related to a general tendency to attenuate, perhaps selectively, perceptual input. hare (1970) has speculated regarding the implications of this tendency. He noted that many of the cues essential for adequate social functioning are subtle and of low intensity. Consequently, some of these cues would be below threshold for the psychopath and, therefore, relatively ineffective. At the same time, in an attempt to attain an optimal level of arousal, the 
psychopath is likely to actively seek intense, exciting stimulation, missing, or perhaps ignoring, social cues that are needed for the guidance of behavior. With relevance to criminal behavior, Petrie, McCullough and Kazdin (1961) add that, given the nature of our urban culture and the conditions under which the vast majority of delinquent children live, sensory deprivation is likely to occur in those individuals who even only moderately attenuate sensory input. Consistent with this, it might be said that poverty and poor supervisory involvement limit the avenues available for engaging in behavior which has arousing qualities and is at the same time legal.

A look at sources of stimulation available to the psychopath may provide some alternatives to antisocial behavior. One such means of increasing sensory input and cortical arousal is with psychedelic and stimulant drugs. Hill (1947) found that amphetamine produced at least a temporary improvement in the behavior of aggressive psychopaths, whereas Cleckley (1964) observed that alcohol, a cortical depressant, exacerbated aggression in psychopaths.

Dreaming has also been seen as a source of cortical arousal. Roffwarg, Muzio and Demet (1966) suggested that dreams provide endogenous stimulation to higher centers. This function would be particularly important during the intrauterine period and early infancy when external stimulation is reduced. The authors maintained that maturation of sensory processes may be dependent on an adequate source of such endogenous stimulation. Hare (1970) reasoned that the psychopath's heightened need for sensory input may be related to disturbances in dream activity. As mentioned earlier, Farley (1974) proposed that delinquents tend to fulfill their needs for stimulation with overt behavior, while mental 
or covert stimulation-seeking is more characteristic of the highly creative, nondelinquent youngster. Karpman (1961) had earlier observed that the psychopath's fantasy life is dull. These statements are consistent with a number of empirical findings. In partial support of Farley's proposa1, psychopathic subjects in Orris' (1967) study tended to engage in overt self-stimulating behaviors (singing, talking) during a boring vigilance task. Using the TAT, Silver (1963) provided evidence that the fantasy resources of psychopathic delinquents are indeed more limited than those of the non-psychopathic delinquents. Singer (1966) maintained that one of the functions of fantasy is to provide an opportunity for vicarious trial and error in which alternative behaviors are considered prior to taking action. An inability to engage effectively in such behavior might conceivably lead to poor judgment, impulsivity, and lack of foresight. Hare (1970) suspected that what imaginative capacities the psychopath does have are likely to be directed toward exciting themes instead of toward mental planning.

In light of these theoretical and empirical observations regarding the etiology of psychopathy, it would appear that an effective treatment approach would seek to enhance the effectiveness of available perceptual stimuli and to develop fantasy resources as an internal source of stimulation. For a variety of reasons, drugs may not be seen as a viable solution for many clinicians. Similarly, providing richer dream experiences is not a capability within the repertoire of most mental health practioners. The enrichment of fantasy and the enhancement of sensory awareness, however, have been claimed as achievable goals by proponents of a variety of therapeutic orientations. DeRopp (1968) proposed the use of meditation using principles of Eastern philosophy to achieve a 
state of higher consciousness. Coming from a background of experimentation with psychedelic drugs, Masters and Fouston (1972) described techniques which they say, when followed closely, provide a non-chemically induced duplication of the psychedelic experience. The games they describe are designed to allow the individual to be "more imaginative, more creative, more fully able to gain access to their capacities and to use their capacities productively . . For example, images, accelerated mental processes, more acute sense impressions, access to other places of the mind, subjective realities, new space time orientations" are possible with the achievement of altered states of consciousness.

Stevens (1971) presented a number of Gestalt exercises intended to enable the reader to explore, expand and deepen his awareness. His approach focuses on development of three "zones of awareness:" Awareness of the outside world; awareness of the inside world; awareness of fantasy activity. The first of these concentrates on the actual sensory contact with objects and events in the present. The second deals with sensory contact with inner events of the present. Fantasy activity includes all mental activity beyond present awareness of ongoing experience: "A11 explaining, imagining, interpreting, guessing, thinking, comparing, planning, remembering the past, anticipating the future, etc." These exercises are designed not only to enrich the fantasy experience, but to actually augment or clarify awareness of one's sensory input. The approach of Kroger and Fezler (1976) places exclusive emphasis on the development of keener sensory processes. They have argued that, under conditions of relaxation, any sensation that has ever been experienced can be recalled as it was originally felt. Viewing their techniques as a marriage of hypnosis and behavior therapy, they 
have suggested the use of hypnotic induction to elicit the relaxation response, in the context of which are presented images intended to facilitate alterations in sensory experiences.

\section{Hypnosis and the Correlates}

of Psychopathy

Perhaps the most well-publicized use of hypnosis in the treatment of psychopathy was the case of RBW in Lindner's (1944) Rebel Without A Cause. While Lindner's psychoanalytic orientation had little relevance to the arousal theory of psychopathy, the bringing of repressed material into awareness of means of hypnosis was the underlying mechanism in his purportedly successful treatment of his psychopathic client. If one views the repression of perceptual stimuli as a dynamic factor in psychopathy, then a method which would facilitate awareness would indeed be relevant.

If the assumption can be made that sensory awareness produces anxiety in the psychopath and is consequently avoided by means of repression, then this avoidance might be viewed as phobic behavior. The effectiveness of behavior therapy in the treatment of phobic reactions has been well documented, and a review of its literature would be voluminous. Watson and Raynor (1920) were among the first to demonstrate that a conditioned fear response could be extinguished by pairing the feared object with a pleasurable response incompatible with anxiety. This basic principle underlies the more recently developed therapeutic technique of Wolpe (1961). Systematic desensitization generally involves the graduated presentation of an anxiety-evoking stimulus in the context of relaxation, a condition deemed to be nonanxiety-producing. 
While this treatment approach is quite straightforward, its success is dependent on the appropriateness and the effectiveness of the two variables involved. As was noted, relaxation is generally the response paired with the phobic stimulus. Progressive relaxation is generally achieved through the manipulation of various muscle groups (Jacobson, 1938). However, Kroger and Fezler (1976) have stated that relaxation produced by means of hypnotic induction has proven to be much deeper than that obtained by standard procedures. They contended that hypnosis results in more control over the subject's autonomic functioning.

With regard to the stimulus factor, numerous behavior therapists have insisted that vivid and realistic imagery is a prerequisite to success in treatments such as desensitization (Cautela, 1971; Nawas, Maeliea and Fishman, 1971; Wolpe, 1969). Spanos, Demoor and Barber (1973) noted that the subject must be deeply involved in his imaginings in order for treatment to be effective. In reviewing the literature on the subject, Dengrove (1976) concluded that hypnotic vivification can be used to intensify the images used in covert sensitization. Likewise, Kline (1975) had stated that, within the hypnotic process, sensory-motor imagery activity assumes a level of accessibility that is frequently not encountered in the therapeutic settings where hypnosis is not employed.

To test these statements, Gibbons, Kilbourne, Saunders and Castles (1970) compared the effectiveness of systematic desensitization using muscle relaxation with hypnotic induction followed by images of anxietyprovoking test situations. They found that the hypnotic condition produced significantly greater reduction in test anxiety. They attributed their findings to the fact that, with the hypnotized subjects, positive affect could be directly induced rather than inferred to occur as a by- 
product of muscular relaxation. They also found that they could proceed directly to the most anxiety-arousing scenes without diminishing the relaxation of the subject. They further saw the subject under hypnosis as being more completely involved in his imaginings, since he actually believed he was experiencing the condition.

In addition to the enhancement evidenced in traditional behavior therapy with the incorporation of hypnotic techniques, hypnosis has been shown to facilitate a number of cognitive changes which would be relevant to stimulation-seeking and psychopathy. One such effect which has been subject to controversy is the increase or diminution of sensory acuity produced by hypnotic suggestion. At present there is little disagreement that hypnosis can cause a decrease in sensitivity. However, evidence of increases in sensitivity is somewhat more equivocal. As early as the end of the last century, Braid (1899) stated of hypnosis that: "In this process we have acquired the power of raising the sensibility to the most extraordinary degree. . . and that any or all of these senses may be raised to the exalted state of sensibility referred to, almost with the rapidity of thought" (p. 86). Most early speculations regarding this capacity have been based on clinical observation. For example, Bramwell (1913) cited evidence from his practice to show that hypnotic suggestion can markedly improve vision, hearing, sme11, lifted-weight discrimination, two-point limen and temperature discrimination. In reviewing these analyses, Sterling and Miller (1940) noted that the use of anecdotal evidence and poor experimental control rendered the validity of their findings tenuous. They drew into question the method of Prince (1914), who observed enhancement of peripheral vision during hypnosis. The point of contention was that Prince's 
patient was later determined to be subject to dissociative states. On the basis of their own research, Sterling and Miller concluded that hypnosis does not improve sensory acuity in normal subjects.

Zamansky and Brightbill (1964) addressed the issue of change in perceptual threshold in subjects whose initial sensitivity is less than optimal. They reasoned that subjects' initial thresholds may be inflated as a result of their expectancies for hypnosis. Their conclusion was that hypnosis could only improve sensitivity to the pre-existing level. Their research thus supports the observation of Sterling and Miller that acuity can be developed only to a set physiological limit and no further. It should be remembered, however, that diminution of cortical and physiological reactivity can be a chronic condition resulting from early traumatization (Salama and Ilunt, 1964) and that this condition has been demonstrated to exist in the psychopath. Consequently, with reference to psychopathy, baseline measures of reactance need not be interpreted as either transitory states associated with momentary expectancies nor an indication of genetic limitations. Therefore, these potentially discouraging findings in effect support the usefulness of the procedure specifically in the treatment of the psychopathic condition.

Sullivan's (1953) contention that regression to genetically older thought processes and to infantile and prenatal mental functions helps to reintegrate masses of life experience which have escaped structuralization into a functional unity may also have relevance to the use of hypnotherapy with psychopaths. Kline (1975) pointed out that the use of sensory hypnotic procedures frequently leads to a rapid regression to a rather complete sensory and motor level of behavior with vivid intensification of imagery. At such times, the entire hypnotic experience 
may proceed on a completely nonverbal level. Kline indicated that the experience or thought that remains within the sensory order becomes much more available to the hypnotic patient. While Schneck (1952) was more concerned with the psychoanalytic interpretation of such phenomena, he observed that considerable spontaneous sensory and motor activity was elicited during hypnoanalysis. Kline compared material evoked during these periods to "inner speech." He viewed the process of hypnotherapy as helping teach the patient how to communicate with himself, to become more aware of his own inner speech and inner sensory articulations, and to begin to develop comfort, ease and spontaneity in learning how to speak to himself.

Kroger (1976) noted that inner speech based on scene visualization of past experiences enhances control of functioning of the autonomic nervous system, which recent research (e.g. Miller, 1969) has indicated is not as autonomic as had previously been thought. Kroger termed the procedure "sensory imagery conditioning" and has seen this to be easily accomplished by an initial focus on ontogentically primitive, instinctual reflexes such as heaviness and lightness, which are readily mobilized since they are necessary to preserve the integrity of the organism.

Recent support for such theoretical reasoning comes from findings by Walker, Garrett and Wallace (1976) that earlier modes of sensory processing accompany hypnotic age regression. They investigated eidetic imagery, which involves the ability to examine a visual stimulus briefly, such as a picture or a design, and later project onto a neutral surface an image that represents an exact duplication of the original. This phenomenon, essentially nonexistent in adults, is found in a minority of 
children. Having been given instructions to regress to an earlier age, a smal1 percentage of the hypnotized subjects developed the capacity for eidetic imagery. The percentage exhibiting this ability was approximately equal to the ratio observed in children. None of the subjects had demonstrated eidetic imagery prior to age regression.

A related finding is that of Mysior (1971), who demonstrated that it is possible to convert certain types of mental processes from one sensory modality to another by means of hypnosis. Mysior trained subjects to accomplish the multiplication of large numbers through a purely visual process rather than the typical conceptual mode. He attributed the results to the removal of conditioned inhibitors which had previously constrained natural, simpler means of handling information. It would appear that with or without age regression, hypnosis provides a viable method of gaining access to faculties which, because of repression, disuse, incompatibility or some other causative factor, have become non-functional.

The ability of hypnosis to develop non-verbal capacities has also been demonstrated by Gur and Reyher (1976). Their results indicated that hypnosis led to significantly greater figural, but not verbal, creativity than did waking and simulation states. They viewed this as confirmation that hypnosis activates the nonverbal cerebral hemisphere.

The research on creativity and hypnosis has special relevance to the concept of psychopathy. Krippner (1968) noted that the transcendance of culturally-imposed imprints and of societal conditioning has always been a hallmark of creative persons. The applicability of this characteristic to psychopathic individuals as well is readily apparent. As cited earlier, the similarity between psychopaths and creative 
persons in their need for stimulation and their differences in its mode of gratification had been elucidated by Farley and Sewel1 (1976).

In contrast to the study of Gur and Reyher, Rosenberg (1976) observed the enhancing effects of hypnosis on verbal creativity. In this instance, writer's block was alleviated by post-hypnotic suggestion. That hypnosis unblocks by means of the removal of defensive structures was demonstrated in a quite thorough investigation by Bowers (1965). While she found that increased creativity was evidenced when hypnotized subjects were given instructions to be clever, original, flexible and fluent, the gains were not as appreciable as when the instructions included defensereducing suggestions to ignore the possibility of criticism and to feel confident about their ability. With regard to the specific utility of hypnosis, she found that non-hypnotized subjects who had participated in a relaxation program of equal length showed no significant gains in creativity scores as a result of the suggestions.

As noted previously, one possible method of increasing internal sources of stimulation, and perhaps also increase the much needed problemsolving capacity of the psychopath, is the development of fantasy resources. In view of the research on creativity, it appears that hypnotic procedures are particularly well-suited to help achieve this end. Whether this result may be achieved by removal of defensive structures, increased sensitivity, fostering an internal orientation of control, or by providing access to preverbal impressions, to unconscious material and to intuitive processes needs to be further clarified. In the meantime, it appears that a number of these potential mediating factors have particular relevance to the arousal theory of psychopathy. Since hypnosis is known to have an appreciable effect on these factors, it appears 
that hypnotherapeutic techniques may provide an appropriate resource in the modification of psychopathic behavior.

\section{Hypotheses to be Tested}

The present investigation proposed to show that individuals exhibiting a psychopathic orientation tend to be more reliant on repressive defenses in response to emotionally threatening stimuli than do nonpsychopaths. It was further proposed that, among those subjects demonstrating a repressive perceptual style, the correlative tendencies to attenuate perceptual input, to seek exaggerated amounts of stimulation, and to display an external orientation can be modified in both psychopathic and non-psychopathic subjects through the use of hypnosis in the context of sensory imagery conditioning techniques. In light of the particular relevance of this treatment procedure to the psychopathic condition, it is expected that the psychopathic and non-psychopathic subjects will be equally responsive to the treatment, while no change will be evidenced by the untreated control subjects. 


\section{CHAPTER III}

NETHODOLOGY

\section{Subjects}

The subjects of the present investigation were inmates at the State Reformatory for Men, a maximum security institution for adjudicated adult male felons under 21 years of age. They reside in the reception unit of the institution awaiting their initial appearance before the parole board, the body which officially assigns them to the Reformatory to serve their sentences. As such, they have not yet been assigned to the institution's education and work programs. They are generally confined to their single-occupant cells except during meals and recreational periods. Inmates are typically transferred from this cellhouse to other parts of the institution two to three months after their admission to the Reformatory. All subjects were experiencing their first incarceration in this institution. Because of the demonstrated effect of age on the relevant variables, only subjects between 18 and 21 years of age were considered for inclusion.

Design

The initial hypothesis of the present investigation proposes that psychopaths tend to be more reliant on repressive defenses in response to emotionally threatening stimuli than are non-psychopaths. To test this, a comparison of repressive tendencies was made between all men who entered the institution during the period of investigation who were 
viewed as displaying a psychopathic orientation and those who evidenced no psychiatric disturbances. Testing which enabled the classification and comparison of subjects was conducted within two weeks of their admission to the Reformatory.

The second hypothesis states that repressive and stimulation-seeking tendencies of both the psychopaths and non-psychopaths will be modified by the experimental procedure, remaining unchanged in those not receiving treatment. Therefore, within both the psychopathic and nonpsychopathic groups, subjects who were found to display repressive defenses were assigned on an alternating basis to the experimental and control conditions. Assignment to the conditions alternated in a numerical progression according to the inmates' institutional numbers. The result was a $2 \times 2$ experimental design. The investigation was conducted until it was possible to assign 15 subjects to each cell of the design, with 30 in the experimental condition and 30 control subjects (see Table 1).

TABLE 1

SUBJECT ASSIGNMENT

$\begin{array}{cc}\text { Psychopathic } & \text { Non-Psychopathic } \\ \text { Subjects } & \text { Subjects }\end{array}$

\begin{tabular}{|c|c|c|}
\hline $\begin{array}{c}\text { Experimental } \\
\text { Condition }\end{array}$ & $\mathrm{N}=15$ & $\mathrm{~N}=15$ \\
\hline $\begin{array}{l}\text { Control } \\
\text { Condition }\end{array}$ & $\mathrm{N}=15$ & $\mathrm{~N}=15$ \\
\hline
\end{tabular}

To enable a comparison of the amount of change demonstrated by each group, pre- and post-experimental measures were taken for each 
subject. Pre-testing was conducted one month following each subject's admission to the Reformatory. Post-testing occurred within three days following completion of experimental involvement. The difference observed in the two measures was used as the index of change.

\section{Instruments}

All inmates being used in the current study demonstrated an average or above average level of intellectual performance on the Army General Classification Test (AGCT). They were differentiated into psychopathic and non-psychopathic groups using the Minnesota Multiphasic Personality Inventory (MMPI) as a criterion. Dahlstrom and Welsh (1960) reported that psychopaths generally obtain MMPI profiles that are somewhat different than those obtained by normal subjects and other psychiatric groups. They described individuals with high Psychopathic Deviate (Pd) and Hypomania (Ma) scores as showing clear manifestation of psychopathic behavior. Hare (1970) cited a number of studies which indicate that the MMPI can reliably differentiate between psychopathic and nonpsychopathic criminals. Among these studies was his own research, which supported the validity of using the $\underline{\mathrm{Pd}}$ and $\underline{\mathrm{Ma}}$ scales as indicative of psychopathy. His findings were consistent with those obtained earlier by Craddick (1962) who demonstrated the concurrent validity of the two scales as an index of psychopathy. He devised a checklist of 56 characteristics considered by psychiatrists to be significant in diagnosing the psychopath. He subsequently found that the 27 prisoners who were diagnosed as psychopathic as a result of obtaining high scores on the checklist also obtained mean $\underline{t}$ scores of 70 or greater on the $\underline{\mathrm{Pd}}$ and $\mathrm{Ma}$ scales. Scores on the other subscales were equivalent to $t$ scores of 
less than 70. Two years after Craddick's study, a follow-up indicated that sixteen of the psychopathic group and two of the non-psychopathic group had returned to a prison during that time period, thereby giving considerable support to the predictive validity of the relevant indices.

In light of these findings, the criterion for psychopathy selected for use in the present study was an MMPI profile in which the $\underline{\mathrm{Pd}}$ and $\underline{\mathrm{Ma}}$ subscales were the only scores which yielded $\underline{t}$ scores greater than 70 . The non-psychopathic group consisted of subjects who obtained a normal limits profile on the MMPI, with all scores falling between $\underline{t}$ scores of 30 and 70.

The MMPI protocols were subjected to an additional screening utilizing the embedded version of the Revised Repression-Sensitization Scale (Byrne, Barry and Nelson, 1963). This scale, consisting of 182 items from the MMPI, is designed to be an indicator of the extent to which an individual utilizes repressive defenses in responding to emotionally threatening stimuli. The repression-sensitization dimension represents a continum, with those individuals falling at the repressive and exhibiting a relatively elevated threshold for emotional material and sensitizers demonstrating a relatively lowered threshold for such material. Byrne (1961) presented results from studies by a number of investigators supporting the concurrent and construct validity of the RepressionSensitization Scale as a measure of defensive behavior. A high degree of correlation has been demonstrated between scores on the RepressionSensitization Scale and other measures of perceptual defense. The Revised Repression-Sensitization Scale represents a slight refinement of the original scale achieved through item-analysis of the latter. To test the first hypothesis, all subjects falling into the psychopathic 
group were compared with those in the non-psychopathic group with respect to their scores on the Revised Repression-Sensitization Scale. As was indicated earlier, Zamansky and Brightbill (1964) presented evidence that perceptual thresholds could be lowered only in subjects who, supposedly because of their expectancies for hypnosis, initially exhibited inflated thresholds. In order to maximally demonstrate the effect of the experimental condition, it was necessary that the subjects initially exhibit evidence of the repressive tendency that was to be modified. Using norms established by the authors of the RepressionSensitization Scale, it was determined that, for the present sample, a mean score of 31 would be statistically significantly lower than the normative sample mean of 42 . Therefore, this was used as a cutting score, and only subjects who obtained a score of 31 or less were included in the experimental and control groups. These subjects, used to evaluate the second hypothesis that certain correlates of psychopathy could be modified by sensory imagery conditioning techniques, were placed on the pre-post testing schedule. In addition to a post-experimental measure of repression-sensitization, this included administration of Form V of the Sensation Seeking Scale (SS V: Zuckerman, Eysenck and Eysenck, 1978; see Appendix A), Rotter's (1966) Internal-External Locus of Control Scale, and the Kinesthetic After Effects Test (Petrie, 1967). As was indicated earlier, Petrie utilized the Kinesthetic After Effects Test in an effort to identify those subjects who tend to attenuate incoming sensory stimulation. She termed such individuals "reducers" and those who exaggerated the magnitude of sensory input "augmenters." The decision to use this index in the present investigation represents an attempt to respond to the recommendation of Bergin and Strupp (1972) 
concerning the distinction between external behavior and the internal experience. They noted that both are significant, and they contended that the evaluation of any therapeutic technique should consider change in both domains. It is felt by the present author that the dimensions of repression-sensitization and reduction-augmentation are descriptive of essentially the same process. Repression-sensitization appears to represent a characteristic mental set present in the perceptual process, whereas the reduction-augmentation score may be viewed as an index of the behavioral equivalent of this repressing or sensitizing tendency.

The kinesthetic sensory modality had been chosen by Petrie because it affords the advantages of minimal technical complexity, task familiarity, and less susceptibility to distraction. The validity of the Kinesthetic After Effects Test has been established in a number of studies, including those cited earlier which have related the reductionaugmentation tendency thus measured to physiological responsiveness (average evoked response, reaction time, and auditory threshold) and to behavioral indices of the need for stimulation (social extroversion, preference for complex stimuli, and scores on the Sensation Seeking Scale). Sales, Guydosh and Iacona (1974) have proposed that augmentingreducing is essentially the same concept as Pavlov's "strength of the nervous system" and suggested that some of the Pavlovian measures of strength would provide a more reliable and valid measure of the perceptual tendency. They noted that the Kinesthetic After Effects Test may be subject to weaknesses inherent in measures relying on change scores; i.e., change scores based on correlated responses have a low true-score component. However, subsequent research by kish et al. (1976) has failed to substantiate the superiority of Pavlovian measures, and the 
authors concluded that there is little justification for the use of these measures as a substitute for the after effects test.

In the present investigation, subjects were individually administered the Kinesthetic After Effects Test according to the instruction given by Petrie (see Appendix B). Petrie reasoned that those subjects who underestimate the magnitude of a stimulus tend generally to attenuate stimulation. The procedure outlined is designed to provide an analysis of the subject's kinesthetic sensory perception of an object. From this, a characteristic perceptual style may be inferred. Blindfolded subjects were presented with (1) a 30 inch long, wedge-shaped block which increased from .5 inch wide at its narrowest end to four inches wide at its widest end and (2) a 1.5 inch wide rectangular block. The subjects were asked to grasp the rectangular block with their preferred hand and then run their other hand forward along the tapered block until they reached the point where the width of the wedge seemed to be the same as the width of the rectangle. Average readings on the first six trials represented a baseline measure. This procedure was repeated three times. The four sets of trials were interspersed with 90 second rest periods during which the subjects held between the fingers of their dominant hand a block of wood 2.5 inches in width. The augmentation-reduction score was the difference between the baseline measurement and the average of measures obtained on subsequent trials. A second measure was taken approximately 48 hours after the first. In an effort to counter-balance the first administration, a relatively larger two inch block was used to obtain measures on the baseline and subsequent trials. A one inch block provided contrast stimulation during the intermittent rest periods. The subjects' augmentation-reduction score con- 
sisted of the average score for the two days, a negative score being indicative of a reducing tendency and a positive score indicating a tendency toward sensitization.

Bergin and Strupp also cited Cattell's (1966) argument in favor of distinguishing between source traits and surface traits. Source traits are underlying sources of behavior, while surface traits refer to the behavior itself. Reduction-augmentation and repression-sensitization both represent measures of perceptual defense. In the arousal theories of psychopathy, this tends to be viewed as a dynamic, etiological factor. The Sensation Seeking Scale, on the other hand, yields a measure of the subject's tendency to seek stimulation in an attempt to enhance the less than optimal level of arousal presumably resulting from a repressive perceptual style.

The SSS is a 40-item, forced-choice questionnaire with scales designed to measure the hypothesized dimensions of sensation-seeking: Thrill and Adventure Seeking ( $\underline{\text { TAS }})$; Experience Seeking ( $\underline{\text { ES }}$ ); Disinhibition (Dis); and Boredom Susceptibility (BS). TAS is defined as an interest in engaging in sports or other activities involving speed and danger. ES includes items indicating wanderlust, exhibitionism in dress and behavior, the use of marijuana and hallucinatory drugs, associating with unusual and unconventional persons, a liking of modern, arousing music and art, and contempt for authority. The Dis factor represents the desire for social and sexual disirhibition in the form of drinking, partying, gambling and variety in sexual partners. BS refers to a dislike of repetition, routine, and dull people, with restlessness resulting when things are unchanging. Each subscale of Form $V$ consists of 10 items, with higher scores being indicative of a 
relatively greater tendency to engage in the respective form of stimulation-seeking. A Total Score is obtained by summing all scored responses on the Scale.

The original SSS (SSS II: Zuckerman, Kolin, Price and Zoob, 1964) consisted of a General Scale derived from factor analyses of many diverse kinds of items reflecting a positive reaction to or desire for stimulating, exciting and novel kinds of experiences. Studies by Farley (1967) and Zuckerman and Link. (1968) suggested that the sensationseeking dimension may have more than one factor. In a comparison of global and specified measures of novelty-seeking, Pearson (1970) subsequently found, using the Novelty Experiencing Scale which she devised, that it was possible to divide the tendency to experience novelty into smaller, more homogeneous subconstructs which do not overlap. She concluded that relevant information is thus lost when global measures are employed.

Zuckerman (1971) factor analyzed the items of the original sSs, identifying four factors which showed good reliability for male subjects. Data presented by Stewart and MacGriffith (1975) substantially validated Zuckerman's analysis. Zuckerman et al. (1978) recently shortened the SSS, refined it so that its reliability across cultural groups was increased, and provided normative data on the resultant SSS V. As has been noted earlier, the various versions of the SSS have been used extensively in research establishing sensation-seeking as a correlate of psychopathy.

Rotter's Interna1-External Locus of Control Scale consists of 29 forced-choice items intended to distinguish between those individuals who perceive the occurrence of positive and negative events as being a 
consequence of one's own actions and thereby under personal control from those who perceive such occurrences as being unrelated to their own behavior and therefore beyond personal control. Rotter (1966) reported findings relative to the reliability of the Scale, and Brown (1974) has reviewed numerous studies testifying to its validity and usefulness as a measure of institutional adjustment in a correctional setting. Because the Scale contains six buffer items, 23 is the maximem score obtainable, indicating a relatively pronounced external orientation.

The second hypothesis that, unlike controls, experimental subjects would evidence change in their tendencies to repress, to seek exaggerated amounts of stimulation and to display an external orientation was evaluated by an examination of the amount of change observed between their pre- and post- experimental scores on the Repression-Sensitization Scale, the Kinesthetic After Effects Test, the Sensation Seeking Scale, and Rotter's Interna1-External Locus of Control Scale.

\section{Experimental Procedure}

Because of their emphasis on sensory processes in their approach to imagery conditioning, the techniques outlined by Kroger and Fezler (1976) were selected as constituting the experimental condition. Following pre-testing, experimental subjects were individually instructed in a modified version of the authors' double-bind hypnotic induction technique (see Appendix C). Elements of the Stanford Hypnotic Susceptibility Scale (Weitzenhoffer and Hilgard, 1959) were incorporated into the induction. The intention was to produce a state of deep relaxation and consequent heightened alertness and suggestibility. At the end of 
this introductory induction, the subjects were instructed in a method of autohypnosis adapted from Salter (1941) and asked to practice this five to ten minutes three times a day (see Appendix D).

Approximately three days following the initial session, the subjects began the imagery conditioning sessions. Each session opened with the standard hypnotic induction. Three of the 25 standardized images of Kroger and Fezler were then presented (see Appendix E). The purpose of the structured images was to produce relaxation and deepen the hypnosis so that conditioning would be stronger and more rapid. Each image consisted of a scene laden with impressions designed to stimulate one or a combination of the five sensory modalities. The images were presented so as to become increasingly complex, progressing from those sensory experiences which are easiest to recall to those which are more difficult. The more advanced scenes incorporated the experiences of time distortion and age regression as well. The intention of the pairing of the hypnotically-induced relaxation with the sensory-laden images was to reduce the amount of anxiety and consequent avoidance evidenced by the psychopath in his perceptual response to sensory input.

In order to provide continuity and familiarity in an attempt to enhance the deepening effect of the induction, the final scene from each preceding series was used as the initial scene during each session. The 25 scenes were thus presented in a total of twelve sessions. Discussion of the frequency of and the difficulties encountered in the practice sessions took place at the beginning of each experimental contact. 
Recent research (Barber and Calverly, 1964) has tended to support the legitimacy of using taped audio hypnotic induction procedures with college students. However, there is some evidence (Johnson and Wiese, 1979, in press) that taped procedures may be somewhat less effective than live when applied to a clinical population. Therefore, the initial induction was presented live, as was the induction during the third and seventh experimental contact, with the remaining inductions and the standardized images being presented using audio cassette tapes. It was felt that periodic personal contact would not only provide more effective hypnotic induction, but would help to maintain enthusiasm on the part of the subjects and thus enhance their motivation to practice the autohypnosis.

Post-testing of subjects in the experimental condition was conducted within three days following the final imagery conditioning session. This included repetition of the Sensation Seeking Scale, the Repression-Sensitization Scale, Rotter's Locus of Control Scale, and another measurement of the augmentation-reduction tendency using the Kinesthetic After Effects Test.

\section{Control Condition}

Subjects assigned to the control condition received no treatment. Although randomization was used in group assignment, the groups were scrutinized in an effort to assess the artifactual influence of age, educational background, socioeconomic status and nature of the commitment offense and to determine if any alteration in the assignment procedure was necessary. Since subjects were entering into the research at various times, a like number of control subjects were pre-tested on the 
days experimental subjects were first tested. Control subjects were post-tested on the days their experimental counterparts were posttested. Because of the highly structured environment which the control and experimental subjects share, it was felt that a difference in the amount of change observed in the subjects' test scores could be attributed to the experimental procedure.

\section{Follow-Up Interview}

Although the principal purpose of the present investigation was to modify the perceptual style of the experimental subjects, it was expected that changes consequent to this would be evident in their stimulation-seeking behavior and ultimately in their psychopathic orientation. In order to evaluate the magnitude, quality and permanence of such changes, a follow-up interview was conducted approximately six weeks following each experimental subject's completion of the sensory imagery conditioning regimen. The interview followed a semi-structured format (see Appendix F), with the experimenter rating subjects on a number of variables seen as relevant to institutional adjustment: Use of alcohol and drugs; difficulties with other inmates; involvement in institutional programming; amount of time spent in cell; feelings of boredom; difficulties in sleeping; somatic complaints; anxiety and depression. The rating took the form of a five-point Likert scale, with anchor points pertaining to increases or decreases in the frequency of experience. Incidence of positive or negative institutional behavior reports was also examined. Subjective impressions were solicited from each experimental subject regarding the perceived intent and effectiveness of the experimental procedure and its applicability to his circum- 
stances. Fina1ly, all items from the MMPI relevant to the entire $\underline{P d}$ and Ma subscales were administered in an attempt to gain an objective measure of change in psychopathic orientation.

Since it was felt desirable to obtain the post-test and follow-up measures at graduated points in time, and since both the RepressionSensitization Scale and the $\underline{\mathrm{Pd}}$ and $\underline{\mathrm{Ma}}$ subscales were taken from the MMPI, it was not viewed as feasible to administer the MMPI in toto on each occasion. A number of theorists have questioned the practice of presenting and interpreting the results of subscales given out of the context of the larger scale. Kestenbaum and Hammersla (1976), however, noted that an inspection of the literature revealed that the use of filler items has been accepted with 1ittle or no research as to whether the inclusion of such items in a test actually accomplishes any of the following: Prevents subjects from determining the purpose of the test; results in different scores than would be yielded if the test were administered without the filler items; or prevents subjects from responding in a socially desirable way. Their own research indicated that the presence of the filler items on Rotter's Locus of Control Scale did not in fact achieve any of these purposes. Similar results were obtained by Strahan and Wilson (1976), who found that the intent of the MarloweCrowne Social Desirability Scale was equally evident to subjects despite the addition of buffer items. Kestenbaum and Hammersla interpreted their findings as bringing into question the need to present an entire inventory rather than its individual subscales. Relative to this question, Newmark and Finch (1976) found that the diagnostic efficacy of the MMPI was not significantly affected when the larger inventory was abbreviated to the first 168 items. Therefore, in presenting individu- 
ally the Repression-Sensitization Scale and the Pd and Ma subscales, it is recognized that administering their respective 127 and 90 items is not equivalent to experiencing the entire 566-item inventory. However, it appears that the differential effect is not appreciable and should be distributed equally among all subjects.

\section{Statistical Analysis}

In order to assess the extent to which repressive tendencies are a correlate of psychopathy in a prison population, a $t$ test was conducted on the scores on the Repression-Sensitization Scale between subjects entering the institution during the investigation period who were determined, on the basis of the MMPI, to be psychopathic and those diagnosed as non-psychopathic.

The second hypothesis relating to the effects of the sensory imagery conditioning procedure was evaluated using the amount of change observed in subjects' scores on the pre- and post-measures of the RepressionSensitization Scale, Rotter's Locus of Control Scale, the Sensation Seeking Scale and the Kinesthetic After Effects Test. Bearing in mind the advantages of each procedure, the use of change scores was seen as more efficacious than analysis of covariance, and the decision was thus made to use the former. The change scores were subjected to a two-way analysis of variance in order to determine the main and interaction effects present in a comparison of psychopathic and non-psychopathic subjects in the experimental and control conditions. Finally, a correlation was computed to determine the magnitude and direction of the relationship between change in scores on the four measures and the amount of practice in autohypnosis reported to have been engaged in by the experimental subjects. 


\section{CHAPTER IV}

\section{RESULTS}

Repression-Sensitization as a Function of Pre-Experimental Psychopathic Orientation

During the period in which the present investigation was conducted, 103 new admissions to the Reformatory obtained profiles on the MMPI and scores on the AGCT which qualified them for inclusion in the study. Fifty-six were classified as psychopathic based on an MMPI profile with elevations on the $\underline{\mathrm{Pd}}$ and $\underline{\mathrm{Ma}}$ subscales. Forty-seven obtained normal limits profiles and were classified non-psychopathic. The protocols for these subjects were subsequently scored on Byrne's (1963) RepressionSensitization Scale. Since there is considerable item overlap between the Byrne scale and the subscales used to delineate the subjects by psychopathic status, a spuriously large discrepancy would be expected between the groups' mean repression-sensitization scores. However, this did not prove to be the case. The psychopathic and non-psychopathic groups obtained means of 29.46 and 29.57 respectively, with corresponding standard deviations of 10.95 and 14.00. A t test computed on this slight discrepancy yielded a non-significant $t(101)=.055$. Although the means of both samples indicate that the subjects tend to be more repressive than Byrne's standardization sample, which obtained a mean score of 42.25 , the results appear not to support the first hypothesis that psychopaths differ from non-psychopaths in the extent to which they 
rely on repressive defenses. However, this conclusion may be somewhat tempered by the results of the subsequent pre-experimental testing.

\section{Pre-Experimenta1 Group Comparisons}

Sixty-four percent of each diagnostic category received repressionsensitization scores of 31 or 1ess. These subjects were acceptable for. inclusion in the experimental and control conditions. Thirty subjects each from the psychopathic and non-psychopathic groups were assigned on an alternating basis to the two conditions. Two subjects from the psychopathic group had refused to participate in the experimental condition and were thus not considered for inclusion. Examination of the resulting four groups with respect to certain demographic variables, including age, nature of commitment offense, socioeconomic background and level of education, revealed no marked disparities, and it was decicled that no adjustments were necessary in the assignment technique.

Mean pre-test scores for the four groups on the RepressionSensitization Scale, Rotter's Locus of Control Scale, the Kinesthetic After Effects Test, and the Sensation Seeking Scale are reported in Table 2. F ratios related to the sources of variance among the means were computed and are reported in Table 3, along with the probability of each ratio and an index $\left(\omega^{2}\right)$ of the strength of the association between the particular effect and the total variance. Significant $\underline{F}$ ratios occur among the means of the Locus of Control Scale, the Kinesthetic After Effects Test and three measures of the Sensation Seeking Scale: Total Score; Experience Seeking; and Boredom Susceptibility. Significant main effects are present among the means of the three measures on the SSS as well as for the Kinesthetic After Effects Test. 
TABLE 2

GROUP MEANS AND STANDARD ERROR FOR TEST SCORES PRIOR TO SENSORY IMAGERY CONDITIONING

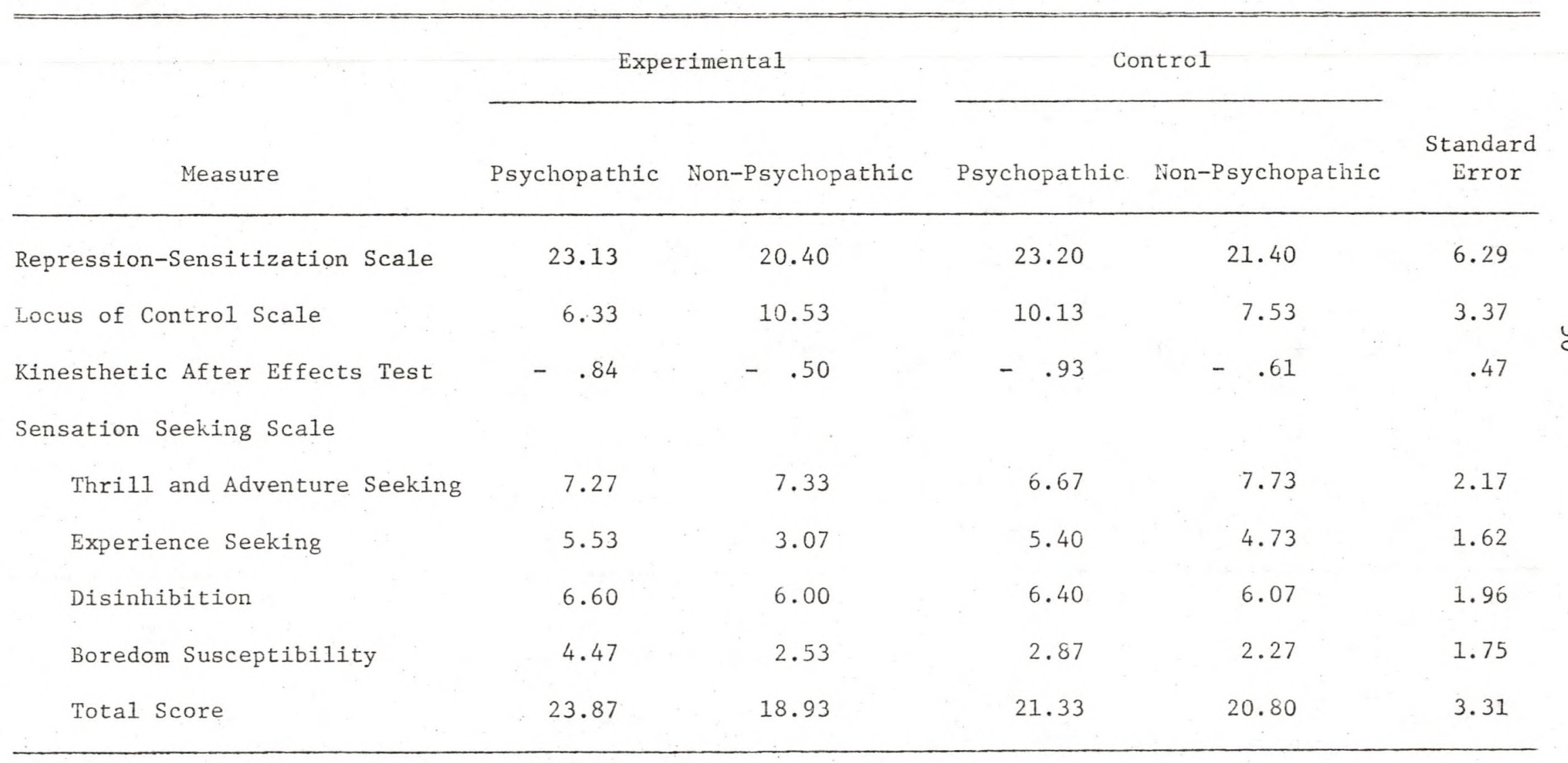


TABLE 3

F RATIOS FOR SOURCES OF VARIATION, PROBABILITY AND $\omega^{2}$ FOR MEAN TEST SCORES PRIOR TO SENSORY IMAGERY CONDITIONING*

\begin{tabular}{|c|c|c|c|c|c|c|c|c|c|}
\hline Measure & $\begin{array}{c}\text { Classification } \\
\text { Effect }\end{array}$ & $\begin{array}{l}\text { Proba- } \\
\text { bility }\end{array}$ & $\omega^{2}$ & $\begin{array}{c}\text { Experimental } \\
\text { Effect }\end{array}$ & $\begin{array}{l}\text { Proba- } \\
\text { bility }\end{array}$ & $\omega^{2}$ & $\begin{array}{c}\text { Interaction } \\
\text { Effect }\end{array}$ & $\begin{array}{l}\text { Proba- } \\
\text { bility }\end{array}$ & $\omega^{2}$ \\
\hline Repression-Sensitization Scale & 1.95 & .1685 & .016 & .11 & .7439 & .000 & .08 & .7750 & .000 \\
\hline Locus of Control Scale & .85 & .3613 & .000 & .21 & .6471 & .000 & 15.30 & .0003 & .195 \\
\hline Kinesthetic After Effects Test & 4.15 & .0463 & .048 & 400 & .0504 & .046 & .61 & .4381 & .000 \\
\hline Sensation Seeking Scale & & & & & & & & & \\
\hline Thri11 and Adventure Seeking & 1.02 & .3169 & .000 & .03 & .8592 & .000 & .79 & .3768 & .000 \\
\hline Experience Seeking & 14.01 & .0004 & .165 & 3.35 & .0724 & .030 & 4.62 & .0359 & .046 \\
\hline Disinhibition & .85 & .3615 & .000 & .02 & .8959 & .000 & .07 & .7936 & .000 \\
\hline Boredom Susceptibility & 7.83 & .0070 & .096 & 4.25 & .0439 & .046 & 2.17 & .1464 & .016 \\
\hline Total Score & 10.21 & .0023 & .125 & .15 & .6982 & .000 & 6.62 & .0128 & .076 \\
\hline
\end{tabular}

$* \mathrm{df}=1 / 56$ 
The largest E's were obtained for the SSS scores, which indicate a generally stronger approach to stimulation among the psychopaths relative to their non-psychopathic counterparts. The Newman-Keuls multiple comparison statistic indicates that, while the contrast is most pronounced when the comparison is with the non-psychopathic experimental subjects, the mean of the experimental psychopaths is significantly higher than that of any other group. The major contribution to this result comes from the scores on the Boredom Susceptibility subscale, for which post hoc comparisons yield similar results. However, the main effect for this latter measure also indicates that the experimental subjects as a whole tend to be more susceptible to boredom than do the controls. This finding, coupled with the apparent tendency of nonpsychopathic controls to engage in more Experience Seeking activities than those in the experimental group, who exhibit significantly less of this tendency than any other group, results in a significant interaction effect on the composite SSS Total Score. On the aftereffects measure, psychopathic subjects appear to attenuate incoming stimulation to a greater degree than do non-psychopathic.

Therefore, it appears that, while Repression-Sensitization Scale scores speak against a significant difference between psychopaths and non-psychopaths in their repressive tendencies, scores on the Sensation Seeking Scale and the Kinesthetic After Effects Test do indeed indicate some differences between the two groups in their perceptual style and the presumably consequent need for stimulation.

While not relating directly to the repressive dimension, the initial scores on Rotter's I-E Scale indicate that a pronounced interaction effect is operative in the expressed locus of control. Within 
the psychopathic group, control subjects tend to display a more external orientation than do experimental subjects, while the opposite is true for non-psychopathic subjects.

\section{Effects of Sensory Imagery}

\section{Conditioning}

The experimental procedure was conducted over a period of 14 weeks. The length of involvement by individual subjects ranged from 24 to 30 days. One experimental subject from the psychopathic group indicated a desire to terminate his participation following the initial hypnotic induction. His pre-test scores were consequently not included in the reported data.

An analysis of variance was computed on the change scores resulting from the pre- and post-experimental measures on the four scales. These results are presented in tabular form in Tables 4 and 5 and graphically in Figure 1. Significantly large $\mathrm{F}$ ratios accompany all four measures, generally indicating support for the hypothesized change in the direction of a less repressive style and consequent reduced stimulationseeking on the part of the experimental subjects relative to their controls. Consistent with previous research on psychopathy, it appears that, although psychopathic subjects show some evidence of change, they appear less responsive to ameliorative attempts than do non-psychopathic individua1s.

While repression-sensitization is conceptualized as a bipolar concept, with scores at either extreme being indicative of defensive operations, all scores obtained in the present sample are well below Byrne's (1963) standardization sample mean of 42.25 and would, therefore, appear to denote repressive defenses only. In light of this, it is possible to 
TABLE 4

GROUP MEANS AND STANDARD ERROR FOR TEST SCORES FOLLOWING SENSORY IMAGERY CONDITIONING

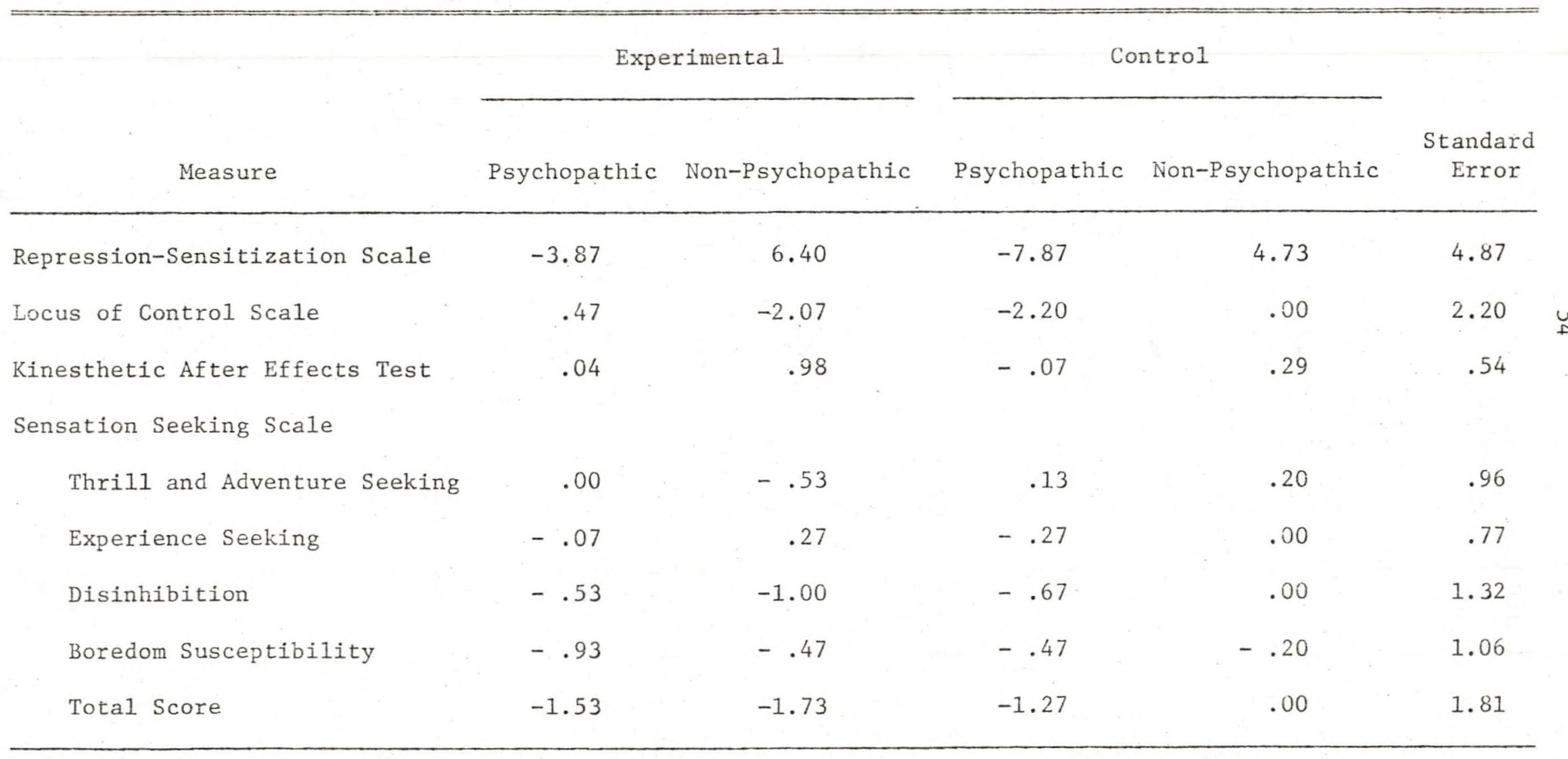




\section{TABLE 5}

E RATIOS FOR SOURCES OF VARIATION, PROBABILITY AIND $\omega^{2}$ FOR MEAN TEST SCORES FOLLOWING SENSORY IMAGERY CONDITIONING*

\begin{tabular}{|c|c|c|c|c|c|c|c|c|c|}
\hline Measure & $\begin{array}{c}\text { Classification } \\
\text { Effect }\end{array}$ & $\begin{array}{l}\text { Proba- } \\
\text { bility }\end{array}$ & $\omega^{2}$ & $\begin{array}{c}\text { Experimenta1 } \\
\text { Effect }\end{array}$ & $\begin{array}{l}\text { Proba- } \\
\text { bility }\end{array}$ & $\omega^{2}$ & $\begin{array}{c}\text { Interaction } \\
\text { Effect }\end{array}$ & $\begin{array}{l}\text { Proba- } \\
\text { bility }\end{array}$ & $\omega^{2}$ \\
\hline Repression-Sensitization Scale & 81.56 & .0001 & .557 & 5.31 & .0249 & .030 & .76 & .3859 & .000 \\
\hline Locus of Control Scale & .12 & .7261 & .000 & .34 & .5597 & .000 & 17.85 & .0001 & .224 \\
\hline Kinesthetic After Effects Test & 21.95 & .0001 & .228 & 8.51 & .0051 & .081 & 4.33 & .0420 & .036 \\
\hline \multicolumn{10}{|l|}{ Sensation Seeking Scale } \\
\hline Thrill and Adventure Seeking & .88 & .3518 & .000 & 3.04 & .0867 & .033 & 1.46 & .2324 & .007 \\
\hline Experience Seeking & 2.30 & .1346 & .021 & 1.39 & .2427 & .006 & .03 & .8667 & .000 \\
\hline Disinhibition & .09 & .7697 & .000 & 1.62 & .2077 & .010 & 2.78 & .1011 & .029 \\
\hline Boredom Susceptibility & 1.80 & .1853 & .013 & 1.80 & .1853 & .013 & .13 & .7159 & .000 \\
\hline Total Score & .51 & .4775 & .000 & 5.24 & .0259 & .063 & 4.01 & .0501 & .045 \\
\hline
\end{tabular}

$\star \mathrm{df}=1 / 56$ 
Repression-Sensitization Scale

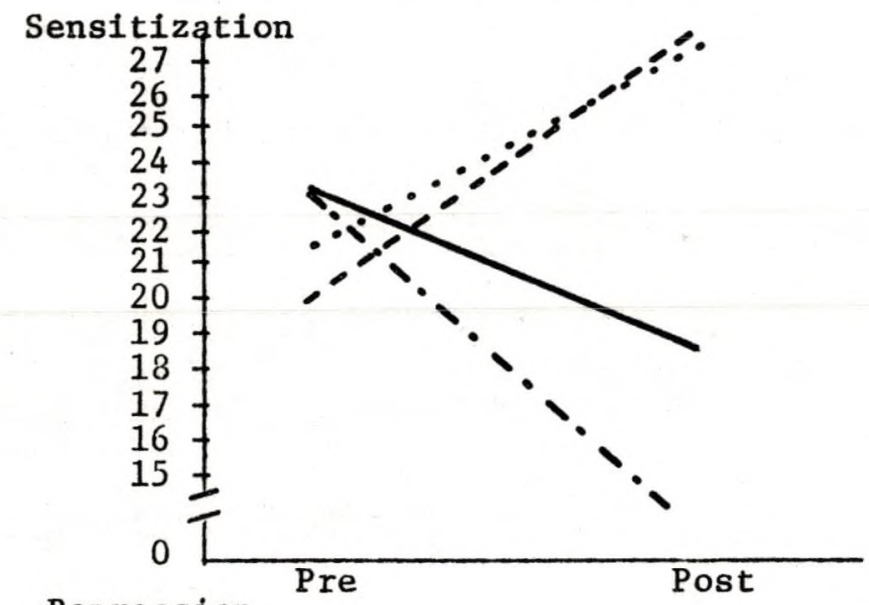

Repression

Sensation Seeking Scale - Total Score High

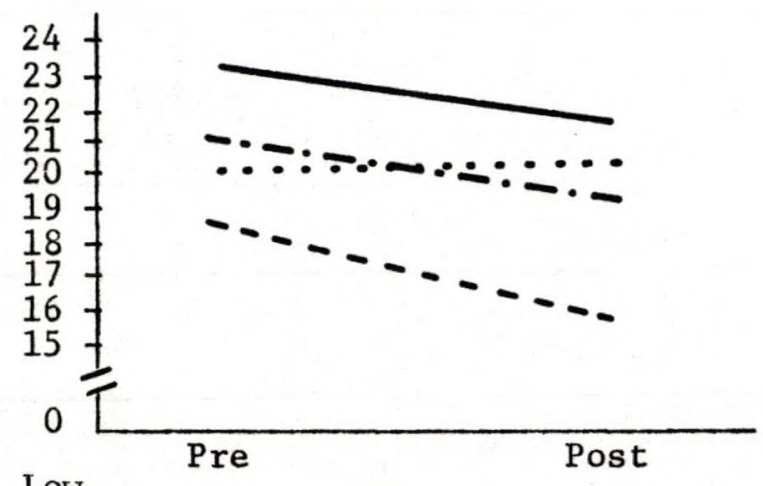

Low

Experimental - Psychopathic Experimental - Non-Psychopathic - - - -
Kinesthetic After Effects Test

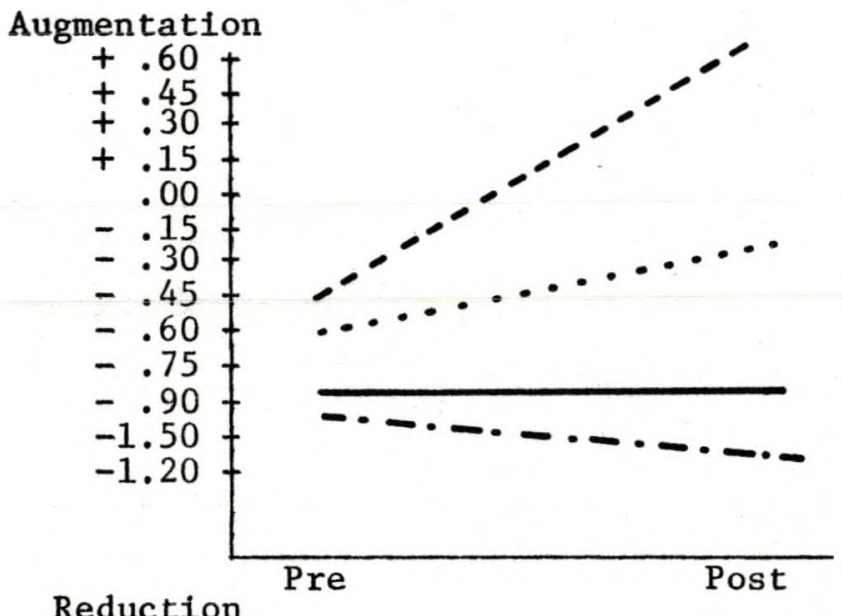

Locus of Control Scale

\section{Externa1}

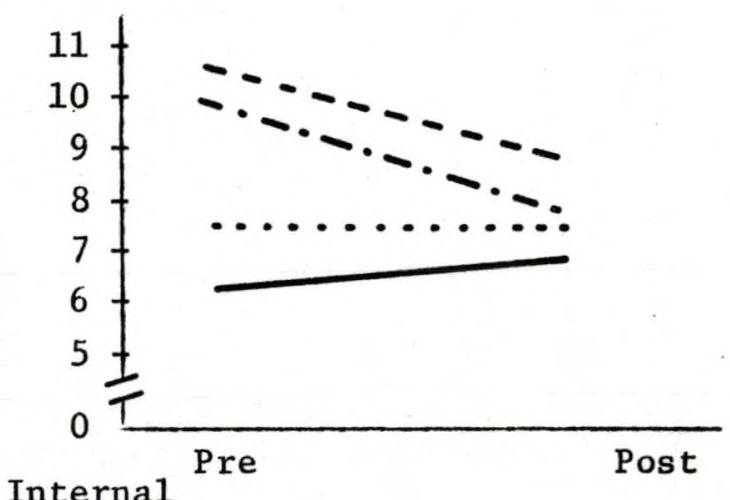

Contro1 - Psychopathic -...Contro1 - Non-Psychopathic ........

Fig. 1. Group Means for Pre- and Post-Testing 
view the change scores on the Repression-Sensitization Scale as indicating that non-psychopathic subjects tend to become less repressive, while the psychopathic group becomes more so. However, movement toward repression is less pronounced for the experimental psychopaths than for their control counterparts. Similarly, the non-psychopaths in the experimental condition show greater movement from repression than do their controls.

A change pattern similar to that observed in the scores on the Repression-Sensitization Scale is evident with the Kinesthetic After Effects Test. Once again, non-psychopathic subjects show a greater tendency toward auginentation, or at least a lesser tendency to reduce incoming stimulation, than do the psychopathic subjects. Also consistent with the pattern observed in the theoretically similar repressionsensitization dimension is the finding of a significant experimental main effect. The Newman-Keuls Test indicates that non-Psychopathic experimental subjects evidence considerably greater movement toward augmentation than do their controls. The same configuration exists among psychopathic subjects, but to an insignificant degree. This rate disparity contributes to the finding of a significant interaction effect. With regards to the Sensation Seeking Scale, only the change index on the Total Score yields a significant $\underline{F}$ ratio. In this instance, experimental subjects demonstrate a more pronounced shift away from stimulation-seeking behavior than do controls. While the $\underline{E}$ value for the interaction effect does not reach significance, an a posteriori comparison using the Newman-Keuls Test indicates that the bulk of the disparity can be attributed to the difference between the two non-psychopathic groups. 
Change scores on the Locus of Control Scale do show a significant interaction effect, the cause of which appears to have been the moderation of differences observed among the groups on the pre-test. While the non-psychopathic subjects in the control group evidence no change, those in the experimental condition show movement in the direction of displaying a more internal locus of control. The reverse condition appears to exist among the psychopathic subjects, with little change evident in the experimental group, who already exhibited relative internality, and a more internal locus apparent among the relatively external controls.

\section{Effect of Practice in Autohypnosis}

As was noted previously, a record was maintained of the amount of , time each experimental subject independently practiced autohypnosis between the experimental contacts (see Appendix G). Each subject had been requested to practice this procedure 20 to 30 minutes per day. A tally was made for each day in which the subject reported having practiced at least 20 minutes. Reported amounts of practice for subjects in both groups ranged from one to the maximum of 12 creditable days. The mean number of days in which psychopathic experimental subjects engaged in adequate practice is 5.67. The mean for the non-psychopathic group is 7. A comparison of these two means yielded a non-significant t $(28)$ of .926 .

In order to determine the relationship between the amount of practice in which a subject engaged and the amount of change observed in his test scores, a product moment correlation coefficient was computed. The computational results are reported in Table 6 . Only one of the 
resulting $\mathrm{r}^{\prime} \mathrm{s}$ is associated with a significantly small probability of occurrence. This resulted from the correlation of practice with change scores on the Repression-Sensitization Scale, indicating that those subjects who engaged in greater amounts of practice in autohypnosis tend to evidence greater movement away from the repressive end of the repression-sensitization continuum.

TABLE 6

PRODUCT MOMENT CORRELATION COEFFICIENTS FOR THE RELATIONSHIP BETWEEN CHANGE SCORES AND PRACTICE IN AUTOHYPNOSIS

\begin{tabular}{lcc}
\multicolumn{1}{c}{ Measure } & $\underline{r}$ & F-Value* \\
\hline Repression-Sensitization Scale & 0.44 & $6.57 * *$ \\
Locus of Control Scale & -0.12 & 0.43 \\
Kinesthetic After Effects Test & 0.30 & 2.78 \\
Sensation Seeking Scale & & 0.50 \\
Thrill and Adventure Seeking & -0.13 & 0.56 \\
Experience Seeking & 0.10 & 1.08 \\
Disinhibition & -0.19 & 1.09 \\
Boredom Susceptibility & 0.19 & 0.04 \\
\hline Total Score & -0.04 & \\
\hline
\end{tabular}

$$
* \underline{\mathrm{df}}=1 / 28
$$$$
* *_{p}<.05
$$

\section{Follow-Up Interview}

The data from the follow-up interview tend to support the conclusion that enhancement in global personal effectiveness resulting from the experimental procedure is not enduring in the institutional setting. 
An analysis of the amount of change observed on the $\underline{\mathrm{Pd}}$ and $\mathrm{Ma}$ subscales of the MMPI resulted in non-significant $\mathrm{F}$ ratios for all effects on both measures (see Tables 7 and 8). Although the mean change scores for the experimental group do tend to be larger, indicating relatively greater reduction in the profile elevation, than those of the control subjects, the results of the analysis of variance lead to the conclusion that changes in the experimental subjects' psychopathic orientation are either not appreciable or have not endured during the six weeks following experimental involvement.

TABLE 7

GROUP MEANS AND STANDARD ERROR FOR CHANGGE SCORES ON MMPI SUBSCALES

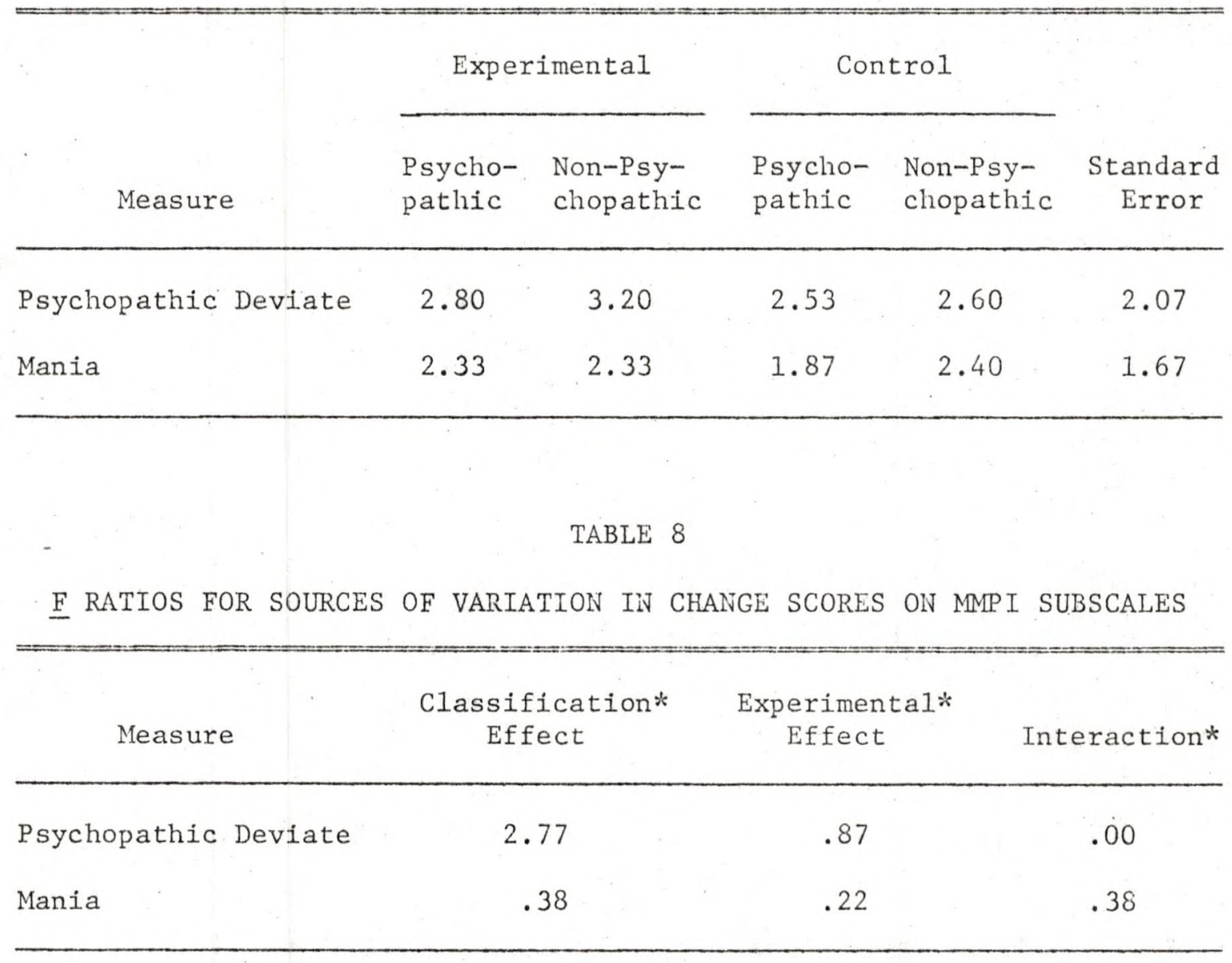

$* d f=1 / 56$ 
Other indices of adjustment investigated during the follow-up support this conclusion. An examination of the number of negative behavior reports incurred by the members of the various groups reveals no real differences from what would have been expected with any similar group of inmates. Once again, non-significant $\underline{F}$ ratios resulted from this comparison (see Tables 9 and 10). The respective means of .70 and .36 for the psychopathic and non-psychopathic subjects is consistent with Suinn's (1972) observation that psychopaths are guilty of more infractions in prisons than non-psychopathic inmates, but the presently observed discrepancy is not large enough to allow the conclusion of a significant difference between the groups.

TABLE 9

MEAN NUMBER OF BEHAVIOR REPORTS INCURRED DURING INVESTIGATION PERIOD

Experimenta1

Psychopathic Non-Psychopathic Psychopathic Non-Psychopathic

\section{Control}

Standard Error

\begin{tabular}{lllll}
.67 & .33 & .73 & .40 & .82 \\
\hline
\end{tabular}

TABLE 10

F RATIOS FOR SOURCES OF VARIATION IN NUMBER OF BEHAVIOR REPORTS

\begin{tabular}{ccc} 
Classification Effect* & Experimental Effect* & Interaction* \\
\hline 2.49 & .10 & .00 \\
\hline
\end{tabular}

$* \mathrm{~d} f=1 / 56$ 
Only one of the nine likert items on the follow-up inventory yielded scores indicative of a significant difference among the groups (see Tables 11 and 12). This involves the amount of time spent in the cell engaged in solitary activities. An $\mathrm{E}$ ratio of 4.15 indicates that a significant experimental effect is operative for this item. It appears that those who underwent the experimental procedure are subsequently more inclined to forego opportunities for interpersonal involvement in favor of more reclusive activities. 
TABLE 11

GROUP MEANS AND STANDARD ERROR FOR LIKERT-SCALED FOLLOW-UP MEASURES*

\begin{tabular}{|c|c|c|c|c|c|}
\hline \multirow[b]{2}{*}{ Measure } & \multicolumn{2}{|c|}{ Experimental } & \multicolumn{2}{|c|}{ Control } & \multirow[b]{2}{*}{$\begin{array}{c}\text { Standard } \\
\text { Error }\end{array}$} \\
\hline & Psychopathic & Non-Psychopathic & Psychopathic & Non-Psychopathic & \\
\hline Use of alcohol and drugs & 3.07 & 3.07 & 2.80 & 2.67 & .95 \\
\hline Difficulties with other inmates. & 2.87 & 3.20 & 3.13 & 3.00 & .73 \\
\hline Involvement in group activities & 2.67 & 2.73 & 2.47 & 2.60 & .82 \\
\hline Amount of time spent in cell & 2.87 & 2.80 & 3.27 & 3.20 & .80 \\
\hline Feelings of boredom & 2.47 & 2.53 & 2.60 & 2.47 & .89 \\
\hline Difficulties in sleeping & 2.60 & 2.73 & 2.73 & 2.60 & .77 \\
\hline Somatic complaints & 2.53 & 2.73 & 2.47 & 2.67 & .70 \\
\hline Anxiety, depression & 2.13 & 2.47 & 2.60 & 2.47 & 1.01 \\
\hline Vividness of mental imagery & 2.67 & 2.87 & 3.00 & 2.80 & .71 \\
\hline
\end{tabular}

$\star$ Scaling

$\begin{array}{llll}1 & 2 & 3 & 4\end{array}$


TABLE 12

F RATIOS FOR SOURCES OF VARIATION AMONG SCORES ON LIKERT-SCALED FOLLOW-UP MEASURES

\begin{tabular}{lccc}
\hline \multicolumn{1}{c}{ Measure } & Classification Effect* & Experimental Effect* & Interaction* \\
\hline Use of alcohol and drugs & .08 & 1.86 \\
Difficulties with other inmates & .28 & .04 & .07 \\
Involvement in group activities & .64 & .23 & .53 \\
Amount of time spent in cell & .11 & .02 & .03 \\
Feelings of Boredom & .03 & .00 & .00 \\
Difficulties in sleeping & .00 & .14 \\
Somatic complaints & 1.20 & .81 \\
Anxiety, depression & .15 & .06 \\
Vividness of mental imagery & .00 & .00 \\
\hline
\end{tabular}

$$
\begin{aligned}
& * \mathrm{~d} f=1 / 56 \\
& * *_{p}<.05
\end{aligned}
$$




\section{CHAPTER V}

DISCUSSION

The present investigation has attempted to provide some clarification of the dynamics of the psychopathic condition and to evaluate a therapeutic regimen intended to modify certain correlates related to an arousal theory of psychopathy. It was hypothesized that psychopaths would exhibit a more repressive perceptual style than non-psychopaths. The subjective effect of perceptual repression is presumably a less than optimal level of arousal and subsequent stimulation-seeking behavior, which may take the form of antisocial activity. A second hypothesis proposed that the perceptual style could be altered through the use of hypnosis and sensory imagery conditioning.

\section{Initial Group Differences}

The current findings do not lend substantial support to the contention that those incarcerated subjects diagnosed on the basis of the MMPI as psychopaths are initially more repressive in their perceptual style than are those diagnosed as normal. However, both groups evidence a significantly greater tendency toward repression than did the group upon which the Repression-Sensitization Scale was standardized. This outcome is consistent with the findings of Kilpatrick et a1. (1971), who also observed no significant differences in the repressive tendencies of normal and psychopathic prisoners. They concluded that both groups displayed a more repressive style than non-institutionalized, 
normal subjects. The variety of criteria they used for diagnosing psychopathy, all of which utilized MMPI subscales, indicated that a number of critical score configurations yielded slightly dissimilar results, giving the impression that psychopathy, at least as it relates to the repression-sensitization dimension, is a continuous rather than discrete variable. A comparison of the two groups in the present study with respect to their initial $\underline{\mathrm{Pd}}$ and $\underline{\mathrm{Ma}}$ scores yielded significant $\underline{\mathrm{t}}$ (101) scores of 7.04 for the Pd subscale and 10.40 for the Ma subscale, both of which are significant at the .01 level. Nevertheless, it might be surmised that the use of more stringent cutting scores or the use of a buffer range whose occupants were excluded from the study would have resulted in more disparate groups.

It is also conceivable that the groups in the present study are in fact quite similar with respect to certain correlates of psychopathy and not with others, with the two groups being more similar to one another on certain relevant variables than either is to a non-clinical population. Since most conceptualizations of psychopathy propose a multidimensional concept, the MMPI may differentiate psychopaths from non-psychopaths on some variables and not on others, repressionsensitization being one of those not adequately discriminated. Research by Unger (1970) and more recently Millimet and Cohen (1973) had led to the conclusion that Repression-Sensitization Scale scores may reflect a tendency to respond in a socially desirable way, with subjects viewing sensitizing behavior as indicative of personal maladjustment. Since the $\underline{\mathrm{Pd}}$ and Ma subscales are corrected for a social desirability bias, an excessively elevated score on the $\underline{\mathrm{K}}$ subscale would invalidate the measures. Although Kilpatrick et al. excluded subjects with elevations 
on the $\underline{F}$ scale, they apparently did not screen for extremes on $\underline{K}$. Theoretically, high scores on $\underline{\mathrm{K}}$ would inflate $\underline{\mathrm{Pd}}$ and $\underline{\mathrm{Ma}}$ scores and, at the same time, increase the likelihood of these subjects receiving scores on the Repression-Sensitization Scale that would be indicative of repressive tendencies. This may account for his finding of nonsignificant differences on the R-S Scale. While the present study attempted to reduce this possibility by screening for elevations on $\underline{\mathrm{K}}$, the effect of social desirability as well as of other potentially confounding variables may not have been effectively eliminated.

A source of potential bias might also lie in the recruitment method used in the present study. Since three subjects from the psychopathic group had refused to participate in the experimental condition, the remaining subjects could represent a sample which would be more open to a new experience and less concerned about maintaining a socially desirable posture than psychopaths in general. Kibrick (1975), however, observed that subjects of hypnosis experiments tended to show no significant differences in Repression-Sensitization Scale scores regardless of whether participation had been coerced or purely voluntary. Therefore, it appears that this source of bias would not be virulent with respect to the repression-sensitization dimension.

Despite the fact that voluntarism tends not to confound results as they pertain to the need for social approval, there is some evidence that the subjects' degree of openness to new experiences may result in group imbalance. Recent research (Stanton, 1976; Zuckerman, Schultz and Hopkins, 1966; and Zuckerman, 1978) has found that volunteers for experiments in hypnosis and sensory deprivation tend to score higher on the Sensation Seeking Scale than do non-volunteers. They attributed 
this finding to the subjects' expectations that participation in these activities would lead to strange and bizarre sensations, such as hallucinations. In the present study, significant pre-treatment differences among the groups on the SSS are predominantly the result of the exaggerated need for stimulation expressed by the psychopathic subjects in the experimental condition, with other groups closely approximating the standardization sample means reported by Zuckerman et al. (1978). Since this is the only group in which some subjects had either refused to participate or had terminated their involvement in the study prematurely, it is conceivable that attrition could account for the elevation observed in the scores of those psychopathic subjects who did volunteer for the experimental treatment.

A similar response pattern emerges for the Kinesthetic After Effects Test. Psychopathic respondents show a greater initial tendency toward reduction than do non-psychopaths. Once again, evidence can be cited (Zamansky and Brightbil1, 1964) which demonstrated that physiological threshold levels are often elevated due to expectancies created in subjects prior to hypnosis. In the present instance, hovever, both the experimental and the control groups contribute almost equally to the discrepancy between psychopathic and non-psychopathic mean scores. Therefore, it would appear that the observed difference is not due solely to momentary expectancies. Additionally, in light of the fact that the Kinesthetic After Effects Test is a measure of psychophysical threshold, it would appear unlikely that it would be a subject to the effects of a social desirability bias as is the Repression-Sensitization Scale. 
With regard to the aforementioned sources of bias which could potentially confound the results of the present investigation, it does not appear as though any would be consistently operative across the three measures. Therefore, accepting the results as they stand, it appears that the MMPI has differentiated two groups which differ in their reported tendency to seek variety in their sensory experience and in their demonstrated tendency to attenuate the stimulation that is available to them. It did not, however, delineate subjects according to their verbally reported tendency to repress emotionally threatening stimuli. It is possible that, with respect to threatening stimuli, the differential effect of the psychopathic factor is less potent and thus negated by the desire of all incarcerated subjects to place themselves in a socially desirable light.

\section{Treatment Effects}

Change scores on the three indices (the Repression-Sensitization Scale, the Kinesthetic After Effects Test, and the Sensation Seeking Scale) give support to the efficacy of the experimental procedure. On each measure, the mean change score for the experimental group shows greater change away from repressive, reductive and sensation-seeking tendencies than do those of the controls, regardless of psychopathic status, thus giving support to the hypothesis that these characteristics can be mollified. In light of their theoretical relevance to psychopathy, it appears that the present procedure has a demonstrated usefulness with this population.

The one measure for which significant treatment effects are not evident is the Locus of Control Scale, change scores on which appear 
not related in any consistent fashion to the experimental procedure. Austrin and Periera (1978) have observed that, for males, externality is not related to hypnotic susceptibility. Miller (1976) had earlier noted that, irrespective of a subject's position on the internalexternal dimension, reported hypnotic responsiveness did not differ. regardless of whether the subject engaged in self-hypnosis or conventional hetero-hypnosis. Therefore, it would appear that this dimension is unrelated to susceptibility regardless of induction technique. However, it would also seem that, as a subject gains mastery over his physiological or perceptual processes, he would exhibit greater internality in his expressed locus of control. Obviously, this has not proven to be the case in the present instance.

It may well be that the elements of the hypnotic procedure used in the present study are not particularly well-suited to the modification of locus of control in this essentially externally-oriented population. Subjects had initially received a standard hypnotic induction and were then instructed in techniques of self-hypnosis. Ruch (1975) has found that conventional heterohypnosis inhibits subsequent attempts at selfhypnosis. Therefore, it may be that the present subjects found selfhypnosis less rewarding, were primarily responsive to the heterohypnotic condition, and continued to view themselves as passive participants. In light of research by Johnson and Weight (1976) which showed that heterohypnosis was more likely to lead to a sense of loss of bodily control, the present induction sequence would not seem conducive to a positive change toward a more internal orientation.

While the scores on the Locus of Control Scale do not lend support to the efficacy of the experimental procedure, the finding of signifi- 
cant interaction effects among the means on both administrations of the Scale should be addressed. Initially, psychopathic subjects in the experimental condition expressed a relatively internal orientation, as did the non-psychopathic controls. The reverse was true for the remaining two groups. These results appear rather inexplicable according to any dynamic theory of psychopathy. However, the Scale appears quite susceptible to response sets. As was noted earlier, the items are straightforward, and buffer items do little to disguise the objective of the inventory. While the reasoning is admittedly conjectural, it is conceivable that psychopathic subjects, who tend to be high sensation-seekers and exhibit an attitude of approach toward hypnosis experiments, may have experienced disappointment and a feeling of impotence upon being excluded from participation (A number of subjects did in fact express a desire to experience the conditioning procedure at a later date). The opposite condition might exist for the non-psychopathic, experimental subjects who should be less inclined to seek such an experience and may view it as an imposition. Such an attitude might easily be converted to an expressed posture of externality. Some support for such a rationale may lie in an analysis of the change scores. Again a significant, but reverse interaction effect is present, resulting in a moderation of the differences among the groups. Post-test scores for all groups closely approximate the mean for incarcerated subjects reported by Brown (1974). Therefore, it would appear that differences were transitory and perhaps situationally determined and that Locus of Control scores are probably not related to psychopathy or the effectiveness of the present experimental procedure in a stable and significant manner. 


\section{$\underline{\text { Classification Effects }}$}

On certain measures, the effect of the imagery conditioning appears considerably more potent with the non-psychopathic group, a finding which may be seen as lending some credence to the notion that the psychopathic condition is intractable. This occurrence is most marked in the scores on the Repression-Sensitization Scale. As was noted earlier, both groups of psychopathic subjects show movement toward greater repression, but with the magnitude of change twice as great for the controls. If repression is in fact a defense mechanism upon which the psychopath is particularly reliant, then one might expect that, under periods of increased stress, this reliance would become more pronounced. Viewing incarceration and the accompanying restriction in outlets for stimulation-seeking as a stress-inducing condition, the present finding gives some support for the contention that repression is a dynamic factor in psychopathy. With regard to the experimental procedure, it appears that sensory imagery conditioning may at least serve to retard the mobilization of this maladaptive defensive operation.

Unlike the Repression-Sensitization Scale, change scores on the Kinesthetic After Effects Test show favorable movement away from a reduction tendency for both of the experimental groups as well as for the non-psychopathic control group. However, here, too, the change was more pronounced for the non-psychopathic subjects. As had been mentioned earlier, the suitability of the Kinesthetic After Effects Test has been challenged. However, in light of the observation that the relative configuration of scores on this test and those on the Repression-Sensitization Scale tend to parallel one another (a product moment correlation computed between the change scores on the two measures 
yielded an $\underline{r}$ or .545$)$, the concurrent validity of the two measures receives some substantiation.

A significant change is evident only in the composite score of the sub-scales of the Sensation Seeking Scale. For this Total Score, only the difference in change between the experimental and control subjects is significant. However, the interaction effect barely fails to reach significance, having an associated $\underline{F}$ ratio with a probability of occurrence of less than .06. Therefore, it might be said that the trend in the data is consistent with that for the other measures: Experimental subjects evidence greater change in the hypothesized direction; the experimental effect is less pronounced among psychopathic subjects than non-psychopaths.

One possible explanation for the finding that scores on the SSS do not exactly coincide with those of the other scales may be that the SSS is not particularly sensitive to momentary changes in the stimulationseeking tendency. Zuckerman (1976) discussed the distinction between state and trait indices and concluded that the latter give an indication of the madal state of the subject and are not as sensitive to change. Neary (1975) noted that the trait SSS has failed to predict situation specific responses and attempted to develop a state scale to measure changes in optimal levels of stimulation. While the reliability of this scale has not yet been adequately demonstrated, Neary's findings highlight a potential shortcoming of the SSS that may have a bearing on the current results.

\section{Effects of Practice in Autohypnosis}

A variable which does not appear to have had a material or consistent effect on outcome is the amount of practice in autohypnosis in 
which experimental subjects engaged. It might be concluded from the results that practice is simply unrelated to the effectiveness of the hypnotic suggestions. Mather and Degun (1975) found that, among their subjects, variations in amount of practice in hypnosis did not have a significant effect on the performance of posthypnotic suggestions. The previously cited findings of Ruch (1975) may also be relevant. The effectiveness of the entire autohypnotic element may have been undermined by apparently incompatible prior training in conventional hypnosis . Subsequent research, however, has failed to replicate this finding. Noting Ruch's arbitrary distinction between heterohypnosis and selfhypnosis and the minimal instruction subjects received regarding the accomplishment of self-hypnosis, research by Johnson (1979, in press) did not indicate that an inhibition effect was operative when selfhypnosis was preceded by heterohypnosis.

With specific relevance to the practice effect, Johnson, Johnson, 01son, and Newman (1978) found that, among children with learning disabilities, improved self-esteem was highly correlated with practice in self-hypnosis in the context of sensory imagery conditioning procedures. In the present investigation, the low correlations observed may, therefore, reflect aspects of the experimental procedure which were not conducive to a true analysis of the practice effect. Zuckerman (1978) noted that, while high sensation-seekers are attracted to the novelty which hypnosis and sensory deprivation experiments promise, they do not usually persist in isolated activities such as meditation, which they find boring, a relevant finding considering the isolated nature of autohypnosis. In examining the daily tallies for practice, it is apparent that, among those subjects who did not report a full contingent 
of sessions, the bulk of their practice occurred in the earliest portion of the experimental regimen. This appears to be particularly true for the psychopathic subjects (see Figure 2). Since post-testing was conducted at a considerably later date, it is likely that, for these subjects, substantial dimunition of the experimental effect due to practice had already taken place.

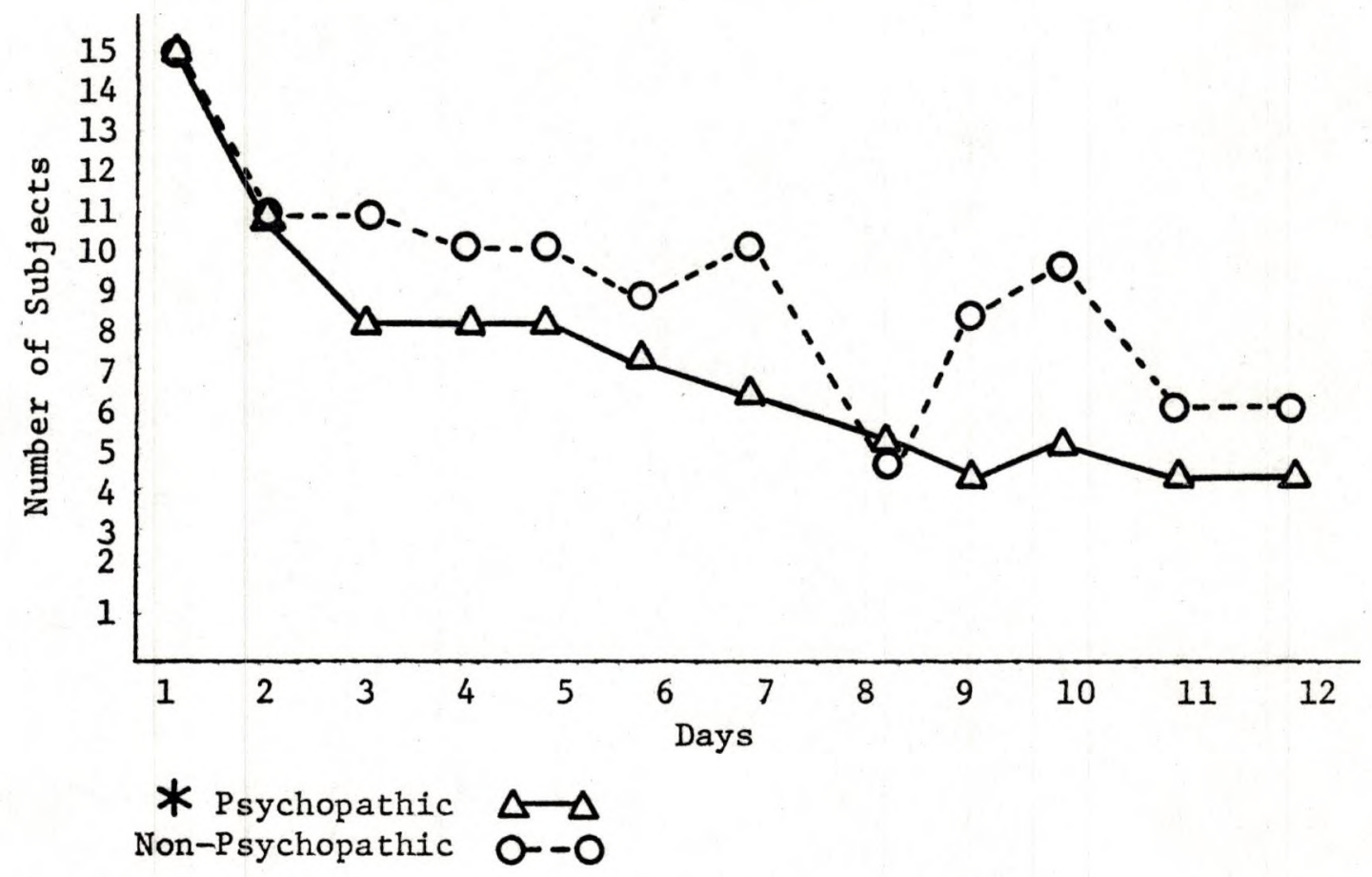

Fig. 2. Number of subjects engaged in at least twenty minutes of practice on each experimental day.*

\section{Follow-Up Interview}

With regard to the follow-up data, an analysis of the amount of change observed on the $\underline{\mathrm{Pd}}$ and $\underline{\mathrm{Ma}}$ subscales of the MNPI resulted in nonsignificant $\underline{F}$ ratios. This finding may be taken as evidence that the effect of the experimental procedure although yielding changes in the perceptual process, is not enduring or that it does not generalize sufficiently to significantly alter the psychopathic personality structure. 
However, an equally plausible explanation is that the relevant subscales of the MMPI are not particularly sensitive, or at least not immediately responsive, to sma11 or momentary personality changes. A relatively large number of these items refer to events in the subject's personal history and, therefore, are unlikely to change without a drastic change in his perception of these events. A number of other items involve activities in which incarcerated subjects have no opportunity to engage. Nevertheless, other indices of change covered in the follow-up interview tend to support a conclusion of negligible enhancement in personal effectiveness of a general or enduring nature.

The only measure which appears related in any appreciable way to the experimental condition is the amount of time inmates spend in their cells. Those who participated in the experimental treatment procedure tend to spend more time engaged in this solitary activity than do those in the control groups. Presumably these subjects are either exhibiting a reduced need for stimulation or have developed intrinsic sources of stimulation. Although no significant difference was observed among the groups in the change they noticed in the vividness of their mental imagery, a number of subjects did comment that they were more able to make themselves content in their cells by daydreaming. Greater reliance on this mental activity may help account for the observed difference in cell time.

Shortcomings in the follow-up procedure may have contributed to the scarcity of significant differences among the groups. Aside from the scores on the MMPI, the problems with which have already been discussed, none of the follow-up measures had a pre-experimental baseline against which they could be compared. The Likert-scaled items relied 
upon the subject's recollection of his experience during what may have been a particularly upsetting period (i.e. the first weeks of his first adult incarceration) and not especially conducive to introspection or evaluation of his status. The item dealing with the amount of time spent in the cell is perhaps the least affectively-tinged of all the items and thus may be associated with a more objective evaluation.

A further difficulty with these items is their reliance on the experimenter as a rater. While the obvious problem of experimenter bias may have been a factor, Barber (1967) has alluded to an additional difficulty in such an arrangement. He noted that experimental subjects in hypnosis experiments receive a greater share of the experimenter's time and interest than do controls and are more inclined to comply with his instructions or suggestions. This compliance may manifest itself in a desire to demonstrate enhanced functioning for the experimenter's benefit. While this tendency is not readily apparent in light of the lack of significant findings, the procedure is nonetheless subject to an interaction of biases on the part of both the experimenter and subject which could best be eliminated through the use of independent raters.

Among the experimental subjects, a number of inmates gave credit to the experimental procedure for their self-observation that they were now able to tolerate better the boredom inherent in confinement. In spite of the singularity of the significant change indices, subjective impressions as to the effectiveness of the procedure were generally positive, although most perceived the purpose of the project as relaxation training. Some behavioral support for the credibility of these assertions is found in the observation that a considerably larger pro- 
portion of the experimental subjects have subsequently sought further contact with the experimenter than have the controls.

\section{Recommendations}

Keeping in mind Barber's comments regarding the establishment of rapport, this latter observation may merely be the result of the greater amount of contact and consequent familiarity engendered by the frequent experimental sessions. In fact, a number of observed differences among subjects may be artifactual and not specifically due to the psychopathic personality structure or to the experimental procedure. However, it does appear that a number of positive changes have occurred in subjects during the course of their involvement in the treatment condition. It remains for future research to determine whether this is in fact another placebo effect or, if not, which particular elements in the design were most efficacious.

The use of a greater variety of comparison groups might serve to pinpoint sources of variance. It is suspected that, in the present study, the effect of incarceration may have been quite profound for these first admissions and may have obscured the effects of the treatment procedure. A comparison between non-institutional samples might eliminate the effects of negative affect stemming from confinement as we11 as allow greater opportunity for change and measurement in a context which is not so limited in the sources of stimulation available. Additional treatment procedures might also be employed. A number of studies already cited (Gibbons et al., 1970; Gur and Reyher, 1976; Mather and Degun, 1975) have noted the superiority of hypnosis over relaxation and free-imagery in enhancing creativity and modifying 
affect. However, other investigators have presented modifications of these latter techniques which they feel are as effective as hypnotic induction. From his series of experiments, Barber (1969) concluded that his task motivating instructions (TMI) provide one such procedure. Starker (1974) supported this contention by demonstrating no difference in the vividness of visual imagery when either hypnosis or task motivation was employed. While some investigators (e.g. Barrios, 1976) view Barber's TMI as merely another form of hypnotic induction, it nonetheless offers an alternate, yet analogous, procedure that might be employed. Without reference to the form of hypnotic induction, Schofield and Platoni (1976) highlighted the importance of the hypnotist's verbal reinforcements in stimulating imagery, thereby providing a potentially enhancing modification of conventional technique still within the hypnotic framework.

The relative benefits of heterohypnosis and autohypnosis have already been discussed to some extent. Studies by Johnson and Weight (1976) and Ruch (1975) have both concluded that the two methods yield similar results. However, with respect to the present population, other considerations may tend to complicate matters. While some subjects in the present study indicated that they felt more comfortable in the imagery conditioning sessions when the experimenter was absent, in light of Zuckerman's (1978) comments regarding the tendency not to persist in isolated activities, it would seem that more favorable results might be achieved if the hypnotic inductions and sensory images were all presented individually by the experimenter. It is likely that this could have the effect of instilling greater enthusiasm in the subject and perhaps motivate more strict adherence to a practice routine, as 
well as enabling the experimenter to gauge better the effect of practice on the subject's daily experimental effectiveness.

With respect to the measures that might be employed, a number of options have already been considered: The use of a neutral range in the delineation of psychopathic and non-psychopathic subjects; the selection of instruments sensitive to state changes such as Neary's (1975) modification of the SSS and certain physiological indices of arousal; the elimination of social desirability bias. This latter refinement might be accomplished through procedures which more obviously ensure anonymity and with the use of independent raters who do not have an established relationship with the subject and who are not viewed as having authority over the subject's institutional management.

In spite of the fact that the present findings are not unequivocally encouraging, they do indicate that small inroads are possible with specific correlates of psychopathy, a condition heretofore all too often viewed as totally intractable. 


\section{REFERENCES}

Albert, R. S., Brigante, T. R., \& Chase, M. The psychopathic personality: A content analysis of the concept. Journal of General Psychology, 1959, 60, 17-28.

American Psychiatric Association. Diagnostic and statistical manual II: Mental disorders. Washington, D.C.: APA, 1968.

Austrin, H. R., \& Pereira, M. J. Locus of control as a predictor of hypnotic susceptibility. American Journal of Clinical Hypnosis, $1978,20,199-202$.

Barber, T. X. "Hypnotic" phenomena: A critique of experimental methods. In J. E. Gordon (Ed.), Hypnosis. New York: Macmillan, 1967.

Barber, T. X. Hypnosis: A scientific approach. New York: Van Nostrand, 1969.

Barber, T. X., \& Calverly, D. S. Comparative effects on "hypnotic-like" suggestibility of recorded and spoken suggestions. Journal of Consulting Psychology, 1964, 28, 384.

Barios, A. A. Posthypnotic suggestions as higher-order conditioning. In E. Dengrove (Ed.), Hypnosis and behavior therapy. Springfield: Charles C. Thomas, 1976.

Bergin, A. E., \& Strupp, H. H. Changing frontiers in the science of psychotherapy. Chicago: Aldine, 1972 .

Bowers, P. G. Effect of hypnosis and suggestions of reduced defensiveness on creativity test performance. Dissertation Abstracts Internationa1, 1965, 26, 2864-2865. (University Microfilms No. $65-11,745)$

Braid, J. Braid on hypnotism. In A. E. Waite (Ed.), Neurypnology. Edinburgh: A \& C Black, 1899.

Bramwe11, J. M. Hypnotism. London: W. Rider \& Sons, 1913.

Brown, J. G. Internal-external locus of control and adjustment in a correctional institution. FCI Research Reports, 1974, 6(4).

Bruner, J. S. \& Postman, L. Emotional selectivity in perception and reaction. Journal of Personality, 1947, 16, 69-77.

Buss, A. H. Psychopathology. New York: John Wiley \& Sons, 1966. 
Byrne, D. The repression-sensitization scale: Rationale, reliability, and validity. Journal of Personality, 1961, 29, 334-349.

Byrne, D., Barry, J., \& Nelson, D. Relation of the revised repressionsensitization scale to measures of self-description. Psychological Reports, 1963, 13, 323-334.

Cautela, J. R. Covert extinction. Behavior Therapy, 1971, 2, 192-200.

Chesno, F. A., \& Kilman, P. R, Effects of stimulation intensity on sociopathic avoidance learning. Journal of Abnormal Psychology, $1975,84,144-150$.

Cleckley, H. Psychopathic states. In S. Arieti (Ed.). American handbook of psychiatry (Vo1. 1). New York: Basic Books, 1959.

Cleckley, H. The mask of sanity (4th ed.). St. Louis: Mosby, 1964.

Craddick, R. A. Selection of psychopathic from non-psychopathic prisoners within a Canadian prison. Psychological Reports, 1962, 10, 495-499.

Dahlstrom, W. M., \& Welch, G. S. An MMPI handbook: A guide to use in clinical practice and research. Minneapolis; University of Minnesota Press, 1960.

Davison, G. C., \& Neale, J. M. Abnormal psychology: An experimental approach. New York: John Wiley \& Sons, 1978.

Davison, P. O., \& Bobey, M. J. Repressor-sensitizer differences on repeated exposures to pain. Perceptual and Motor Skills, 1970, 31, 711-71.4.

Denenberg, V. H. The interactive effects of infantile and adult shock levels upon learning. Psychological Reports, 1959, 5, 357-364.

Dengrove, E. Hypnosis and behavior therapy. Springfield: Charles C. Thomas, 1976 .

DeRopp, R. S. The master game: Pathways to higher consciousness beyond the drug experience. New York: Belecorte Press, 1968.

Ellingson, R. J. Incidence of EEG abnormality among patients with mental disorders of apparently nonorganic origin: A criminal review. American Journa1 of Psychiatry, 1954, 111, 263-275.

Eysenck, H. J. The dynamics of anxiety and hysteria. London: Routeledge \& Kegan Paul, 1957.

Eysenck, H. J., \& Eysenck, S. B. An improved short questionnaire for the measurement of extraversion and neuroticism. Life Sciences, $1964,3,1103-1109$.

Eysenck, H. J., \& Eysenck, S. B. Personality structure and measurement. San Diego: Knapp, 1969. 
Farley, F. H. Social desirability and dimensionality in the sensation seeking scale. Acta Psychologica, 1967, 26, 89-96

Farley, F. H. The stimulation-seeking motive and extraversion in adolescents and adults. Adolescence, 1977, 12, 65-71.

Farley, F. H., \& Sewe11, T. Test of an arousal theory of delinquency. Criminal Justice and Behavior, $1976, \underline{3}, 315-320$.

Farley, F. H., \& Cox, S. 0. Stimulus-seeking motivation in adolescents as a function of age and sex. Adolescence, 1971, 6 , 207-218.

Garmezy, N. Vulnerability research and the issue of primary prevention. American Journal of Orthopsychiatry, 1971, 41, 101-116.

Gibbons, D., Kilbourne, L., Saunders, A., \& Castle, C. The cognitive control of behavior: A comparison of systematic desensitization and hypnotically-induced "directed experience" techniques. American Journal of Clinical Hypnosis, 1970, 12, 141-145.

Gray, K. C., \& Hutchison, H. C. The psychopathic personality: A Survey of Canadian psychiatrists' opinions. Canadian Psychiatric Association Journa1, 1964 , 9., 452-461.

Greenacre, P. Problems of patient-therapist relationship in the treatment of psychopaths. In R. M. Lindner \& R. V. Seliger (Eds.), Handbook of correctional psychology. New York: Philosophical Library, 1947.

Greer, S. Study of parental loss in neurotics and sociopaths. Archives of General Psychiatry, 1964, 11, 177-180.

Gur, R. C., \& Reyher, J. Enhancement of creativity via free-imagery and hypnosis. American Journal of Clinical Hypnosis, 1976, 18, $237-249$.

Hare, R. D. Detection threshold for electric shock in psychopaths. Journa1 of Abnorma1 Psychology, 1968, 73, 268-272.

Hare, R. D. Psychopathy: Theory and research. New York: John Wiley \& Sons, 1970.

Hare, R. D., \& Thorvaldson, S. A. Psychopathy and response to electrical stimulation. Journal of Abnormal Psychology, 1970, 76, 370374 .

Hebb, D. O. On the nature of fear. Psychological Review, 1946, 53, $259-276$.

Henderson, D. K. Psychopathic states. New York: Norton, 1939.

Hi11, A. B. Extraversion and variety-seeking in a monotonous task. British Journa1 of Psychology, 1975, 66, 9-13. 
Hi11, D. Amphetamine in psychopathic states. British Journal of Addiction, $1947,44,50-54$.

Hutchings, B. E., \& Mednick, S. A. Registered criminality in the adoptive and biological parents of registered male adoptees. In S. A. Mednick, F. Schulsinger, J. Higgins, \& B. Bell (Eds.), Genetics, environment and psychopathology. New York: Elsevir, 1974 .

Jacobs, K. W. Intercorrelation of the sensation seeking scale, Eysenck personality inventory, and Rotter's internal-external control scale. Southern Journal of Lducational Research, 1977, 11, 9-16.

Jacobson, E, Progressive relaxation. Chicago: University of Chicago Press, 1938.

Johnson, D. L., Johnson, L. S., O1son, M., \& Newman, J. P. The uses of hypnotherapy with learning disabled children. Paper presented at a meeting of the Canadian Council on Exceptional Children, Winnipeg, October 1978.

Johnson, L. S. Self-hypnosis, behavioral and phenomenological comparisons with heterohypnosis. International Journal of Clinical and Experimental Hypnosis, 1979, in press.

Johnson, L. S. \& Weight, D. G. Self-hypnosis versus heterohypnosis: Experiential and behavioral comparisons. Journal of Abnormal Psychology, 1976, 85, 523-526.

Johnson, L. S. \& Weise, K. F. Live versus tape-recorded assessments of hypnotic responsiveness in pain-control patients. International Journal of Clinical and Experimental Hypnosis, 1979, in press.

Karpman, B. The structure of neurosis: With special differentials between neurosis, psychosis, homosexuality, alcoholism, psychopathy, and criminality. Archives of Criminal Psychodynamics, 1961, 4, $599-646$.

Kavka, J. Pinel's conception of the psychopathic states: An historical critique. Bulletin of historical medicine, 1949, 23, 461-468.

Kestenbaum, J. M., \& Hammersla, J. Filler items and social desirability in Rotter's locus of control scale. Journal of Personality Assessment, $1976, \underline{40}, 162-168$.

Kibrick, S. A. Characteristics of volunteers for hypnosis research under three recruitment conditions. Dissertation Abstracts Internationa1, $1976,36,5879 B$.

Kilpatrick, D. G., Cauthen, N. R., \& Roitzsch, J. C. Psychopathy, repression-sensitization, and anxiety. Psychological Reports, $1971,28,615-618$.

Kline, M. V. Sensory hypnotherapy and repression during psychological stress. Clinical Social Work Journa1, 1975, 3, 298-308. 
Kroger, W. S. Behavior modification and hypnotic conditioning in psychotherapy. In E. Dengrove (Ed.), Hypnosis and behavior therapy. Springfield: Charles C. Thomas, 1976.

Kish, G. B., Franke1, A., Masters, J. J., \& Berry, R. A. Augmentingreducing and sensation seeking: A test of Sales' hypothesis. Journal of Clinical Psychology, 1976, 32, 302-305.

Krippner, S. The psychedelic state, the hypnotic trance, and the creative act. Journal of Humanistic Psychology, 1968, 8, 49-67.

Kroger, W. S., \& Fezler, W. D. Hypnosis and behavior modification: Inagery conditioning. Philadelphia: Lippencott, 1976.

Lefcourt, H. M., \& Ladwig, G. W. Alienation in Negro and white reformatory inmates. Journal of Social Psychology, 1966, 68, 153-157.

Lindner, R. Rebe1 without a cause. New York: Grune \& Stratton, 1944.

Lindsley, D. B. Emotions and the encephalogram. In M. L. Reymert (Ed.), Feelings and emotions. New York: McGraw-Hi11, 1950.

Lykken, D. T. A study of anxiety in the sociopathic personality. Unpublished doctoral dissertation, University of Minnesota, 1955.

Lynn, R., \& Eysenck, H. J. Tolerance for pain, extraversion, and neuroticism. Perceptual and Motor Skills, 1961, 12, 161-162.

Masters, R., \& Houston, J. Mind games. New York: Viking Press, 1972.

Mather, M. D., \& Degun, G. S. A comparative study of hypnosis and relaxation. British Journal of Medical Psychology, 1975, 48, 55-63.

Maughs, S. Concept of psychopathy and psychopathic personality: Its evolution and historical development. Journal of Criminal Psychodynamics, 1941, 2, 329.

McCleary, R. A. Response-modulating functions of the limbic system: Initiation and suppression. In E. Stellar \& J. Sprague (Eds.), Progress in physiological psychology (Vo1. 1). New York: Academic Press, 1966.

McCord, W., \& McCord, J. Psychopathy and delinquency. New York: Grune and Stratton, 1956.

McCord, W., \& McCord, J. The psychopath: An essay on the criminal mind. Princeton: Van Nostrand, 1964.

Miller, L. J. A Comparison of hypnotic susceptibility for internal and external locus of control subjects in hetero- and self-hypnotic treatments. Dissertation Abstracts International, 1976, 37, 978B979B. (University Microfilms No. 76-18, 342) 
Miller, N. A. Learning of visceral and glandular responses. Science, $1969,163,434$.

Millimet, C. R., \& Cohen, H. J. Repression-sensitization: A Reflection of test-taking set or personal adjustment. Journal of Personality Assessment, 1973, 37, 255-259.

Montagu, A. Chromosomes and crime. Psychology Today, 1968, 2, 42-49.

Mysior, A. Shifting from conceptual to visual problem solving facilitated by hypnosis. American Journal of Clinical Hypnosis, 1971, 14, 97-101.

Nawas, N. M., Meiliea, W. L., Jr., \& Fishman, S. T. Systematic desensitization as counter conditioning: A retest with adequate controls. Behavior Therapy, 1971, 2, 345-356.

Neary, R. S. The development and validation of a state measure of sensation seeking. Dissertation Abstracts International, 1975, 36, 450B-451B. (University Microfilms No. 75-14, 969)

Newmark, C. S., \& Finch, A. J. Comparing the diagnostic validity of an abbreviated and standard MMPI. Journal of Personality Assessment, $1976, \underline{40}, 10-12$.

Patterson, C. H. Theories of counseling and psychotherapy. New York: Harper and Row, 1966.

Pearson, P. H. Relationships between global and specified measures of novelty seeking. Journal of Consulting and Clinical Psychology, $1970,34,199-204$.

Petrie, A. Individuality in pain and suffering. Chicago: University of Chicago Press, 1967.

Petrie, A., McCullough, R., \& Kazdin, P. The perceptual characteristics of juvenile delinquents. Journal of Nervous and Mental Disease, $1961,34,415-421$.

Pribram, K. H. Emotion: Toward a neuropsychological theory. In D. C. Glass (Ed.), Neurophysiology and emotion. New York: Rockefeller University Press, 1967.

Prince, M. The unconscious. New York: Macmillan, 1914.

Quay, H. C. Psychopathic personality as pathological stimulationseeking. American Journal of Psychiatry, 1965, 122, 180-183.

Robins, L. N. Deviant children grow up. Baltimore: Williams and Wilkins, 1966 .

Roffwarg, H., Muzio, J., \& Demet, W. Ontogenetic development of the human sleep-dream cycle. Science, 1966, 152, 604-619. 
Rose, R. J. Preliminary study of three indicants of arousa1: Measurement, interrelationships, and clinical correlates. Unpublished doctoral dissertation, University of Minnesota, 1964.

Rosenberg, M. Releasing the creative imagination. Journal of Creative Behavior, 1976, 10, 203-209.

Rotter, J. B. Generalized expectancies for internal versus external control of reinforcement. Psychological Monographs: General and Applied, 1966, 80, (1, Whole No. 609).

Ruch, J. C. Self-hypnosis: The result of heterohypnosis or vice versa? International Journal of Clinical and Experimental Hypnosis, 1975, 23, 282-304.

Salama, A. A., \& Hunt, J. McV. "Fixation" in the rat as a function of infantile shocking, handling and gentling. Journal of Genetic Psychology, 1964, 105, 135-162.

Sales, S. M. Need for stimulation as a factor in social behavior. Journal of Personality and Social Psychology, 1971, 19, 124-134.

Sales, S. M. Need for stimulation as a factor in preferences for different stimuli. Journal of Personality Assessment, 1972, 36, 5561 .

Sales, S. M., Guydosh, R. M., \& Iacono, W. Relationship between "strength of the nervous system" and the need for stimulation. Journal of Personality and Social Psychology, 1974, 29, 16-22.

Sales, S. M., \& Throop, W. F. Relationship between kinethetic aftereffects and "strength of the nervous system." Psychophysiology, $1972, \underline{9}, 492-497$.

Salter, A. Three techniques of autohypnosis. Journal of General Psychology, 1941, 24, 423-438.

Schacter, S., \& Latane, B. Crime cognition and the autonomic nervous system. In M. Jones (Ed.), Nebraska Symposium on Motivation. Lincoln: University of Nebraska Press, 1964.

Schalling, D., \& Levander, S. Rating of anxiety proneness and response to electrical pain stimulation. Scandinavian Journal of Psychology, $1964,5,1-9$.

Schill, T., \& Althoff, M. Auditory perceptual thresholds for sensitizers, defensive and nondefensive repressors. Perceptual and Motor Skills, 1968, 27, 935-938.

Schmauk, F. J. Punishment, arousal and avoidance learning in sociopaths. Journal of Abnorma1 Psychology, 1970, 76, 325-335. 
Schneck, J. M. The elucidation of spontaneous sensory and motor phenomena during hypnoanalysis. Psychoanalytic Review, 1952, 39, 79-89.

Schoenherr, J. C. Avoidance of noxious stimulation in psychopathic personality. Dissertation Abstracts Internationa1, 1964, 25, 20552056. (University Microfilms No. 64-8334)

Schofield, L. J., \& Platoni, K. Manipulation of visual imagery under various hypnosis conditions. American Journal of Clinical Hypnosis, 1976, 18, 191-199.

Schuenaman, A. L., King, H., Sandman, C. A., \& Deabler, H. L. Reaction time and temperament type. Perceptual and Motor Skills, 1970, 30, 162 .

Schulsinger, F. Psychopathy: Heredity and environment. International Journal of Mental Health, 1972, 1, 190-206.

Schwade, E. D., \& Geiger, S. G. Abnormal electroencephalographic findings in severe behavior disorders. Diseases of the Nervous System, $1965,17,307-317$.

Seeman, J. M. Alienation and social learning in a reformatory. Journal of Sociology, 1963, 69, 270-289.

Silver, A. W. TAT and MMPI psychopathic deviate scale differences between delinquent and nondelinquent adolescents. Journa1 of Consulting Psychology, 1963, 27, 370 .

Singer, J. L. Daydreaming. New York: Random House, 1966.

Skrzypek, G. J. Effect of perceptual isolation and arousal on anxiety, complexity preference, and novelty preference in psychopathic and neurotic delinquents. Journal of Abnormal Psychology, 1969, 74, $321-329$.

Spanos, N. P., Demoor, W., \& Barber, T. X. Hypnosis and behavior therapy: Common denominators. American Journal of Clinical Hypnosis, 1973, 16, 45-64.

Spilker, B., \& Callaway, E. "Augmenting" and "reducing" in averaged visual evoked responses to sine wave light. Psychophysiology, $1969, \underline{6}, 49-57$.

Stanton, H. E. Hypnosis and encounter group volunteers: A validation study of the sensation-seeking scale. Journal of Consulting and Clinica1 Psychology, 1976, 44, 692.

Starker, S. Effects of hypnotic induction upon visual imagery. Journal of Nervous and Mental Disease, 1974, 159, 433-437.

Sterling, K., \& Miller, J. G. The effect of hypnosis upon visual and auditory acuity. American Journa1 of Psychology, 1940, 53, 269-276. 
Stevens, J. 0. Awareness: Exploring, experimenting, experiencing. Lafayette, Calif.: Real People Press, 1971.

Stewart, D. W., \& MacGriffith, G. Factor analysis of Zuckerman's sensation seeking scale. Psychological Reports, 1975, 37, 849-850.

Strahan, R. F., \& Wilson, D. W. Buffer items, insight, and the MarloweCrowne social desirability scale. Journal of Personality Assessment, $1976,40,320-323$.

Suinn, R. M. Fundamentals of behavior pathology. New York: John Wiley \& Sons, 1970.

Sullivan, H. S. Conceptions of Modern Psychiatry (2nd ed.). New York: Norton, 1953.

Thorne, F. C. The etiology of sociopathic reactions. American Journa1 of Psychotherapy, 1959, 28, 229-243.

Unger, B. L. The repression-sensitization scale as a measure of repression. Dissertation Abstracts International, 1971, 31, $4348 \mathrm{~B}$. (University Microfilms No. 70-26, 885)

Walker, N. S., Garrett, J. B., \& Wallace, B. Restoration of eidetic imagery via hypnotic age regression: A preliminary report. Journal of Abnormal Psychology, 1976, 85, 335-337.

Watson, C. G. Pain adaptation and emotional deficit. Journal of Clinical Psychology, 1977, 33, 555-557.

Watson, J. B., \& Raynor, R. Conditioned emotional reactions. Journal of Experimenta1 Psychology, 1920, 3, 1-14.

Weitzenhoffer, A. M., \& Hilgard, E. R. Stanford Hypnotic susceptibility scale, forms $a$ and b. Palo Alto: Consulting Psychologists Press, 1959.

Whitehill, M., Capin, S. D., \& Scott, T. J. Stimulation seeking in antisocial preadolescent children. Journal of Abnormal Psychology, $1976,85,101-104$.

Wiggins, J. Inconsistent socialization. Psychological Reports, 1968, $\underline{23}, 303-336$.

Witkin, H. Criminality in XYY and XXY men: The elevated crime rate of $\mathrm{XYY}$ males is not related to aggression. It may be related to low. intelligence. Science, 1976, 193, 547-555.

Wolpe, J. The systematic desensitization treatment of neuroses. Journal of Nervous and Mental Disease, 1961, 132, 189.

Wolpe, J. The practice of behavior therapy. New York: Pergamon Press, 1969 . 
Wood, B. S., Wilson, G. G., Jessor, R., \& Hogan, J. B. Trouble making behavior in a correctional institution: Relationships to inmates' definition of their situation. American Journal of Orthopsychiatry, $1966,26,795-802$.

Zamansky, H. S., \& Brightbill, R. Modification of the word-recognition threshold by hypnotic suggestion and monetary reward. Perceptual and Motor Skills, 1964, 18, 805-812.

Zuckerman, M. Dimensions of sensation seeking. Journal of Consulting and Clinical Psychology, 1971, 36, 45-52.

Zuckerman, M. Sensation seeking. In H. London \& J. Exner (Eds.), Dimensions of personality. New York: John Wiley \& Sons, 1974.

Zuckerman, M. Sensation-seeking and anxiety traits and states as determinants of behavior in novel situations. In I. Sarason \& C. D. Spielberger (Eds.), Stress and anxiety (Vol. 3). New York: Halsted Press, 1976.

Zuckerman, M. The search for high sensation. Psychology Today, 1978, $12,38-43 ; 46 ; 96-99$.

Zuckerman, M., Eysenck, S., \& Eysenck, H. G. Sensation seeking in England and America: Cross-cultural, age and sex comparisons. Journal of Consulting and Clinical Psychology, 1978, 46, 139-149.

Zuckerman, M., Kolin, E. A., Price, L., \& Zoob, I. Development of a sensation seeking scale. Journal of Consulting and Clinical Psychology, 1964, 28, 477-482.

Zuckerman, M., \& Link, K. Construct validity for the sensation seeking scale. Journal of Consulting and Clinical Psychology, 1968, 32, 420-426.

Zuckerman, M., Schultz, D. P., \& Hopkins, T. R. Sensation seeking and volunteering for sensory deprivation and hypnosis experiments. Journal of Consulting Psychology, 1967, 31, 358-363. 
APPENDIX A

SENSATION SEEKING SCALE V

DIRECTIONS: Each of the items below contains two choices, $A$ and $B$. Please indicate on your answer sheet which of the choices most describes your likes or the way you feel. In some cases you may find items in which both choices describe your likes or feelings. Please choose the one which better describes your likes or feelings. In some cases you may find items in which you do not like either choice. In these cases mark the choice you dislike least. Do not leave any items blank.

It is important you respond to a11 items with only one choice, A or B. We are interested only in your likes or feelings, not in how others feel about these things or how one is supposed to feel. There are no right or wrong answers as in other kinds of tests. Be frank and give your honest appraisal of yourself.

1. A. I like "wild" uninhibited parties.

B. I prefer quiet parties with good conversation.

2. A. There are some movies I enjoy seeing a second or even a third time.

B. I can't stand watching a movie that I've seen before.

3. A. I often wish I could be a mountain climber.

B. I can't understand people who risk their necks climbing mountains.

4. A. I dislike all body odors.

B. I like some of the earthy body smells.

5. A. I get bored seeing the same old faces.

B. I like the comfortable familiarity of everyday friends.

6. A. I like to explore a strange city or section of town by myself, even if it means getting lost.

B. I prefer a guide when I am in a place I don't know well.

7. A. I dislike people who do or say things just to shock or upset others.

B. When you can predict almost everything a person will do and say he or she must be a bore.

8. A. I usually don't enjoy a movie or play where I can predict what will happen in advance.

B. I don't mind watching a movie or play where I can predict what will happen in advance. 
9. A. I have tried marijuana or would like to.

B. I would never smoke marijuana.

10. A. I would not like to try any drug which might produce strange and dangerous effects on me.

B. I would like to try some of the new drugs that produce hallucinactions.

11. A. A sensible person avoids activities that are dangerous.

B. I sometimes like to do things that are a little frightening.

12. A. I dislike "swingers."

B. I enjoy the company of real "swingers."

13. A. I find that stimulants make me uncomfortable.

B. I often like to get high (drinking liquor or smoking marijuana).

14. A. I. like to try new foods that I have never tasted before.

B. I order the dishes with which I am familiar, so as to avoid disappointment and unpleasantness.

15. A. I enjoy looking at home movies or travel slides.

B. Looking at someone's home movies or trave1 slides bores me tremendously.

16. A. I would like to take up the sport of water-skiing.

B. I would not like to take up water-skiing.

17. A. I would like to try surf-board riding.

B. I would not like to try surf-board riding.

13. A. I would like to take off on a trip with no pre-planned or definite routes, or timetable.

B. When I go on a trip I like to plan my route and timetable fairly carefully.

19. A. I prefer the "down-to-earth" kinds of people as friends.

B. I would like to make friends in some of the "far-out" groups like artists or "hippies."

20. A. I would not like to learn to fly an airplane.

B. I would like to learn to fly an airplane.

21. A. I prefer the surface of the water to the depths.

B. I would like to go scuba diving.

22. A. I would like to meet some persons who are homosexual (men or women).

B. I stay away from anyone I suspect of being "queer."

23. A. I would like to try parachute jumping.

B. I would never want to try jumping out of a plane with or without a parachute. 
24. A. I prefer friends who are excitingly unpredictable.

B. I prefer friends who are reliable and predictable.

25. A. I am not interested in experience for its own sake.

B. I like to have new and exciting experiences and sensations even if they are a little frightening, unconventional or illegal.

26. A. The essence of good art is in its clarity, symmetry of form and harmony of colors.

B. I often find beauty in the "clashing" colors and irregular forms of modern paintings.

27. A. I enjoy spending time in the familiar surroundings of home.

B. I get very restless if I have to stay around home for any length of time.

28. A. I like to dive off the high board.

B. I don't like the feeling I get standing on the high board (or

I don't go near it at al1).

29. A. I like to date members of the opposite sex who are physically exciting.

B. I like to date members of the opposite sex who share my values.

30. A. Heavy drinking usually ruins a party because some people get loud and boisterous.

B. Keeping the drinks full is the key to a good party.

31. A. The worst social sin is to be rude.

B. The worst social sin is to be a bore.

32. A. A person should have considerable sexual experience before marriage.

B. It's better if two married persons begin their sexual experience with each other.

33. A. Even if I had the money I would not care to associate with flighty persons like those in the "jet set."

B. I could conceive of myself seeking pleasures around the world with the "jet set."

34. A. I like people who are sharp and witty even if they do sometimes insult others.

B. I dislike people who have their fun at the expense of hurting the feelings of others.

35. A. There is altogether too much portrayal of sex in movies.

B. I enjoy watching many of the "sexy" scenes in movies.

36. A. I feel best after taking a couple of drinks.

B. Something is wrong with people who need liquor to feel good. 
37. A. People should dress according to some standards of taste, neatness, and style.

B. People should dress in individual ways even if the effects are sometimes strange.

38. A. Sailing a long distance in small sailing crafts is foolhardy.

B. I would like to sail a long distance in a small but seaworthy sailing craft.

39. A. I have no patience with dull or boring persons.

B. I find something interesting in almost every person I talk with.

40. A. Skiing fast down a high mountain slope is a good way to end up on crutches.

B. I think I would enjoy the sensations of skiing very fast down a high mountain slope. 
APPENDIX B

\section{INSTRUCTIONS FOR THE KINESTHETIC DETERMINATION}

OF AUGMENTATION AND REDUCTION

\section{A. Equipment}

The equipment consists of a box containing:

1. One long tapered block of wood. It is called the tapered block and is used only in conjunction with the measuring block. The tapered block is used in the subject's left hand so that he can indicate the width of the measuring block in his right hand. (This position is reversed for left-handed subjects.) Running the length of the block, which is 30 inches long, is a ruler marked in 1 inch and also one-eighth inch and mounted around the ruler is a pair of parallel sticks used for finger guides. The block tapers from one-half inch at its narrow end to 4 inches at its wide end.

2. Four rectangular blocks measuring $1,1.5,2$, and 2.5 inches in width. Each of these blocks is 6 inches long and is equipped with finger guides. These four rectangular blocks are the stimulating and measuring blocks.

3. One stand to act as a base for the four rectangular blocks whenever they are in use.

4. One blindfold, stopwatch, pad of paper, and pen.

B. Large-Block and Sma11-Block Stimulating Tests

Two tests are administered with the equipment described. Both of these tests are given to the subject, but they must be separated by a 48-hour interval. The procedure for giving both the largeblock and the small-block stimulation tests is identical, except for the sizes of the rectangular blocks used for stimulation and measurement.

In the large-block stimulation test, the largest block, measuring 2.5 inches in width, is used for stimulation, and the 1.5 inch block is used for measurement. In the small-block stimulation test, the smallest block, 1 inch in width, is used for stimulation, and the 2 inch block is used for measurement. 
The block is always held between the fingers of the subject's right hand, unless he is left-handed. (If the subject is lefthanded, the tapered block is on the right, and the stimulating and measuring blocks are held in the left hand.)

The function of the tapered block is to enable the subject to indicate to the tester, with his left hand, the width of the block in his right hand.

C. Procedure

The subject is seated at a table large enough for the equipment. The tester blindfolds the subject before placing the equipment on the table. The long tapered block is placed by the subject's left hand, with the narrow end toward the subject. The measuring block is set on the stand and placed by the subject's right hand.

Taking care not to touch the subject's fingers, the tester lifts the subject's right hand and places his fingers in position between the finger guides on the measuring block. The tester must repeatedly check the subject's fingers to be sure they are touching the block.

The tester now indicates, by sliding the subject's hand, that the sides are parallel. The tester ther places the subject's left hand on the narrow end of the tapered block.

The subject's arms must be above the table--not resting on it. The subject's thumb and index finger are between the finger guides, and the tester slides the subject's hand toward the wider end of the block so that the subject can feel that the block tapers. The tester must take care not to slide the guide beyond the 8 -inch reading on the tapered block. The hand is then returned all the way to the narrow end of the block (the end nearest the subject) and must always be in this position at the beginning of measuring.

The tester asks the subject to find with his left hand on the tapered block the place that feels to him just as wide as the measuring block between the fingers of his right hand. The tester then reads the position reached by the front end of the central finger guide on the ruler and records this number to the nearest one-eighth inch as the first baseline measurement.

The subject now slides his hand back to the narrow end of the tapered block and makes another measurement. Altogether the tester records six successive baseline measurements. The finger guide must always be returned to the narrow end of the tapered block between measurements.

The subject must be told to say "Here" when he has found the size that feels equivalent, and he must hold his fingers in place for a moment until the measurement can be recorded. 
The tester then removes the subject's left hand from the tapered block and guides it to a position, palm upwards, on the table, instructing the subject to let the hand rest in this position. The tester next tells the subject to keep his fingers on the block in his right hand. Then the tester and the subject lift the measuring block off the stand and the tester rapidly places the stimulating block on the stand. The block and its stand are moved to a position roughly parallel to the edge of the table, a position which is less fatiguing for the subject. This position is, however, used only during the stimulating period.

The tester next removes the subject's right hand from the measuring block and places it on the stimulating block, instructing him to rub the block by sliding his fingers along its whole length, backwards and forwards, at any rate he likes, until he is told to stop. The total time for this stimulation period is 90 seconds.

Immediately following the 90 seconds of rubbing, the tester lifts the stimulating block from the stand and, while the subject's fingers remain on the stimulating block, the tester replaces the measuring block on the stand and returns block and stand to original position for measuring. The tester again places subject's right hand on the measuring block and his left hand on the long tapered block and asks him to find the place on the tapered block that feels the same as the width of the measuring block. This value is recorded and three more measurements are then made and recorded.

The subject's left hand is again rested and his right hand stimulated as before by rubbing for 90 seconds. After this stimulation, four more measurements are made. The subject then rubs the stimulating block for 120 seconds. Four more measurements are made and recorded. This completes the second part of the procedure, and the tester should now have 18 recorded numbers.

The tester then removes all equipment from the table and takes off the subject's blindfold.

\section{Completing a Record}

Only the last four measurements of the baseline are used. The first two are practice measurements and are necessary to enable the blindfolded subject to become familiar with the feel of the apparatus and with the procedure. An average is taken of each group of four measurements. The baseline average is subtracted from each average to give the three differences which occurred after stimulation. Averaging them gives the final average which, when compared with the comparable average for the sma11-block stimulation, gives rise to a classification of the subject as a reducer, augmenter, moderate, or stimulus-governed. In many investigations the concern, however, will be with the degree of reduction and augmentation rather than with an absolute classification. 
APPENDIX C

STANDARD HYPIOTIC INDUCTION

First you will look at a spot directly above your forehead. Pick a spot on the ceiling just above your hairline. Keep staring at it. As you keep staring at it the first sensation that you will learn how to control is that of heaviness. Your lids are getting very, very heavy. Getting heavier and heavier. Your eyes are beginning to blink. Your eyes are blinking and you swallow. That's a good sign that you are going deeper and deeper relaxed. And now at the count of 3 if you really wish to gain control over your sensations you will gently control the closing of your lids. At this point you will notice that you want to close your lids because they are getting very, very tired. Promptly, precisely and exactly at the count of 3 you will close your lids, not because you have to but because you really want to. Don't close your lids too rapidly, but close them gently at the count of 3 . Your eyes are closing. $1-2-3$. Lids are closing tighter and tighter together. And I really want you to feel that tightness. Good, this is still another sensation that you are gaining control over.

Now let your eyeballs roll up into the back of your head. Now let the eyeballs roll back down into their normal position. And as they return to their normal position you will notice that your lids are stuck even tighter and tighter together.

Just relax. Don't be tense. Pay close attention to my voice. Try to pay attention to it as much as you can. Should your attention wander away from it, that will be all right. Just bring your attention back to it. After a while you may find that my voice seems to become faint or to recede from you or again changes in quality. That is all right. Should you get sleepier, that will be fine, too. Whatever happens, let it happen and just keep listening to my voice while you become more and more relaxed. More and more relaxed. Just 1isten and relax. Whatever you feel is happening, just let it happen.

Relax completely. Relax every muscle of your body. Relax the muscles of your legs. Relax the muscles of your feet. Relax the muscles of your hands, of your fingers. Relax the muscles of your neck, of your chest. Relax all the muscles of your body. Let yourself be limp, limp, limp. Relax more and more, more and more. Relax completely. Relax completely.

As you relax more and more, a feeling of heaviness comes over your body. A feeling of heaviness is coming into your legs and your arms, into your feet, into your whole body. Your legs feel heavy and limp, 
heavy and limp. Your arms are heavy, heavy. Your whole body feels heavy, heavier and heavier. Like lead. You are beginning to feel drowsy, drowsy and sleepy. Your breathing is becoming slow and regular. You are getting drowsy and sleepy, more and more drowsy and sleepy while your entire body becomes more and more relaxed, more and more relaxed.

You are relaxed, quite relaxed. But you can relax even more if you allow yourself to do so. You will soon attain a state of deep, of complete relaxation. You are becoming increasingly drowsy and sleepy. There is a pleasant feeling of warmth and heaviness throughout your body. You feel so relaxed, so sleepy. You are losing interest in everything else but my voice, to which you listen sleepily. Soon there will be nothing else to attend to but my volce. All the while you keep becoming more and more deeply relaxed.

You are relaxed, very relaxed. There is a pleasant feeling of warmth and heaviness throughout your body. You are tired and drowsy. Tired and sleepy. Sleepy. Sleepy. You want only to listen to my voice. Pay attention to nothing else but my voice. You have no cares, no worries now. You are pleasantly, deeply relaxed, getting more deeply relaxed all the time. Everything else but my voice is becoming remote, quite remote. Nothing else but my voice and what I have to say to you now seems of interest. And even my voice may come to you as in a dream as you relax more and more, as you sink deeper into this lethargy, this deep state of relaxation. Relax, relax. Deeply relaxed. Deeper and deeper all the time.

You feel drowsy and sleepy. Just keep listening to my voice. Pay close attention to it. Keep your thoughts on what I am saying. Just listen. You are going to get much more drowsy and sleepy. Soon you will be deep asleep but you will continue to hear me. You will not awaken until I tell you to do so. I shall now begin to count. At each count you will feel yourself going down, down, into a deep comfortable, deep restful sleep. A sleep in which you will be able to do all sorts of things I ask you to do. 1...you are going to go deeply asleep... $2 \ldots$ down, down into a deep, sound sleep...3..4...more and more, more and more asleep..5.6. . . . . you are sinking, sinking into a deep, deep sleep. Nothing will disturb you. Pay attention only to my voice and only to such things as I may call to your attention. I would like you to keep on paying attention to my voice and the things I tell you ..8..9..10..11..12...deeper and deeper, always deeper asleep...13 ..14...15...although deep asleep you can clearly hear me. You will always hear me no matter how deeply asleep you may feel yourself to be $\ldots 16 \ldots 17 \ldots 18 \ldots$ deep asleep, fast asleep. Nothing will disturb you. You are going to experience many things that I will tell you to experience...19...20...Deep asleep! You will not awaken until I tell you to do so. You will wish to sleep and will have the experiences I shall presently describe. 
APPENDIX D

\title{
IINSTRUCTIONS FOR AUTOHYPNOSIS USING
}

\author{
POSTHYPNOTIC SUGGESTION
}

Any time in the future that you wish to induce a deep state of hypnosis in yourself, even deeper than the one in which you are now, you will be able to do so. All you will need to do is to place yourself in a comfortable position, stare at a fixed object and relax by taking a few deep breaths and think of relaxing as you did when I hypnotized you a while ago. When you are relaxed, tell yourself mentally that you are going to go into a deep hypnotic state, then take ten or twelve deep breaths and you will gradually go into a deep trance. During hypnosis you will be able to think and will have full command of yourself. You will be able to give yourself any suggestion you wish while hypnotized and you will be able to bring about any hypnotic phenomena you desire. To awaken you will only need to tell yourself that you are going to wake up. You will then count to three, and at the last count you will be wide awake. Should any emergency arise while you are hypnotized you will immediately and automatically awaken ready to take whatever action is necessary. Until I tell you otherwise, any time that you have hypnotized yourself, you will always be able to hear me and you will carry out any suggestions I give you, even if they are contradictory to some you have given yourself. But you will not listen to anyone else or accept suggestions from others unless you have previously decided to do so. You will always employ good judgment in using selfhypnosis, and will not use it excessively. You can use it to remove any pains and aches from which you suffer, but you will always consult a physician if they are persistent. You can produce hallucinations if you wish, but you will be careful to do so only when others are not around, or if they are, only if they know what you are doing. You will never give yourself hallucinations that could lead you to harm yourself or others. These suggestions will be effective until I change or remove them. No one else, including you, can change or remove them. 
APPENDIX E

STANDARDIZED IMAGES

Image I

Beach Scene. You are walking along the beach; it is mid-July. It is very, very warm. It is five o'clock in the afternoon. The sun has not yet begun to set but it is getting low on the horizon. The sun is a golden blazing yellow, the sky a brilliant blue, the sand a dazzling glistening white in the sunlight. Feel the cold, wet, firm, hard-packed sand beneath your feet. . . Taste and smell the salt in the air. There is a residue of salt deposited on your lips from the ocean spray. You can taste it if you lick your lips. Hear the beating of the waves, the rhythmic lapping to and fro, back and forth of the water against the shore. Hear the far-off cry of a distant gull as you continue to walk. . .

Suddenly you come to a sand dune, a mound of pure white sand. . . Covering the mound are bright yellow buttercups, deep pink moss roses. You sit down on its crest and look out to sea. The sea is like a mirror of silver reflecting the sun's rays, a mass of pure white light, and you are gazing intently into this light. As you continue to stare into the sun's reflection off the water, you begin to see flecks of violet, darting spots of purple intermingled with the silver. Everywhere there is silver and violet. There is a violet line along the horizon. . . a violet halo around the flowers. Now the sun is beginning to set. With each movement, with each motion of the sun into the sea you become deeper and deeper relaxed. (It is important to pair physical sensations such as breathing with elements in the image so that the imaginal elements will cue relaxation.) The sky is turning crimson, scarlet, pink, amber, gold, orange as the sun sets . . . you are engulfed in a deep purple twilight, a velvety blue haze. . you look up to the night sky. It is a brilliant starry night. The beating of the waves, the smell and taste of the salt, the sea, the sky, . . . and you feel yourself carried upward and outward into space, one with the universe.. . I am now going to count to 3. At the count of 3 , you will open your eyes, you will feel completely refreshed, totally relaxed, 1, 2, 3. (The subject is always brought out of hypnosis by reciting the above three lines.)

The last two lines in this image should produce a feeling of detachment and often dissociation. 
Image II

Mountain Cabin Scene. You are in a cabin in the mountains. It is midnight. It is the dead of winter. Outside the wind is howling. Inside you are sitting in front of a fireplace, gazing fixedly into the embers, staring intently into the coals. Feel the warmth of the flames against your body, feel the heat from the fire against your skin. There is a prickling almost itching sensation in your thighs; the heat on the front of your body is so intense. Hear the crackling of the logs as the sap hits the fire. Smell the smoke from the burning pine logs. See the flickering shadows on the wall. The only source of light comes from the fire. The rest of the cabin is in darkness.

Now you get up. You walk over to the window. There is a lace-like pattern of frost on the window pane. You put your warm fingertips to the cold, hard glass of the windowpane. Feel the heat from your fingers melt the frost. You look outside. The moon is full and silver, the snow a dazzling, sparkling white in the moonlight. There are tall, dark green fir trees casting deep purple shadows across the snowy whiteness. You are going to open the window. Feel it give way against the pressure of your hand. It opens. You take a big deep breath of cool, clean, crisp, fresh, pure mountain air. (The subject should actually take a deep breath at this point and the therapist takes a big breath while recounting it.) Your entire rib cage collapses in total, utter relaxation. It feels so good to breathe. Smell the pine!

Now you close the window. You walk to the fire. Feel its warmth. You lie down beside the fire on a bearskin rug. A drowsy feeling is coming over you. The howling of the wind, the warmth from the fire, the smell of the smoke, the crackling of the logs . . all those sights and sounds and smells getting very, very far away . . . as you drift - . and float and dream in that cabin that winter night (the word very is often said in rhythm with the subject's inhalations and exhalations).

Image III

Garden Scene. You are in the middle of a vast garden. It is midnight. It is mid-summer. The air is warm and balmy. The garden stretches for miles and miles. You are walking down a path on either side of which are orange trees. The moon is full and yellow. The orange trees are deep green with brilliant orange oranges, phosphorescent in the moonlight. There are oranges on the ground. They are very ripe. The sme11 of orange is heavy in the air. You reach up. You pick an orange from the branch. Bite into the orange. . the sweet orange juice squirts into your mouth, running down your throat and into your stomach. Taste the orange. Now you continue walking till you come to a place where two paths cross . . . you turn right, walking down a path on either side of which are lemon trees, bright yellow in the moonlight. You pick a lemon. Feel the rough outer texture of the lemon peel. You peel the lemon. Smell the lemony fragrance of the lemon rind. You. sink your teeth into the lemon. The sour lemon juice squirts into your 
mouth. Taste the lemon. The saliva flows. Your mouth puckers as you swallow the sour lemon juice. You continue walking, the taste and smell of lemon lingering with you.

Suddenly before you is a long, descending, white marble staircase. Dazzling white in the moonlight. You begin to descend the stairs. With every step downward you become deeper and deeper relaxed. When you reach the base of the stairs you will be in a profound state of relaxation . . you are now standing at the base of the stairs. In front of you is a huge marble swimming pool. All around the pool are red and white and yellow roses, velvety soft in the moonlight, covered with dew. The smell of roses is heavy in the air. You take off your clothes. You glide into the pool. The pool is filled with billions of rose petals. You float on your back in the rose water looking up at the stars, buoyant in the water.

Now you get out of the water. You stand up. The cool night air touches your wet body. It sends chills down your spine. You are shivering. Goose flesh appears. Suddenly you smell smoke. You look to the direction from which the smell is coming. There is a wooded area on the other side of the pool. You walk over toward the forest, the smell of smoke growing ever stronger in intensity as you approach the wooded area. You walk into the forest. There before you is a blazing bonfire of burning leaves. It smells like fall, it smells like autumn. You lie down beside the fire in a bed of dry leaves. The smell of wet earth beneath you, the smell of burning leaves beside you, the starry sky above you; you drift, you float, you dream . . that mid-summer's night.

\section{Image IV}

Mountain Cabin Scene with Glove Anesthesia. You are in a cabin in the mountains. It is midnight. Outside the wind is howling. Inside you are sitting in front of a fireplace, staring into the embers, gazing fixedly into the coals. Feel the heat from the fire. Feel the warmth from the flames against your skin. There is a prickling, almost itching sensation in your thighs; the heat on the front of your body is so intense. See the flickering shadows on the wall. Hear the crackling of the pine logs as the sap hits the fire. Smell the smoke from the burning pine logs. The only source of light comes from the fire; the rest of the cabin is in darkness.

Now you get up. You are going to go outside. You bundle up. You put on a coat, gloves, cap, boots. You go to the door. Feel the door give way against the pressure of your hand. You are outside in the cold winter air! Take a big deep breath of cool, fresh, pure, mountain air. Smell the pine. It feels so good to breathe! Your entire rib cage collapses in total, utter relaxation. The door closes behind you. The moon is full and silvery. It is 20 degrees below zero, bitter cold. You can see your breath in white puffs. You begin walking down a path on either side of which are tall deep green pine trees laden with snow. The snow is knee deep. Everything has a bluish tinge to it; even the snow looks blue. Ten minutes pass, twenty minutes, thirty minutes. You stop, take the glove off your right hand and thrust your warm hand 
into the snow making a fist compressing the snow into an ice bal1 in the palm of your hand. . . . You feel a numb, wooden, leathery-like sensation beginning in your right palm, spreading throughout your hand. When you feel this sensation I want you to place your right hand upon your right cheek. [The subject does as directed.] Good, now let all that numbness drain from your hand into your cheek. Your cheek is becoming numb, leathery, wooden, just as if Novocaine had been injected into it. Your hand is becoming warm, alive; the blood is rushing back into it. When all the numbness has drained from your hand into your cheek, place your hand once again at your side. [The subject does as directed.] Now once again place your hand on your cheek and let all the numbness in your cheek drain back into your hand. Your hand is becoming numb, leathery, woodenlike, just like a block of wood with nails in it. Your cheek is becoming hot, flushed, the blood is rushing to the surface of the skin in your cheek. When all that numbness has drained from your cheek back into your hand once again place your hand at your side. [The subject does so.]

Good! Now place the glove back on your right hand. You turn around and begin tracing your footsteps back to the cabin. Ten minutes pass, twenty minutes, thirty minutes. You are back to the cabin. You go inside. You take off your outer wraps and walk over to the fire. Hold your hands over the fire. Feel the warmth spreading throughout your body. (This suggestion eliminates the numbness and returns the hand to its normal condition.) You lie down beside the fire on a bearskin rug. The warmth of the fire, the smell of the pine smoke, the crackling of. the logs, the howling outside of the wind, all these sights, and smells and sounds seem very, very far away as you drift further and further away.

\section{Image $\mathrm{V}$}

Desert Scene. Everything is very, very dark. It is pitch black. It is warm. You are barefoot. Beneath your feet you can feel coarse, cracked clay. The ground is perfectly flat. Now it is beginning to get light. Every breath you take, the sky gets bluer and bluer. Every breath you take, it gets warmer and warmer. You now see that there is nothing but sunbaked clay as far as the eye can see. Everythirg is perfectly flat. There are no mountains, no hills, no vegetation... nothing but clay to the horizon line, to the vanishing point. It is like a surrealistic landscape. It is getting warmer and warmer, hotter and hotter, 80 degrees, 90 degrees, 100 degrees, 110 degrees. Beads of perspiration are running down your back, down your armpits. Your hair is matted to your forehead. Clothes are clinging and sticking to your body. Eyes are stinging from the salt in your perspiration. You are wringing wet with sweat. Throat is getting parched. . . lips are dry . . tongue is thickening. You are having difficulty swallowing.

Suddenly before you is a large, freshwater sea. . . a vast expanse of cool, fresh, pure water. You take off your clothes. You glide into the water. It is crystal clear. You drink, quenching your thirst. You float on your back in the water gazing up at the blue desert sky. Night falls. You get out of the water. The cool night air touches your wet 
body. It sends chills down your spine. You are shivering. Goose flesh appears. You wade to shore. Your feet touch the sand, which is still warm from the day, still retaining the heat from the sun. You lie down. A gentle breeze begins to cover you with a warm blanket of sand, inch by inch, layer by layer. . . feel the ever increasing pressure as the shifting sand covers you layer by layer. You are protected in a warm cocoon, safe, secure, at peace with the world, tranquil under the desert stars.

Image VI

Space Scene. One minute of actual time will seem like 10 minutes to you. Time will go by very, very slowly. It will seem like an eternity. In less than 10 minutes you can watch an entire motion picture again and actually see it better than when you first saw it.

You are lying on your back on a large round bed in a gigantic circular, black marble room. It is midnight. You are looking up at the ceiling, which is a glass dome, a clear, transparent bubble. The night is clear. The sky is filled with stars. You are gazing at the heavens.

Suddenly you notice that the room is beginning to turn. Ever so slightly at first, gradually picking up momentum. It is revolving like a turntable on a record player. Going round, and round and round, and round, and round [The therapist continues saying this faster and faster] and the room is spinning. You are hurled upward and outward off the bed. The dome opens and you shoot out into space, traveling at an incredible rate of speed, going faster than the speed of light, a dizzy sensation in the pit of your stomach. Flashes of light streak into view as you pass other planets, other solar systems, other galaxies, hurling wildly through space.

Now you are beginning to fall. You are falling back to the point from which you came. Falling through space. You are now back to your source, but there is no bed, there is no room, there is no Earth. The Earth has long ceased to exist. You have been gone billions of Earth years. You are suspended in space, in a vacuum. No sound, no touch, no smell . . suspended animation.

Image VII

Farm Scene. You are in a very warm, snug, comfortable bed. It is very early morning. The covers feel so good. You are in a farmhouse in Kansas. It is late August. You hear a rooster crow. It is 5:30 in the morning. You drift off back to sleep. Suddenly you are awakened by the shrill sound of an alarm clock. It is 6:00 in the morning. You get out of bed and go to the window. The sun is just beginning to rise. The sky is turning scarlet, crimson, gold, orange, amber. Every breath you take the sky gets bluer and bluer. You go into the kitchen. There on a blue platter is a sizzling stack of smoked bacon, hot from the 
frying pan. Next to it on a white platter are piping hot squares of corn bread covered with rich melted butter. You sink your teeth into the bacon; feel it crunch between your teeth. Taste the smoky flavor. Now you eat the corn bread, feel the coarse texture of the bread and creamy taste of the butter. It is 6:30 in the morning.

You go out onto the porch. You sit down in a rocking chair and rock back and forth, to and fro, listening to the creaking of the porch boards beneath the weight of the rocker. You look out over the farm yard. You see the mud yard with ruts from the tractor, a white henhouse, a red barn, a garden with cucumbers, tomatoes, lettuce, squash, pumpkins, radishes, peas, and carrots, a ditch, a gravel road, bright green corn field, brilliant blue sky. Suddenly off to your left you hear the voices of children. You turn your head and see three boys, age 8, hurrying off to school. It is five minutes to nine and they are late. They rush down the gravel road, up the hill to your right, and disappear into a white schoolhouse. You continue rocking. You are getting hungry again. It is now 10:00. You go back into the kitchen. There on the table is a blue platter with a piping hot stack of blueberry muffins fresh from the oven. You sink your teeth into a muffin. The ripe blueberries burst in your mouth. Taste the sweet blueberry juice. Taste the nutty flavor of the muffin.

You go back out onto the porch and continue to rock. Now you walk down the porch steps, across the farm yard, down the ditch, over the gravel road and into the corn field. Feel the dry corn rustle against your body. Now you come out into a field of sunflowers. Huge yellow flowers against the bright blue sky with large round brown centers. Next you find yourself in a field of clover. It smells like honey. Butterflies are darting back and forth among the clover blossoms. You lie down in the clover, the smell of wet earth beneath you, the smell of honey around you. You look at a wisp of a cloud in the blue sky. The sun is straight above you. It is high noon. A lazy, hazy August day. You drift, you float, you doze, in the summer sun, not a care in the world.

\section{Image VIII}

- Jungle Scene. It is very warm, very humid, very close. It is dark. You are in a sleeping bag. You can hear insects humming. Now it is beginning to get light. You sit up. All around you is dense tropical foliage. There are giant ferns and lilies. You are in the middle of a rain forest, a jungle. You hear monkeys chattering, birds cawing. There is steam rising off the jungle floor. It is very early morning. Sunlight is filtering through the canopy of leaves above you, casting a lacelike pattern of light on the jungle floor. You get up. You begin making your way through the dense undergrowth cutting your way through with a machete. The ground is spongelike. It feels like steam heat, like a sauna bath. Perspiration is running down your armpits, the small of your back. Your clothing is clinging to your skin, soaked in sweat. Hair is matted to your forehead, blurring your vision. You continue cutting, making your way forward. 
Suddenly you come to a clearing, to a grotto, a mineral hot spring. The grotto is composed of a white chalklike substance resembling coral, which crunches under the weight of your feet. The strong smell of sulfur is in the air. Interspersed in this white chalky substance are pools of brilliant aqua-blue mineral water. You walk over to one of these pools. You take off your clothes. You glide into the warm mineral water. It is like a whirlpool. Your muscles become soft and pliant. Now you notice a curious thing. The pool is getting larger. First the size of a pond, then a baseball field, then a small lake. You look up and see that the trees are miles high into the sky. You realize that the pool has not been getting larger, you have been getting smaller. You are shrinking. Getting smaller and smaller. A large orange Monarch butterfly lights beside you. You crawl onto his back. He soars high up into the blue sky, dipping and soaring like a roller coaster. Feel that sinking feeling in the pit of your stomach. And you continue to shrink, until finally there is nothing left at all.

Image IX

Pool Scene. You are sitting on a white ice-crean chair beside a table out of the center of which is a yellow and blue striped umbrella. It is mid-August. It is very, very hot-- 95 degrees. Next to you is a large swimming pool and sunken garden. All around the pool are brilliantly colored red hibiscus and coconut palms with monkeys chattering in them. You can also see multicolored parrots in the palms with orange, chartreuse, and purple plumage. On the far side of the pool are Arabian night-like cabanas of vari-colored stripes. In front of you on the table is a cold glass of lemonade. Moisture has condensed in beads running down the cold slippery surface of the glass. You pick up the wet, cold glass in your warm right hand. You are wearing nothing but a white bathing suit. You stand up and walk toward the pool. Your bare feet touch the dry, hot cement of the pool area. You run to the edge of the pool where water has been splashed. The wet cement is still hot but not as hot as where it is dry. You stand there on the hot, wet cement in the blazing sun holding the lemonade. You put the glass to your. lips. Hear the ice cubes clatter against the glass. Feel the ice cold liquid touch your lips, go down your throat and into your stomach. Feel the cold radiate out from the center of your body. Feel the contrast of the hot sun on the outside of your stomach against the cold on the inside of your stomach.

Now you go over and lie down on a chaise lounge. You are getting hotter and hotter, thirstier and thirstier. You see a Coke machine on the other side of the pool. You get up and walk over to the machine. You press your warm, moist body against the cold, dry metal of the Coke machine. You press your cheeks, your stomach, your thighs against the machine. It takes your breath away. Now you put the money into the machine. The Coke is dispensed. Feel the carbonation, the bubbles against your nose as you drink the Coke. Taste it. You walk back over to the edge of the pool. You squat down. You place your right hand flat on the hot, wet cement. When you feel the heat in your hand, I want you to place your right hand against your right cheek. [The subject does as directed.] Good. Now let all that heat drain from your 
hand into your cheek. Your cheek is becoming warm, flushed, your hand is becoming cool. When all the heat has drained from your hand into your cheek, place your hand once again at your side. [The subject does so.]. Now, once again place your right hand upon your right cheek. Let all the heat in your cheek drain back into your hand. Your hand is becoming warm, hot, your cheek is becoming cool, as if a gentle evening breeze were blowing over it. When all the heat has drained from your cheek back into your hand, once again place your hand at your side. [The subject does as directed.] Now, you stand up. You walk over to a grove of palms. You sit down in the shade. A cool breeze blows through the grove. Hear the wind rustling through the palm leaves. It lulls you into a dreamy, drowsy state. You feel limp all over as you drift away.

\section{Image $X$}

Arctic Scene. It is very, very cold. It is 30 degrees below zero. All you can see is bright blue and stark white. There are masses of white snow and mountains of glistening ice. You are at the polar ice cap, you are at the North Pole. The sky is vivid blue, the sun a cold, pale yellow. You are making your way through the snow. You see the mouth of a cavern. All around the mouth are long, slender icicles sparkling in the sunlight. You walk up to the cavern, you take the glove off your right hand, you grasp an icicle. The heat from your hand begins to melt the ice. You run your hand up and down the cold, wet surface of the icicle. Put your glove back on. Now you walk into the cave. In the center of the cave is a large pool of ice cold water, dark and deep. You take a tin cup from a knapsack on your back. You scoop up the water, holding the cup between your hands, you bring the cold, dry metal to your lips. The cold liquid pours down your throat and into your stomach. Feel the cold radiating from the center of your body.

Now you walk to the mouth of the cave. Your footsteps resound among the cavern walls. You stand looking at the white snow. Suddenly above, you hear a shrill mechanical sound. You look up and see a helicopter. A wind is created from the motion of the rotors. It lands. You walk over to the helicopter. You take off the glove from your right hand. You place your hand on the hot, dry metal of the copter where the engine is. When you feel that dry heat in your hand I want you to place your right hand upon your right cheek. [The subject does as instructed.] Now let the dry heat in your right hand drain into your cheek. Your cheek is becoming hot and flushed, the blood is running to the surface of the skin. It feels as if hot air is blowing against it. Your hand is becoming cold. When all the heat has drained from your hand into your cheek, once again place your hand at your side. [The subject does so.] Good. Now once again place your right hand upon your right cheek. Let the dry warmth in your cheek drain back into your hand. When all that warmth has drained back into your hand, once again place your hand at your side. Your hand is becoming hot and dry, your cheek is becoming cool. [The subject places his hand at his side.] Good. 
You get into the helicopter. You fasten your seat belt. Feel the pressure around your midsection. The copter begins to ascend. You are surrounded by a silver mist as you continue to go higher and higher. You look at the altitude gauge. You are now 5,000 feet above sea level. When you go back down to 2,000 feet above sea level, you will land. In front of you on a tray is a sizzling T-bone steak and a bowl of crisp green salad. You begin eating the steak. It tastes delicious. Now you eat the salad. You keep eating and eating and your stomach begins to distend. Notice the contrast between the pressure on the inside of your stomach from the food and the pressure on the outside of your stomach from the seat belt.

Now the copter is beginning to descend. Feel that sinking feeling in the pit of your stomach . . 5,000 feet, 4,000 feet, 3,000 feet, 2,000 feet, 1,000 feet. This is strange. You were to land at 2,000 feet above sea level, but the copter continues to descend. As the plane goes lower and lower it gets hotter and hotter inside the compartment . . 1,000 feet, 80 degrees above zero, sea leve1, 90 degrees above zero, $-1,000$ feet, 100 degrees above zero, $-2,000$ feet, 110 degrees above zero. At 3,000 feet below sea level the copter lands. Beads of perspiration are running down your forehead and your armpits. clothes are clinging to your body. The inside of the compartment is steamed up. Hair is matted to your forehead. It is very stuffy. You open the door. You get out. There before you is the world as it existed millions of years ago, a primeval forest. There are giant redwoods, colossal ferns--thick jungle with gigantic, gnarled trees. You walk over to a river of boiling water. You hold your hand above it. Feel the hot, wet steam collecting on the palm of your right hand. When you feel this wet heat on your right hand, place your right hand upon your right cheek and let that wet heat drain into your cheek. [The subject does as directed.] The cheek is getting wet and hot and sweaty, the hand is cool as if being held in front of a fan. When all the wet heat has drained from your hand into your cheek, once again place your hand at your side. [The subject does so.] Now once again place your right hand upon your right cheek and let the wet heat in your cheek drain back into your hand. When all the wet heat in your cheek has drained back into your hand, once again place your hand at your side. You cheek is becoming cool and dry, your hand is moist and hot as if being held over a pressure cooker. [The subject places his hand again at his side.] Good. Now you lie down beside the river. The smell of wet earth beneath you, you drift in a world as it existed millions of years ago . . drifting and floating . . and dreaming. . .

\section{Image XI}

Clock Scene. Ten minutes of actual time will seem like 1 minute to you. Time will go by very rapidly. It will seem like an instant. In less than 1 hour you can accomplish an entire day's work and accomplish it more effectively than you would ordinarily.

You are in a room on the second floor of a house. It is almost midnight. You are looking at a large bay window with starched white 
curtains. Moonlight is flooding in, illuminating the room, bathing it in silver. There is a toy chest, wooden toy soldiers, a raggedy Ann do11, a large bed with a canopy. It is a child's bedroom. Outside is a city with a tall clock tower, a winding river like a ribbon of silver in the moonlight, a bridge, and rolling countryside. Now the clock tower is beginning to toll the hour of midnight.

It strikes for the first time. You see clouds drift over the moon, transparent in the moonlight. The clock strikes a second time. A breeze blows in the window, ruffling the curtains; it smells like spring. On the third strike of the clock you notice the sweet, heavy scent of lilacs in the air. The clock strikes for the fourth time. You hear a dog bark beneath the window. On the fifth strike of the clock you notice the taste of honey from tea and honey you had earlier that evening. On the sixth chime of the clock you look outside and see what appears to be stardustlike sparklers. The clock strikes for the seventh time. The stardust comes into the room, filling it with a golden glow. On the eighth strike of the clock you feel a sensation of weightlessness. When the clock strikes for the ninth time, you feel your body carried upward and out the window. The tenth strike of the clock sounds very distant. On the eleventh chime you hear a faraway dog bark. When the clock strikes the hour of midnight all sorts of happy childhood memories come to mind . . . sleigh bells, cotton candy, Christmas trees, carnivals, ferris wheels, circuses, rainbows, pots of gold, Easter eggs. You float over the city, over the river, over the countryside, and then straight up toward the stars.

\section{Image XII}

Bluebird Scene. Ten minutes of actual time will seem like one minute to you. Time will go by very, very rapidly. It will seem like an instant. In less than 1 hour you can accomplish an entire day's work and accomplish it more effectively than you would ordinarily.

You are sitting on the bank of a river looking up at the branch of a tree on which is perched a bluebird. It is spring. Smell the freshness in the air. Now the bird has left his perch and is starting to fly toward you. Hear the babbling of the river as the water rushes over the rocks. The bird is drawing closer. Look up the river. At its head you see a pink castle with flags waving from the turrets. The bird is getting still closer. A breeze blows from out of the woods bringing to your nostrils the salty smell of ham from a picnic lunch which is spread before you on a checkered cloth. There is ham, French bread, cheese, and wine. Notice the pattern of the red and white checks in the spread. You feel a feather brush against your hand, tickling your skin. Now you feel the weight and heat of the bird as it lights in your hand. You look into the eyes of the bird. You see in his eyes the reflection of you sitting under a tree by a river. You are surrounded by patches of white and yellow daisies. The tree becomes transparent, turns to glass. Hanging from its branches are long strands of a glittering mosslike substance. The bird closes his eyes. The scene is gone. 
Image XIII

Lake Scene. You are walking barefoot down a gravel road. It is mid-June. It is very warm. You are walking down to the lake. On your right is a thatched-roof cottage with a white picket fence around it. There is a smal1 garden with cucumbers, tomatoes, carrots, rutabagas, radishes, and lettuce growing in it. Beside the garden is an incinerator burning paper. Particles of light, hot paper ash are blowing in the wind. They brush against your skin. They are warm and light and tick1ing against your flesh.

Now you come to a long flight of stone steps leading down a steep bank to the shoreline. You begin descending the steps. They are cool and moist beneath your feet. There is a cool metal railing of pipe. The bank is forested. There are wildflowers growing--lupine, columbine, tiger lilies. You reach the base of the steps and there before you is a wooden dock and a boat house. A dock boy comes out of the boat house. He is loading a white wooden boat, which is tied to the dock. He brings out cushions and oars. You get into the boat. Feel it rock beneath the pressure of your body. The dock boy brings a large red gas can, which he places on the dock. It gets very warm in the sun. He hands you the gas can, which is hot and heavy in your lap. He loads the motor and takes the can from you, placing it in the bottom of the boat. Feel the release of pressure in your lap when the can is removed. The boat is untied and pushed away with an oar. The dock boy starts the motor. Hear the roar of the engine. The boat speeds out into the lake. The water is like glass. Your hair is blowing from the wind created by the motion of the boat. Feel the cold, light spray against your face. It is exhilarating!

You reach the other side of the lake where there are tall rushes growing over 8 feet high. The motor is shut off and you begin to row through the channels of water in the rushes. Feel the pulling in your muscles as you dip and pull the oars. Hear the reeds pressing against the boat. You come to a small clearing in the rushes. The boat is anchored. You lie in the bottom of the boat gently rocking back and forth, to and fro by the motion of the ripples on the water. The summer sun makes you feel so lazy. You drift there for hours. Now it is time to go back. The dock boy pulls up the anchor and places it in your lap; it is cold and heavy. He starts the motor and takes the anchor from you, which he places in the bottom of the boat. Feel the release of pressure in your midsection. The boat speeds out of the rushes and heads straight for the opposite shore and the dock. The boat approaches shore, the motor is turned off, and it is docked. You get out of the boat, walk down the dock, up the cool stone steps, and back down the gravel road, going home.

\section{Image IV}

Thundershower Scene. You are sitting on a patio surrounded by a white fence and flowers. It is mid-June. It is one o'clock in the afternoon. It is 80 degrees above zero. You are looking at the flowers. 
There are bells of Ireland, sweet peas, zinnias, Canterbury be11s, sweet William, roses, and iris. Past the fence are two box elder trees with a clothesline running between them. There is a long lawn of green grass, a large garden surrounded by poplar trees with silver leaves rustling in the wind, and past that a railroad track and a lake. White sheets are billowing on the clothesline. You get up. You gather the sheets in your arms. They are light and fluffy and dry. They smell sweet and fresh and clean. You carry them over to a table on the patio. Running the length of the lawn is a hose with small holes in it, out of which a fine mist of water is being forced. There is a rainbow in the mist. You strip to your underwear and run the length of the hose feeling the light, wet mist against your skin. You sit back down in a chair on the patio in the sun to dry.

Off to the west it is beginning to get dark. Large thick clouds are building up. It is getting cooler. Storm clouds are rolling in. It is three o'clock in the afternoon but it is dark. It is very still. Now a wind begins. It picks up, and soon branches are being torn from the trees as the wind increases in velocity, and it gets still colder; you go into the house and put on a heavy wool sweater. You come back outside and sit. A bolt of lightning streaks across the sky. You hear deafening clashes of thunder. The sky is black and gray with yellow streaks of lightning electricity. It begins to pour rain. Your sweater is soaked. You are cold and shivering. . . . Everything is deep, deep green. The sweater is heavy and wet against your skin.

You go back into the house. You walk down a long corridor and up a winding flight of stairs to the master bedroom. The room is large with a massive oak, wide-beamed ceiling. There is a blazing fire in the fireplace. You crawl into an old Victorian bed with a high needlepoint headboard. Feel the pressure of the dry, heavy quilts over your body. You remove your clothes under the blankets. Smell the smoke from the burning logs, hear the patter of the rain against the window pane... the sweet sound of the rain, the warmth of the fire. You are completely calm, totally secure.

\section{Image XV}

Mansion Scene. You are walking down a very busy street. Hear the traffic, the horns blowing, the brakes screeching. The air is smoggy and polluted. It is mid-July. It is very hot and scorching. Now you turn left and take a side street that winds its way up into the hills. Every step you take the air gets fresher and fresher. Every step you take it gets quieter and quieter. . . Y You walk for half an hour. You come to a large iron gate. You look beyond the gate and see a gigantic gray stone mansion built during the 20 s in the golden era of Hollywood. You walk through the gate. Hear the creak and grate of its hinges. You are in a field of dandelions gone to seed, brightly lit by sunlight, a field of golden light. You walk over to one of the dry dandelions; it looks like a puff of fluff or cotton. You put the seed in your mouth and begin eating large quantities of them. They are dry like feathers in your mouth. They taste like sunflower seeds. They absorb 
all the moisture in your mouth making it dry and cottony. You swallow the seeds. They are hot and dry in your stomach.

Next you go down a flight of stone stairs to another part of the garden. You see a white gazebo yellowing with age covered with ivy. You go over to it and sit down. In front of you is a large glass of limeade. Moisture has condensed on the glass. Beads of water are running down the cool container. You put the glass to your mouth, listening to the ice cubes rattle against the glass. You begin drinking, you swallow one of the ice cubes. It is cold and wet in the pit of your stomach. Feel the cold radiating out from the center of your body.

You get up and go into the house. You find yourself in a large banquet hall. There is a large oak table that seats 30 people. Or the walls is painted a hunting mural with men in redcoats riding horses after a fox. You sit down at the table. There before you is a hot bowl of vegetable soup. You eat the soup. It is tangy and delicious. Feel the hot, wet liquid in your mouth going down your throat and into your stomach. A radiating wave of warmth spreads from your stomach throughout your body. Now you leave the table and go outside behind the house. There is a large rock garden, a waterfa11, and a grove of weeping willow trees. You sit on a cool bench under the willows listening to the falling of the water. There materializes in your right hand a cherry snow cone. The cone is not composed of ordinary ice but of dry ice. You eat the cone. Taste the sweet cherry flavor. The ice is dry and cold in your stomach. It absorbs the moisture from your body. Now you lie down under the willows listening to the steady fall of the water, drifting and floating . . . drifting and floating . . at peace . . lulled to sleep.

\section{Image XVI}

Scuba Diving Scene. You are on a fishing boat in the Florida Keys. It is very warm. The sky is vivid blue, the sun a blazing yellow. The shore is lined with glistening white sand and palm trees. Brilliantly colored flowers are everywhere along the coast. You are wearing gear for skin diving with an oxygen tank on your back. You are perched on the edge of the boat ready to dive. Feel your body turning over, somersaulting into the water, going round and round, head over heels into the warm, tropical water. As you go deeper and deeper the water gets cooler and cooler. As you go deeper and deeper, it gets darker and darker. There are bright salmon-colored coral, fan-shaped plants, multicolored fish. Glinting goldfish and lime green and orange angelfish catch the sunlight as they flash by. Now you see an ice-blue network object. You approach and touch it. It sends a jolt of electricity through you. It feels as if you had touched an electric wire or light socket. The feeling is pleasant, very stimulating, like electricity running through your bones making them hot and dry.

As you continue to go deeper, you get colder and colder. You become encased in ice, encapsulated in a block of ice. Your skin and body are numb, woodenlike. The block of ice surfaces and floats to 
shore, drifting up onto the hot sand. There it melts in the heat of the sun. Your muscles feel like jelly as they thaw. Your bones are still frozen solid, cold and dry. Blood is cold like ice-water, wet and cold in your body, forcing its way through your arteries and veins. You begin to shiver with chills in the blazing tropic sun. Suddenly your eye is caught by the sight of a bottle washed up on shore. You go over to it. It is a bottle of rum. You begin drinking. You become intoxicated, euphoric. Your blood is hot, wet, on fire. You lie down on the sand. All the vivid colors around you begin to mesh and swirl becoming molten. . . . spinning round and round. You feel yourself whirling and spinning in a state of complete euphoria, seeing liquid purples, greens, reds and golds. Then all is calm, all is gray, and you sleep.

Image XVII

Picnic Scene. You are walking down a gravel road in the country. It is late July. It is a warm summer day. You walk off the road and into a ditch of grass. Crawling under a barbed-wire fence, you find yourself in a forested area of tall elms and thick, shortly cropped grass. There is a river winding its way through the woods, which you follow to a spring of crystal clear water shooting up out of the earth. In the water are ice-cold cans of beer, which you begin drinking. You drink can after can, gradually becoming intoxicated. You feel an urge to urinate. You go behind a bush and expel the beer, which comes out as wet and cold as it was when you drank it.

Now you remove your clothes and wade into the river. The water is ice-cold and flowing rapidly. You let the river carry you downstream, your body becoming numb from the cold. You feel frozen right down to the marrow, your bones are cold and dry. The river takes you into a pond of warm water. There is a wooden mill with a paddlewheel turning water and a dock. You float in the warm water, looking up at the sky. Suddenly you spot a bottle on the dock. You swim over to it. It is tequila. You begin drinking the liquor. Your body seems on fire as you become intoxicated with the tequila. Once again your urinate. The urine feels wet and hot as it is expelled. Now you get out of the water and climb onto the dock. You walk away from the pond into a forest coming out into a pasture. The grass is cropped very short like a golf green. You lie down on the grass carpet in the sun. Your skin reflects the sun's heat and your bones feel dry and hot in the sunlight.

\section{Image XVIII}

Shangri-La Scene. You are in a vast meadow with a huge expanse of blue sky above you. It is early spring. Smell the freshness in the air. In the distance you can see snow-covered mountains like the Alps or Himalayas. The meadow is green and covered with white daisies and other wildflowers. You wish to scale the mountaintops. You take an air pump and place the rubber hose in your mouth. You begin pumping your body with air, filling up like a balloon. The light, dry air 
inside your body gives you a sensation of weightlessness. You begin to float up into the blue sky. You are approaching the mountain peaks. It is getting colder as the altitude increases. The cold causes the air inside you to contract. You begin to descend, landing on the ridge of the mountain. It is freezing cold. The wind is blowing bitterly. With your back to the sheer side of the mountain, you inch your way along the ledge, snow blowing in your face.

You come to a pass. On the other side of the pass is another world. You cross the threshold and find yourself in an orchard of peaches. It is warm, like summer. There are fountains and marble statues. Passing through the orchard, you come to a long flight of stone stairs leading to a rock palace. You walk up the steps and into the temple, finding yourself in a large stone chamber. There before you is a teak table on which is a stack of piping-hot pancakes covered with butter and syrup. Next to them is a pitcher of milk. You begin eating the pancakes, washing them down with milk. You are starved! They taste delicious and you eat and eat, shovelling the food down. The pancake batter or dough is getting heavier and heavier in the pit of your stomach, weighing you down with a wet, heavy mass. You cannot even stand up. Suddenly a gong rings. It echoes throughout the chamber. A sliding stone panel opens and an ancient man with a long white beard enters, bearing a frothing glass of pink liquid. It is an ancient yeast drink, a health-food drink. He gives it to you and you drink. The yeast inside your stomach makes your feel lighter and lighter. The light, wet bubbles inside you make you feel airy as a feather. You float along the stone floor as if there were no gravity.

You glide along the floor, out the temple arch, down the steps, and to a river. You float like an innertube in the river to the very point where you entered the orchard. You are once again at the pass. Immediately you feel a heaviness in your bones . . dry, heavy bones. They weigh down your arms and legs as if they were made of lead. You recline to the sound of the wind on the mountain ridge.

Image XIX

Chalk Cliff Scene. You are standing on the edge of a cliff overlooking the sea. Wind is blowing through your hair and the smell of salt from the ocean is strong. There is a great stretch of light blue sky as you stand almost a mile above the sea. Behind you is a cottage with a stone fence around it. The grass is undulating in the wind. Patches of heather are scattered along the cliff side. You begin walking down the cliff. The path is white, composed of chalk. You bend down and pick up some lumps of chalk. You put them in your mouth. They are dry and absorb the moisture in your mouth. You swallow them. They are dry and heavy in the pit of your stomach, soaking up the internal moisture. The chalk mixes with the chemical composition of your blood. . blood feels wet, and heavy. You can feel the thick blood forcing itself through your veins and arteries. The weight from the chalk causes you to fall. You somersault head over heels down the cliff path. The motion of your body causes air to mix with the blood forming bubbles, making it lighter. 
You bounce the remainder of the way down the path to the sand. Your blood is wet and light. You are now in a cove. The beach stretches for over a mile before the water begins. There are strange natural-rock formations like bridges and pinnacles formed from the water's washing away of the rock over the centuries. It looks like a surrealistic landscape. You begin walking to the sea, watching the white sea gulls circling above you in the sky. You come upon an old abandoned ship washed up on a reef from long ago. Climbing on to the deck of the ship you look out to sea. From your pocket you take a package of soda crackers. You begin eating them. They are dry and flaky in your mouth, absorbing the moisture, making your mouth feel dry and cottonlike. You swallow the light, dry cracker crumbs; they feel dry in your stomach. You lie down on the ship deck looking up at the clouds. Feel the sea breeze. You dream, and doze, and sleep.

\section{Image XX}

Volcano Scene. You are standing at the mouth of a large, inactive volcano. It is very cold. The landscape is barren and desolate. Dead, twisted trees are silhouetted against the bleak silver-gray sky. Hear the whistling of the wind. All is dank and sterile. You are looking into the mouth of the volcano. It appears interminably deep and dark. As you continue to gaze into the depths, you feel yourself falling. You are falling down the mouth of the volcano. Tumbling down an infinitely large funnel. Falling and falling. Suddenly you bounce as if on a trampoline. You have landed in a bed of giant mushrooms, bouncing up and down. Your body now remains still and you look around you. The walls are sheer, radiating a purple light like ultraviolet. You begin eating the mushroom. The mushroom changes the chemical composition of the fluid in your body. You urinate. The urine is wet and heavy, liquid, but heavy. Your body fluids have become deuterium or "heavy water." Feel the wet pressure on urination. Now the walls are turning phosphorescent purple, orange, and charteuse. They are beginning to waver and ripple and flow.

You leave the mushroom bed, coming out into an underground field of alfalfa. The sky above is molten red and orange lava, swirling in a spiral. You begin eating the alfalfa sprouts. They form a silage in your stomach, creating much heat and gas. You leave the field, coming to a large lake. Removing your clothes, you glide into the water and float on your back. You begin expelling the light, dry gas from your stomach via your anus. The gas propels you through the water. Feel the bubbles and churning of the water. This brings you to the other side where you walk up on shore. You expel the alfalfa in dry, heavy pellets. You walk through a fringe of ferns into a crystal garden. There are mountains of diamonds, rubies, sapphires, and emeralds, all reflecting multicolored light in streaks like spotlights. Before you is a high amethyst cliff with a waterfall. The liquid comprising the waterfall is very volatile, like alcohol. You drink it. You urinate a fine, purple mist, light and wet. You are engulfed in purple. 
Image XXI

Cantina Scene. You are riding a burro through the desert. It is beginning to get dark. It is dusk. The sand is golden yellow, the hills deep purple. There is a cool breeze blowing. In the distance you can see lights from a small village. You can hear guitars. See the orange light coming from the town. You ride into town, dismount in front of a cantina, tie up your burro. The sky is aflame with pink and crimson from the sunset. Large saguaro cacti are silhouetted against the red. You hear laughter emanating from the cantina. You are very hungry, having ridden all day. You walk inside. Everyone is shouting and laughing. Women are dancing in the center of the room. Drunken men are coaxing them on. You sit down at a table and are served hot tamales with red peppers. You take a large bite of the red pepper. It sets your system on fire. Sweat appears on your forehead. You take gulp after gulp of the hot tamales loaded with Tabasco sauce. They are hot and heavy in your stomach. You are sweating profusely. You take a large glass of cold water and swallow the ice cubes. They are cold and heavy in your stomach. Feel the cold radiating out from the center of your body. Next you drink a large glass of Coke. The carbonation is very strong and produces a cold, light gas in your stomach. You are next presented with a bubbling vessel of hot Alka-Seltzer, which you down in one gulp. Feel the hot, light bubbles in your stomach.

There are now two dancers in the middle of the floor, a young man and woman. They are moving lustily and seductively. The man/woman comes over to you and puts his/her hand on your thighs, massaging them. He/she puts his/her hand in your pants and begins manipulating your genitals. The music glows louder. The heat increases. You feel congestion, a build and surge. You climax! You get up and run out of the cantina into the cool night air. You cross the dirt road to a stable. You lie down in the hay looking at the desert sky, a heavy, throbbing sensation in your loins. A groggy feeling comes over you and you sleep.

\section{Image XXII}

Hayloft Scene. It is late afternoon. It is late summer. You are lying in a hayloft on the second floor of a barn. You are looking out at rolling hills where sheep are grazing. Some of them are winding their way homeward. The landscape is like a Rembrandt, dark siennas and browns and golds; deep, rich colors, Long, dark shadows are being thrown by the trees. The loft is golden from the dust of wheat and hay. The last rays of sunlight filter in, illuminating the grain. The smell of smoke from burning leaves is in the air. You are drinking hot brandy; a pleasant, soothing, wave of relaxation and intoxication is spreading over your body. The alcohol is mixing with your blood; it is becoming lighter and lighter: hot and light in your circulatory system. You leave the loft, sweat pouring down your forehead, your body drenched with perspiration. You climb down a wooden ladder to the ground floor.

You open a large metal door which leads into a walk-in freezer. Hunks of frozen meat are hanging from the ceiling. Your blood becomes 
cool and light. You sit down in the freezer. Your blood begins to thicken from the cold; it is cold and heavy in your system, forcing its way through your body. You get up and walk out of the freezer. The massive door slams behind you. You walk out of the bar to the back. Beef is being barbequed. Sme11 the beef. In a pit are piles of red-hot coals. You walk among these piles, finally reaching the center of the pit. You stand there in the heat and smoke, sweating profusely. More and more water evaporates from your system. Your blood becomes heavy and hot, pushing its way to the surface of your skin. You are hot and flushed. All the moisture is now gone from your body. You ignite. You become fire! [Thinking of yourself as fire will raise your subjective body temperature, just as thinking of yourself as ice will lower it.]

Image XXIII

Sand Pit Scene. "You are walking through a birch forest. It is winter. It is two o'clock in the afternoon. It is 40 degrees above zero and the snow is melting. Smell the wet earth. The sky is vivid blue and clear. There is not a sign of a cloud. The snow is stark white, the birch trees are stark white. You come to a sand pit. There are patches of exposed sand where the snow has melted. It is now getting cooler. The sky is turning silver grey. It begins to sleet. You open your mouth. The sleet goes into your mouth and out every opening in your body; it is cold and light. You walk through the sand pit into a forest of maple trees. Driven into the trees are tent stakes shaped like troughs down which is running maple sap into wooden buckets. You go over to one of the buckets and drink the thin, white, sweet liquid coming from the maple trees.

Now you continue walking through the woods till you come to a blazing fire of burning logs. There is a large black cauldron over the fire, filled with thick maple syrup. The air is heavy with the sweet smell of maple syrup. You drink the hot, heavy syrup. You feel the urge to urinate. The syrup comes out hot and heavy. Feel the heat and the pressure created by the syrup forcing its way through your urinary tract. It is now getting darker and darker. The sky is lead grey. You are sitting in front of the blazing crimson fire. It begins to hail large balls of ice. You open your mouth and swallow the hail. You expel balls of ice through every other opening in your body. They are cold and heavy coming through and out your excretory tracts. You move closer to the fire. Feel the intense heat on the front of your body. The heat melts the hail in your stomach turning it to steam. You urinate hot, light steam. Feel the release of pressure and heat. You feel like a pressure cooker.

Leaving the fire, you walk down a wooded path and come to a frozen pond. The ice is like glass. You walk over the slippery ice and sit down in the snow. You feel warm all over, the snow serving as insulation. A pleasant glowing feeling is stealing over your entire body. 
Mine Scene. You are standing at the mouth of a mine shaft. There is a long tunnel running steeply downhill with a rail for boxcars. You get into a boxcar. It begins ever so slowly to move down the rail. Hear the rusty, grating sound of the wheels as they begin to turn after years of disuse. The car is gradually picking up momentum. There are flecks of sparkling gold dust in the black walls. The car is now racing downward like a roller coaster. Feel that sinking feeling in the pit of your stomach as the boxcar speeds downward at an ever-accelerating pace. It stops abruptly and you are hurled out into the air, landing in a vat of a liquid-gold-like substance. It is hot but does not burn. Your body absorbs the liquid. The surface of your bones takes in the metallic substance. Your dry bones feel hot and heavy weighing you down. The marrow of your bones dissolves. Now a blast of hot air comes dowr upon you from an air furnace above you. The hot air blows through your bones which are now hollow like tubes of aluminum, they are hot and light. The air is becoming cooler and cooler, turning frigid. Bones are now cold and light.

Suddenly from above there descends a glass elevator. You climb into the elevator. It starts its ascent, rapidly picking up speed. Millions of multicolored neon lights pass you by as you shoot upward-flashes and streaks of orange, magenta, chartreuse, amber, platinum, ice blue. The elevator stops. You are in a world of rainbow-colored snow. There are peaks and valleys of glistening snow in every color of the spectrum. Orange shading into red into purple into blue into aqua into green into chartreuse--swirls of brilliant sparkling ice and snow. You feel very light, a sense of weightlessness as you begin walking through the snow. You come to a round tundra or barren area the color of caramel. You stand in the center of this area. It begins to slowly revolve like a turntable on a record player, going round and round and round and round--picking up momentum, round and round and round and round, and it is spinning! The spinning motion creates heat, and the caramel turns to spun caramel cotton candy. You are enveloped in a sugary floss of cotton candy. Your body sinks into the candy and the centers of your bones fill with caramel becoming very heavy. The spinning stops, a chill sets in from the surrounding snow and your bones feel very cold and heavy. The spinning motion begins once again, a wave of warmth coming over you. You are hurled off the turntable, upward into space, drifting and floating, a beautiful, detached feeling coming over you as you coast through space in a state of complete tranquillity.

Image XXV

Autumn Scene. It is a beautiful autumn day. The smell of burning leaves is in the air. You are 12 years old. Remember what was on your mind in the fall of your 12 th year. Who were your friends? What activities were you in? Who was your teacher? What classes were you taking? What did you look like? What did you want to be? What did you think about when you were 12? What did the world look like when you were 12? Think. Feel. Remember. You are standing on the edge of a 
forest. Leaves of orange, gold, and red are falling all around you. Hear them crunch beneath your feet. Squirrels are scurrying among the dry leaves.

On the edge of the forest is a pumpkin field. A light frost has turned the pumpkins brilliant orange and the vines a deep brown. Past the pumpkins are shocks of dry golden corn shaped like tepees. You walk through the pumpkins and corn shocks, coming to a tall haystack. Climb to the top of the hay stack. The sky is a glorious blue; big fluffy, white clouds roll in the sky. You can see over the fields to a farm house and a big, red barn. You jump up into the air . . . landing in the soft spongy hay. A golden dust goes up around you as you smell. the sweet scent of hay. You climb again and jump again, sailing through the air into the hay.

You leave the haystack, coming to a chain of granite quarries. Jagged, high rocks surround pools of clear water, reflecting the orange and gold of the trees. You are standing high above the water on a rock. You take off your clothes. The sun is hot against your skin. You take a deep breath and dive. Feel the air rushing past your skin as you fall through the air and into the cold, clear water. It takes your breath away when you make contact with the water--cold and invigorating! Your whole body feels tingling and alive. You swim over to the rocks, feeling the water move against your body and lift yourself up on the warm granite. You bask nude in the sun on the hot rocks.

Now, you rise and walk along a stretch of granite, coming to another pool. In the center of the pool is a diving raft, a pontoon. You jump feet first into the water and swim to the raft. Climbing up on the raft you feel the warm sun against your wet body. You step onto the diving board. Feel the coarse burlap which covers the diving board under your feet. You walk to the end of the board and begin springing up and down. Feel the resiliency of the board beneath the weight of your body. You spring higher and higher, finally tucking your knees into your chest and somersaulting head over heels through the air and into the water. Your body shoots downward deeper and deeper and then scoops upward. You surface, taking a deep gulp of clean, fresh air. You swim to shore and lie on the warm granite, browning in the sun. You feel young, alive, vibrant, full of health and vigor. 


\section{APPENDIX F}

FOLLOW-UP INTERVIEW

1. Use of alcohol and drugs:

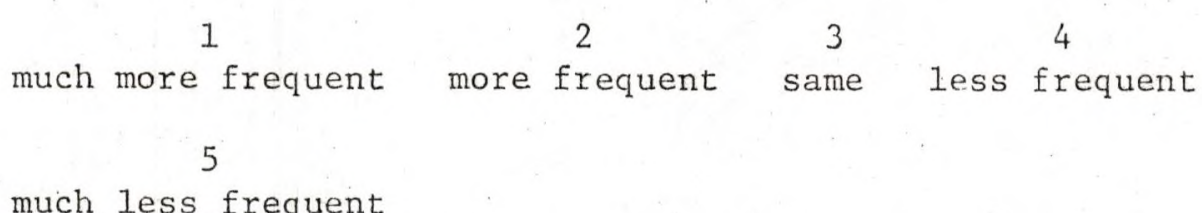

2. Difficulties with other inmates:

\begin{tabular}{|c|c|c|c|}
\hline 1 & 2 & 3 & 4 \\
\hline much more frequent & more frequent & same & less frequent \\
\hline
\end{tabular}

3. Involvement in group recreational activities:

\begin{tabular}{|c|c|c|c|}
\hline 1 & 2 & 3 & 4 \\
\hline 5 & & & \\
\hline
\end{tabular}

4. Amount of time spent in cell:

$\begin{array}{cccc}1 & 2 & 3 & 4 \\ 5 & & 3 & \\ 5 & & \end{array}$

much less frequent

5. Feelings of boredom:

1

2 much more frequent more frequent same less frequent 5 much less frequent 
6. Difficulties in sleeping:

${ }^{1}$ much more frequent $\quad \begin{array}{ccc}2 & 3 & 4 \\ 5 & \end{array}$
much less frequent

7. Somatic complaints:

$\begin{array}{cccc}1 & 2 & 3 & 4 \\ \text { much more frequent } & \text { more frequent same } & \text { less frequent }\end{array}$

much less frequent

8. Feelings of anxiety, depression:

1
much more frequent more frequent $\begin{array}{cc}2 & 4 \\ 5 & \end{array}$

9. Vividness of mental imagery:

$\begin{array}{lllll}1 & 2 & 3 & 4\end{array}$

much more vivid more vivid same less vivid much less vivid

10. Occurrence of positive or negative behavior reports:

非:

Type:

11. Impressions of experimental procedure:

Intent:

Effectiveness:

App1icability: 
APPENDIX G

\section{AUTOHYPNOTIC PRACTICE TALLIES*}

$$
\begin{aligned}
& \begin{array}{rrrrrrrrrrrrrr} 
& 1 & 2 & 3 & 4 & 5 & 6 & 7 & 8 & 9 & 10 & 11 & 12 & \text { Total } \\
1 & \mathrm{X} & \mathrm{X} & \mathrm{X} & \mathrm{X} & \mathrm{X} & \mathrm{X} & & \mathrm{X} & & \mathrm{X} & \mathrm{X} & & 9
\end{array} \\
& 2 \mathrm{X}-1 \\
& 3 \quad \mathrm{X} \quad \mathrm{X} \quad \mathrm{X} \quad 3 \\
& \begin{array}{llllllll}
4 & X & X & X & X & X & 5
\end{array} \\
& \begin{array}{rrrrrrrrrrrrrrr} 
& 5 & X & X & X & X & X & X & X & X & X & X & X & X & 12 \\
.-1 & 6 & X & X & X & & X & X & X & X & & X & & X & 9 \\
.4 & 7 & X & X & & & X & & X & & & & & & 4
\end{array} \\
& \begin{array}{lllllll}
\text { 号 } & 8 & X & X & X & 3
\end{array} \\
& \begin{array}{lllllllllll}
\infty_{1} & 10 & X & X & X & & X & X & X & X & 2 \\
0
\end{array} \\
& 11 \mathrm{X} \quad \mathrm{X}-2 \\
& \begin{array}{llllllllllllllll}
12 & X & X & X & X & X & X & X & X & X & X & X & X & 12
\end{array} \\
& 13 \mathrm{X} \quad \mathrm{X} \quad \mathrm{X} \\
& 14 \mathrm{X} x \mathrm{x}-1
\end{aligned}
$$

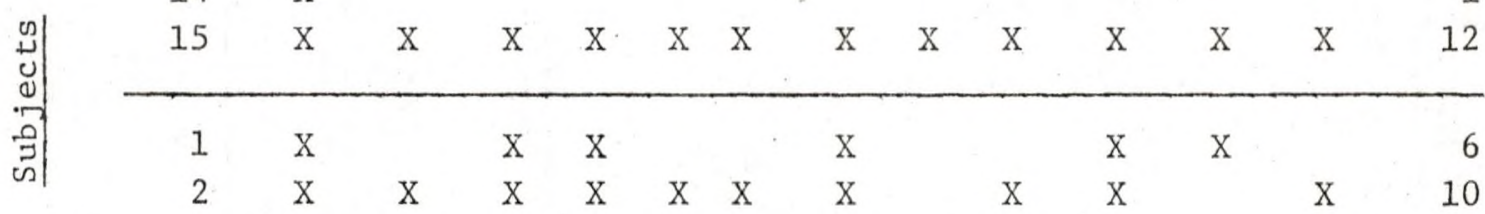

$$
\begin{aligned}
& \begin{array}{llllll}
3 & X & X & X & X
\end{array} \\
& \begin{array}{lllllllllllllll}
4 & X & X & X & X & X & X & X & X & X & X & X & X & 12
\end{array}
\end{aligned}
$$

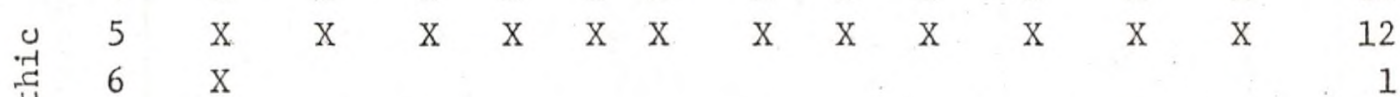

$$
\begin{aligned}
& \begin{array}{lllll}
0 & 7 & X & X & X
\end{array}
\end{aligned}
$$

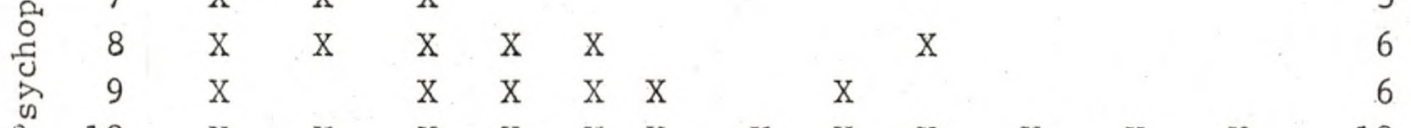

$$
\begin{aligned}
& \begin{array}{lllllllllllllll}
\text { 24 } & 10 & X & X & X & X & X & X & X & X & X & X & X & X & 12
\end{array} \\
& 13 \mathrm{X} x \mathrm{X} x \mathrm{X}-\mathrm{X}-\mathrm{x}-\mathrm{x} \\
& \begin{array}{lllllllllll}
14 & X & X & X & X & & X & X & X & X & 8 \\
15 & X & X & & X & X & X & X & & & 6
\end{array}
\end{aligned}
$$

*Number of days with at least 20 minutes of practice 